\title{
Reconciliation of essential process parameters for an enhanced predictability of Arctic stratospheric ozone loss and its climate interactions (RECONCILE): activities and results
}

\author{
M. von Hobe ${ }^{1}$, S. Bekki ${ }^{2}$, S. Borrmann ${ }^{3}$, F. Cairo ${ }^{4}$, F. D’Amato ${ }^{5}$, G. Di Donfrancesco ${ }^{32}$, A. Dörnbrack ${ }^{6}$, A. Ebersoldt ${ }^{7}$, \\ M. Ebert ${ }^{8}$, C. Emde ${ }^{9}$, I. Engel ${ }^{10, * * * * * *}$, M. Ern ${ }^{1}$, W. Frey ${ }^{3, *}$, S. Genco ${ }^{4}$, S. Griessbach $^{11}$, J.-U. Grooß ${ }^{1}$, T. Gulde ${ }^{12}$, \\ G. Günther ${ }^{1}$, E. Hösen ${ }^{13}$, L. Hoffmann ${ }^{11}$, V. Homonnai ${ }^{14}$, C. R. Hoyle ${ }^{10, * *}$, I. S. A. Isaksen ${ }^{15}$, D. R. Jackson ${ }^{16}$, \\ I. M. Jánosi ${ }^{14}$, R. L. Jones ${ }^{17}$, K. Kandler ${ }^{8}$, C. Kalicinsky ${ }^{13}$, A. Keil ${ }^{18}$, S. M. Khaykin ${ }^{19}$, F. Khosrawi ${ }^{20}$, R. Kivi ${ }^{21}$, \\ J. Kuttippurath ${ }^{2}$, J. C. Laube ${ }^{22}$, F. Lefèvre ${ }^{2}$, R. Lehmann ${ }^{23}$, S. Ludmann ${ }^{24}$, B. P. Luo ${ }^{10}$, M. Marchand ${ }^{2}$, J. Meyer ${ }^{1}$, \\ V. Mitev ${ }^{25}$, S. Molleker ${ }^{3}$, R. Müller ${ }^{1}$, H. Oelhaf ${ }^{12}$, F. Olschewski ${ }^{13}$, Y. Orsolini ${ }^{26}$, T. Peter ${ }^{10}$, K. Pfeilsticker ${ }^{24}$, \\ C. Piesch ${ }^{12}$, M. C. Pitts ${ }^{27}$, L. R. Poole ${ }^{28}$, F. D. Pope ${ }^{17,{ }^{* * *}}$, F. Ravegnani ${ }^{4}$, M. Rex ${ }^{23}$, M. Riese ${ }^{1}$, T. Röckmann ${ }^{29}$, \\ B. Rognerud ${ }^{15}$, A. Roiger ${ }^{6}$, C. Rolf ${ }^{1}$, M. L. Santee ${ }^{30}$, M. Scheibe ${ }^{6}$, C. Schiller ${ }^{1}$, H. Schlager ${ }^{6}$, M. Siciliani de Cumis ${ }^{5}$, \\ N. Sitnikov ${ }^{19}$, O. A. Søvde ${ }^{15}$, R. Spang ${ }^{1}$, N. Spelten ${ }^{1}$, F. Stordal ${ }^{15}$, O. Sumińska-Ebersoldt ${ }^{1}{ }^{\text {***** }}$, A. Ulanovski ${ }^{19}$, \\ J. Ungermann ${ }^{1}$, S. Viciani ${ }^{5}$, C. M. Volk ${ }^{13}$, M. vom Scheidt ${ }^{13}$, P. von der Gathen ${ }^{23}$, K. Walker ${ }^{31}$, T. Wegner ${ }^{1}$, \\ R. Weigel ${ }^{3}$, S. Weinbruch ${ }^{8}$, G. Wetzel ${ }^{12}$, F. G. Wienhold ${ }^{10}$, I. Wohltmann ${ }^{23}$, W. Woiwode ${ }^{12}$, I. A. K. Young ${ }^{17, * * * *}$, \\ V. Yushkov ${ }^{19}$, B. Zobrist $^{10}$, and F. Stroh ${ }^{1}$ \\ ${ }^{1}$ Forschungszentrum Jülich GmbH, Institute of Energy and Climate Research (IEK-7), Jülich, Germany \\ ${ }^{2}$ LATMOS-IPSL, UPMC Univ. Paris 06, Université Versailles St.-Quentin, CNRS/INSU, Paris, France \\ ${ }^{3}$ Max Planck Institute for Chemistry, Particle Chemistry Department, Mainz, Germany \\ ${ }^{4}$ Institute of Atmospheric Science and Climate, ISAC-CNR, Italy \\ ${ }^{5}$ CNR-INO (Istituto Nazionale di Ottica), Largo E. Fermi, 6, 50125 Firenze, Italy \\ ${ }^{6}$ Deutsches Zentrum für Luft- und Raumfahrt (DLR), Institut für Physik der Atmosphäre, Oberpfaffenhofen, 82234 Weßling, \\ Germany \\ ${ }^{7}$ Institute for Data Processing and Electronics, Karlsruhe Institute of Technology, Karlsruhe, Germany \\ ${ }^{8}$ Technische Universität Darmstadt, Institut für Angewandte Geowissenschaften, Umweltmineralogie, Darmstadt, Germany \\ ${ }^{9}$ Meteorologisches Institut, Ludwig-Maximilians-Universität, München, Germany \\ ${ }^{10}$ ETH Zurich, Institute for Atmospheric and Climate Science, Zurich, Switzerland \\ ${ }^{11}$ Jülich Supercomputing Centre (JSC), Forschungszentrum Jülich GmbH, Jülich, Germany \\ ${ }^{12}$ Institute for Meteorology and Climate Research, Karlsruhe Institute of Technology, Karlsruhe, Germany \\ ${ }^{13}$ Department of Physics, University of Wuppertal, Germany \\ ${ }^{14}$ Department of Physics of Complex Systems, Eötvös Loránd University, Pázmány P. s. 1/A, 1117 Budapest, Hungary \\ ${ }^{15}$ Department of Geosciences, University of Oslo, Oslo, Norway \\ ${ }^{16}$ Met Office, Exeter, UK \\ ${ }^{17}$ University of Cambridge, Department of Chemistry, Cambridge, UK \\ ${ }^{18}$ Institute for Atmospheric and Environmental Sciences, Goethe University Frankfurt, Frankfurt, Germany \\ ${ }^{19}$ Central Aerological Observatory, Dolgoprudny, Moskow Region, Russia \\ ${ }^{20}$ MISU, Stockholm University, Stockholm, Sweden \\ ${ }^{21}$ Finnish Meteorological Institute, Arctic Research, Sodankylä, Finland \\ ${ }^{22}$ University of East Anglia, School of Environmental Sciences, Norwich, UK \\ ${ }^{23}$ Alfred Wegener Institute for Polar and Marine Research, Potsdam, Germany \\ ${ }^{24}$ Institut für Umweltphysik, University of Heidelberg, Germany \\ ${ }^{25}$ CSEM Centre Suisse d'Electronique et de Microtechnique SA, Neuchâtel, Switzerland \\ ${ }^{26}$ Norwegian Institute for Air Research, Kjeller, Norway \\ ${ }^{27}$ NASA Langley Research Center, Hampton, VA 23681, USA
}

Published by Copernicus Publications on behalf of the European Geosciences Union. 
${ }^{28}$ Science Systems and Applications, Inc. Hampton, VA 23666, USA

${ }^{29}$ Institute for Marine and Atmospheric Research Utrecht (IMAU), Utrecht University, Utrecht, the Netherlands

${ }^{30}$ JPL/NASA, California Institute of Technology, Pasadena, California, USA

${ }^{31}$ Department of Physics, University of Toronto, Toronto, Canada

${ }^{32}$ Ente Nazionale per le Nuove tecnologie, l'Energia e l'Ambiente, Roma, Italy

*now at: School of Earth Sciences, The University of Melbourne, Melbourne, Australia

**now at: Laboratory of Atmospheric Chemistry, Paul Scherrer Institut, Villigen, Switzerland

*** now at: School of Geography, Earth and Environmental Sciences, University of Birmingham, UK

****now at: Institute for Meteorology and Climate Research, Karlsruhe Institute of Technology, Karlsruhe, Germany

***** now at: The British Museum, London, UK

******now at: Forschungszentrum Jülich GmbH, Institute of Energy and Climate Research (IEK-7), Jülich, Germany

Correspondence to: M. von Hobe (m.von.hobe@fz-juelich.de)

Received: 11 November 2012 - Published in Atmos. Chem. Phys. Discuss.: 27 November 2012

Revised: 30 July 2013 - Accepted: 30 July 2013 - Published: 16 September 2013

\begin{abstract}
The international research project RECONCILE has addressed central questions regarding polar ozone depletion, with the objective to quantify some of the most relevant yet still uncertain physical and chemical processes and thereby improve prognostic modelling capabilities to realistically predict the response of the ozone layer to climate change. This overview paper outlines the scope and the general approach of RECONCILE, and it provides a summary of observations and modelling in 2010 and 2011 that have generated an in many respects unprecedented dataset to study processes in the Arctic winter stratosphere. Principally, it summarises important outcomes of RECONCILE including (i) better constraints and enhanced consistency on the set of parameters governing catalytic ozone destruction cycles, (ii) a better understanding of the role of cold binary aerosols in heterogeneous chlorine activation, (iii) an improved scheme of polar stratospheric cloud (PSC) processes that includes heterogeneous nucleation of nitric acid trihydrate (NAT) and ice on non-volatile background aerosol leading to better model parameterisations with respect to denitrification, and (iv) long transient simulations with a chemistryclimate model (CCM) updated based on the results of RECONCILE that better reproduce past ozone trends in Antarctica and are deemed to produce more reliable predictions of future ozone trends. The process studies and the global simulations conducted in RECONCILE show that in the Arctic, ozone depletion uncertainties in the chemical and microphysical processes are now clearly smaller than the sensitivity to dynamic variability.
\end{abstract}

\section{Introduction}

The international research project RECONCILE, short for "Reconciliation of essential process parameters for an enhanced predictability of Arctic stratospheric ozone loss and its climate interactions", has investigated processes involved in polar ozone depletion with the central aim to better represent the relevant processes in global climate models. The special issue "Chemistry, microphysics and dynamics of the polar stratosphere: ozone loss and climate-chemistry interactions" in Atmospheric Chemistry and Physics compiles the large majority of process studies carried out within the framework of RECONCILE. This paper represents an overview of the project and of the ACP special issue, and aims at putting the main scientific findings into a broader perspective. In this introduction, background information on polar ozone depletion is given, the main objectives and overall strategy of the project are introduced, and the content of this overview paper is outlined.

\subsection{Background: polar stratospheric ozone loss and climate change}

The stratospheric ozone layer shields the Earth's surface from UV radiation. Human activities, primarily the release of chlorofluorocarbons (CFCs) and halons in the second half of the 20th century, have led to a thinning of this protective layer. The 1987 Montreal Protocol and its subsequent amendments have essentially banned CFCs and certain other chlorinated and brominated compounds from being produced. As a result, stratospheric chlorine and bromine levels started to decline in the 1990s. Assuming further decline, the ozone layer is expected to recover during the second half of the century (Eyring et al., 2010; WMO, 2011). A more comprehensive overview and detailed discussions on the science and history of the discovery of the anthropogenic influence on stratospheric ozone are given by Solomon (1999), Brasseur (2008), and Müller (2009). The current state of knowledge is given in the most recent Scientific Assessment of Ozone Depletion (WMO, 2011).

The discovery made in the early 1980 s by Joe Farman, Brian Gardiner, and Jonathan Shanklin of the British Antarctic Survey "that the spring values of total $\mathrm{O}_{3}$ in Antarctica 
have now fallen considerably" (Farman et al., 1985) - soon confirmed by other studies (e.g. Chubachi and Kajiwara, 1986; Gernandt, 1987; Stolarski et al., 1986) - has become widely known as the "Antarctic ozone hole". This exceptionally strong ozone depletion in polar regions in spring (WMO, 2011 ) is due to a number of dynamic and chemical processes that are unique, or at least particularly efficient, in the cold polar stratosphere in winter: (i) isolation of air inside the polar vortex inhibits dilution of active chlorine and replenishment of ozone (McIntyre, 1989; Proffitt et al., 1989); (ii) fast heterogeneous reactions on particle surfaces activate chlorine from the main reservoir gases $\mathrm{HCl}$ and $\mathrm{ClONO}_{2}$ (Solomon et al., 1986); (iii) two catalytic cycles, the $\mathrm{ClO}$ dimer cycle (Molina and Molina, 1987) and the ClO-BrO cycle (McElroy et al., 1986), destroy ozone without the involvement of atomic oxygen and hence work efficiently in the lower stratosphere under cold temperature/high solar zenith angle conditions; and (iv) denitrification, i.e. the removal of $\mathrm{HNO}_{3}$ by sedimenting polar stratospheric cloud (PSC) particles, leads to much reduced $\mathrm{NO}_{2}$ abundance and hence slower chlorine deactivation via the reaction $\mathrm{ClO}+\mathrm{NO}_{2} \rightarrow \mathrm{ClONO}_{2}$, thereby lengthening the ozone loss period in late winter (e.g. Poole and McCormick, 1988; Waibel et al., 1999; Toon et al., 1986).

Polar vortex stability, the rates of heterogeneous chlorine activation and catalytic ozone loss cycles, and the degree of denitrification tend to be greater with lower vortex temperatures. This explains why the ozone hole first and most strongly appeared in the Antarctic winter stratosphere, and why stratospheric ozone loss in Arctic winters shows a rather compact negative correlation with temperature, often conveyed in terms of volume of vortex area exposed to PSC temperatures VPSC (Harris et al., 2010; Rex et al., 2004, 2006). It is not by chance that the most severe ozone loss ever observed over the Arctic (Manney et al., 2011; Kuttippurath et al., 2012) occurred in spring 2011, at the end of the coldest Arctic winter in the stratosphere on record (Fig. 1). The fact that temperature is such an important variable in nearly all key steps in the chain of processes causing polar ozone depletion represents an almost inevitable link to climate change: while the greenhouse effect - to a large extent caused by anthropogenic greenhouse gas (GHG) emissions (IPCC, 2007) - globally leads to a warming at the Earth's surface, the stratosphere largely sits "outside the greenhouse" and is expected to cool. The impact of climate change on stratospheric ozone - which is much more complex than simple temperature effects, and involves changes in dynamics and composition - is illustrated in Fig. 3-22 in WMO (2011) and has been reviewed in detail by Dameris and Baldwin (2012). Further changes in stratospheric chemistry and dynamics could be invoked in future if humans turn to possible geoengineering ventures as a remedy for climate change (Tilmes and Garcia, 2012). State-of-the-art CCM (chemistry-climate model) simulations to estimate ozone layer recovery dates show that alterations to atmospheric dynamics and compo- sition induced by climate change become increasingly important and have a significant impact on stratospheric ozone and consequently on recovery date projections besides the decline in ozone-depleting substances (Eyring et al., 2010; Li et al., 2009; Waugh et al., 2009; WMO, 2011). The ozone layer itself is also an important factor in the Earth's climate system: ozone is a greenhouse gas, it radiatively heats the stratosphere, and by governing UV irradiation at the surface, it can be beneficial for ecosystems and affects feedbacks on the carbon cycle. A noticeable impact of polar ozone loss on atmospheric dynamics and surface climate, particularly in the Southern Hemisphere, has been demonstrated in a number of studies looking at various mechanisms (see Gillett and Son, 2012, for a comprehensive review).

Column ozone loss in any particular Arctic or Antarctic winter can be estimated using empirical relationships with a few parameters such as halogen loading or PSC coverage (e.g. Harris et al., 2010). While these relationships may serve reasonably well to predict ozone loss for the coming decades, it is desirable to be able to realistically predict the response of the ozone layer to the potential atmospheric changes mentioned above using climate models. Therefore, a correct representation of all relevant processes is necessary. The processes involved in polar ozone depletion mentioned above were first described shortly after the discovery of the ozone hole (Solomon, 1999). In the past $25 \mathrm{yr}$, this understanding has been corroborated and refined (see WMO, 2011, for a description of the current state of the art), but full quantitative understanding is still missing. By addressing some of the open questions and augmenting our knowledge and understanding of polar ozone loss, the RECONCILE project described in this paper has continued a fruitful tradition of past international projects as well as other collaborative and individual research efforts.

\subsection{RECONCILE objectives}

At the beginning of the RECONCILE project in 2009, the lack of understanding of stratospheric dynamics and chemistry was most palpable for the catalytic $\mathrm{ClO}_{\mathrm{x}} / \mathrm{BrO}_{\mathrm{x}}$ chemistry, chlorine activation on cold binary aerosol, nitric acid trihydrate (NAT) nucleation mechanisms, and mixing and transport of processed air to lower latitudes. Therefore, the following specific objectives were defined for the RECONCILE project:

- Reduce uncertainties and reach an adequate level of confidence concerning the parameters governing the rate of catalytic ozone loss (see Sect. 3.1).

Uncertainties in various kinetic parameters and the stratospheric bromine budget led to significant uncertainties in model simulations of ozone loss (e.g. Frieler et al., 2006; Kawa et al., 2009). The single most critical parameter governing the rate of catalytic ozone loss in polar spring is the $\mathrm{ClO}$ dimer $(\mathrm{ClOOCl})$ photolysis rate $J_{\mathrm{ClOOCl}}$, i.e. the product 

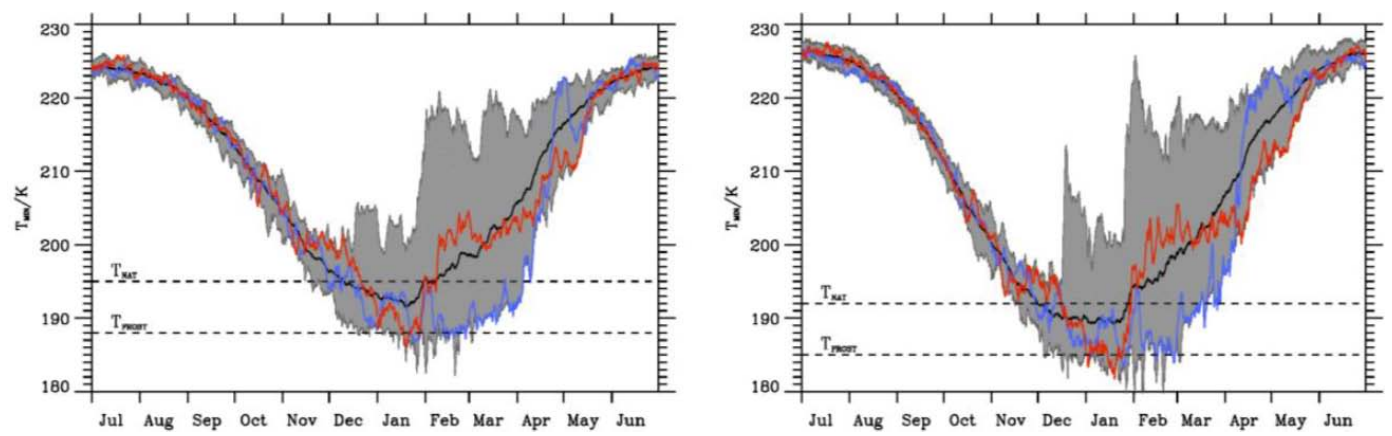

Fig. 1. Minimum temperatures $T_{\mathrm{MIN}}(\mathrm{K})$ between $65^{\circ}$ and $90^{\circ} \mathrm{N}$ on the $50 \mathrm{hPa}$ (left panel) and $30 \mathrm{hPa}$ (right panel) pressure surfaces. Black

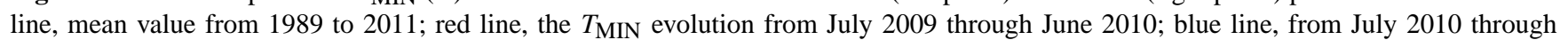
June 2011; and the shaded area encompasses the minimum/maximum $T_{\text {MIN }}$ between 1 January 1989 and 30 June 2012 . Source: ECMWF reanalyses interim (ERA interim; see http://www.ecmwf.int) data provided at 6-hourly temporal resolutions.

of the actinic flux and the $\mathrm{ClOOCl}$ photolysis cross sections $\sigma_{\mathrm{ClOOCl}}$. In 2007, values of $\sigma_{\mathrm{ClOOCl}}$ determined in numerous laboratory experiments differed by up to a factor of 10 , and an experiment by Pope et al. (2007) that suggested the lowest absorption cross sections ever published even put into question our qualitative understanding of the halogen-catalysed ozone loss (von Hobe et al., 2007; Schiermeier, 2007; von Hobe, 2007). Another key variable governing the overall ozone loss rate is the amount of available inorganic bromine $\mathrm{Br}_{\mathrm{y}}$ (Frieler et al., 2006; Salawitch et al., 2005). Stratospheric $\mathrm{Br}_{\mathrm{y}}$ is still not adequately constrained due to uncertainties in the contribution of very short lived species (VSLS) to the overall stratospheric bromine budget (WMO, 2011, and references therein).

\section{- Investigate the role of chlorine activation on cold back- ground aerosol (see Sect. 3.2).}

As described above, fast heterogeneous chlorine activation on particle surfaces, which was first suggested by Solomon et al. (1986), is a key step in the process chain leading to polar stratospheric ozone loss. While PSCs that exclusively occur in the polar winter stratosphere have been identified as an obvious source of heterogeneous reaction surfaces, a potentially significant role of the ubiquitous background aerosol has been pointed out in numerous studies (e.g. Cox et al., 1994; Hanson et al., 1994; Hofmann and Solomon, 1989; Wolff and Mulvaney, 1991; Tabazadeh et al., 1994, 2002). The first evaluation of the role of liquid binaries in the polar winter stratosphere was made by Hanson et al. (1994), who suggested that they could have a significant role to play at temperatures that are too warm for PSCs to form. Drdla and Müller (2012) suggested (1) that the onset of chlorine activation in early winter is actually dominated by reactions on cold binary aerosol and (2) that a temperature threshold for chlorine activation $T_{\mathrm{ACl}}$ (derived from reaction rates on cold binary aerosol) is more appropriate than the commonly used measure $T_{\mathrm{NAT}}$ (i.e. the threshold temperature below which NAT can exist). These suggestions have been subject to de- bate (e.g. Solomon, 2010), and it is particularly important to note that it is the activation rates in mid- and late winter - that is, under sunlit conditions when activation competes with deactivation - rather than the rate of initial activation in early winter that controls winter ozone loss, especially in long and cold winters. As temperatures in the polar stratosphere begin to cool, it does not matter whether the reactions take place on PSCs or binary aerosols since $T_{\mathrm{ACl}}$ and $T_{\text {NAT }}$ are similar. Note that if temperatures cool well below both, PSCs typically supply more surface area than binaries (which eventually start taking up $\mathrm{HNO}_{3}$ and turn into STS), and therefore drive most of the activation. And the additional - and exclusive - role of PSCs for denitrification makes a correct parameterisation of their formation indispensable in models to accurately simulate ozone loss (cf. below as well as Sects. 3.3 and 4.2). One can speculate about a more significant role of chlorine activation on binaries under conditions where $T_{\mathrm{ACl}}$ and $T_{\mathrm{NAT}}$ are different; for example, when $T_{\mathrm{NAT}}$ decreases as a result of denitrification and late winter temperatures are just too warm for PSC formation. While this is unlikely in the Antarctic, where temperatures remain below even a "denitrified" $T_{\mathrm{NAT}}$ and PSCs regularly are observed well into late winter as shown by Pitts et al. (2009), such situations can occur in the Arctic (see Sect. 3.2.1 and Wegner et al., 2012). Conditions in which temperatures are cold enough for chlorine activation but PSCs will not readily form may also be imagined as an eventuality in possible future scenarios related to climate change where the nature and extent of reactive surface area could be altered due to enhanced stratospheric water vapour concentrations (Anderson et al., 2012) or geoengineering concepts to cool the Earth's surface by deliberately enhancing the stratospheric loading of sulfate aerosol (Crutzen, 2006) or other aerosol compositions (Pope et al., 2012). Note that, strictly speaking, non-sulfate aerosol will not directly influence $T_{\mathrm{NAT}}$; however, taking into account heterogeneous NAT nucleation on solid particles (cf. Sect. 3.3.1 below), it may change the actual temperature of NAT formation. 
- Elucidate in detail the processes of NAT nucleation leading to PSC formation, in particular the role of meteoritic dust and other refractory material as condensation nuclei, and the mechanism by which NAT particles grow to rather large sizes forming so-called NAT rocks (see Sect. 3.3).

The conventional understanding of PSC formation based on NAT nucleation depending on prior ice formation has been questioned based on in situ and ground-based lidar observations (Drdla et al., 2003; Pagan et al., 2004; Voigt et al., 2005). However, these in situ and ground-based lidar observations relied on spatially and temporally limited data, and left room for uncertainties. One issue was temperature histories along air parcel trajectories, which were calculated using gridded data from numerical weather prediction (NWP) models. Due to the limited spatial and temporal resolution, these temperature histories were not reliable because, for example, effects of stratospheric mountain waves were not taken into account (Dörnbrack et al., 1998, 1999; Deshler et al., 1994). In addition, the possible role of meteoritic dust and other refractory material as condensation nuclei has been pointed out (Curtius et al., 2005; Voigt et al., 2005; Prather and Rodriguez, 1988). NAT particles with diameters of tens of microns have been observed (Brooks et al., 2003; Fahey et al., 2001), and were termed "NAT rocks" by Fueglistaler et al. (2002). Without a parameterisation that correctly reproduces the number and size of PSC particles, current models often fail to accurately simulate denitrification, and thus ozone loss.

- Understand better the processes governing the stability of the Arctic vortex and transport and mixing across its edge (Sect. 3.4).

The edge of the polar vortex can be defined in several ways (e.g. Dameris et al., 1995; Harvey et al., 2002; Nash et al., 1996; Waugh and Polvani, 2010). Dynamically, it is roughly centred in the polar night jet that develops in the stratosphere over the winter poles in response to seasonal cooling over the respective polar region. The strong circumpolar westerly winds act as a transport barrier and affect both the extent of ozone depletion and the meridional exchange of ozonedepleted air with lower latitudes. Due to the distinct landsea distribution in the Northern Hemisphere, tropospheric weather regimes and associated planetary wave activity modify the strength of the polar night jet and lead to instabilities. Therefore, the persistence of the polar vortex and, eventually, the strength of the transport barrier are rather variable during each winter, and vary inter-annually. Even on timescales of the order of a few days, forecasting the evolution of the polar vortex in any particular winter has been a challenge, and predicting the stratospheric conditions that typically bring about large ozone losses, i.e. a cold and persistent vortex, in advance is currently not possible.
Besides investigating these dynamic, microphysical, and chemical processes, and thus completing our knowledge and understanding of the processes leading to polar ozone depletion, the central aim of RECONCILE has been to develop reliable process parameterisations and implement them in a global CCM (see also Sect. 4). It is worth pointing out that the model spread in stratospheric ozone simulations and projections is particularly wide for the Arctic region (SPARC, 2010). This can be attributed to not only high natural variability but also to very significant model differences in the representation of polar processes.

\subsection{Overall strategy and applied methods}

To address the uncertainties and open questions named above, a comprehensive strategy was used. A central component of this strategy were field observations including an airborne campaign in the Arctic winter 2009/10 and two Match campaigns in 2009/10 and 2010/11, which are described in Sect. 2. Based on the observations as well as data from field campaigns carried out in the framework of other projects and satellites, processes were investigated using different models on all scales. Section 3 briefly describes these process studies - as well as two novel laboratory experiments carried out within RECONCILE - and summarises main scientific findings in terms of process understanding. Where possible, the improved process understanding has been implemented in a CCM to improve the reliability of ozone and climate predictions. Updates made to the model and their impact on the simulation results are presented in Sect. 4 .

\section{RECONCILE field campaigns}

Field measurements were carried out in the Arctic winters 2009/10 and 2010/11. For each winter, a meteorological overview of the polar vortex evolution is given. For 2009/10, this is followed by a detailed description of the field activities with a focus on novel measurements and innovative flight strategies, while for 2010/11 a focus is more on the peculiarities of this winter that saw the strongest ozone loss ever observed in the Arctic. Data from the aircraft and Match campaigns are available online at https://www.fp7-reconcile.eu/ reconciledata.html. Satellite data products (listed in Table 1) were extensively used in flight planning and in some of the process studies described in Sect. 3.

\subsection{The Arctic winter 2009/10 and the Geophysica aircraft campaign}

\subsubsection{Meteorological overview and vortex evolution}

Dörnbrack et al. (2012) have presented a detailed overview of the meteorological situation and dynamical evolution of the polar vortex in the RECONCILE campaign winter. It can be divided into four phases, which are graphically represented 
Table 1. Satellite instruments and data products used in RECONCILE to support the flight planning during the field campaigns and in scientific process studies.

\begin{tabular}{|c|c|c|c|}
\hline $\begin{array}{l}\text { Instrument/ } \\
\text { satellite }\end{array}$ & Data products & Description & References \\
\hline CALIPSO $^{1}$ & $\begin{array}{l}\text { PSC detection and } \\
\text { composition classifi- } \\
\text { cation (supersaturated } \\
\text { ternary solution STS, } \\
\text { liquid/NAT mixtures, } \\
\text { ice, and wave ice) }\end{array}$ & $\begin{array}{l}\text { CALIPSO measures } 532 \mathrm{~nm} \text { scattering ratio and } \\
\text { aerosol depolarisation ratio detected at } 180 \mathrm{~m} \\
\text { vertical resolution and horizontal resolutions } \\
\text { ranging from } 5 \text { to } 135 \mathrm{~km} \text { with daily measure- } \\
\text { ment coverage up to } 82 \text { degrees latitude in both } \\
\text { hemispheres. }\end{array}$ & Pitts et al. $(2009,2011)$ \\
\hline $\begin{array}{l}\text { MLS }^{2} \text { on } \\
\text { EOS-Aura }\end{array}$ & $\begin{array}{l}\text { Vertical profiles of } \\
\mathrm{HNO}_{3}, \mathrm{H}_{2} \mathrm{O}, \mathrm{HCl} \\
\mathrm{ClO}, \mathrm{O}_{3} \text {, temperature }\end{array}$ & $\begin{array}{l}\text { With a polar orbit of } 705 \mathrm{~km} \text { at an inclination } \\
\text { of } 98^{\circ} \text {, MLS provides } \sim 3500 \text { profiles each day } \\
\text { from Earth's surface to } \sim 90 \mathrm{~km} \text { altitude be- } \\
\text { tween } 82^{\circ} \mathrm{N} \text { and } 82^{\circ} \mathrm{S} \text {. Retrieval version } 3.3 \\
\text { was used in all RECONCILE-related studies. }\end{array}$ & $\begin{array}{l}\text { Waters et al. (2006); Santee } \\
\text { et al. (2007a, b); Lambert et } \\
\text { al. (2007); Froidevaux et al. } \\
\text { (2008); Livesey et al. (2012). }\end{array}$ \\
\hline
\end{tabular}

\begin{tabular}{ll}
\hline $\mathrm{OMI}^{3}$ on EOS- & Total column $\mathrm{O}_{3}$ \\
Aura & OMI continues the TOMS record for total \\
& ozone. It employs a hyperspectral imaging in \\
& a push-broom mode to observe solar backscat- \\
& ter radiation in the visible and UV. It provides \\
& global coverage in one day with a spatial reso- \\
& lution of $13 \mathrm{~km} \times 24 \mathrm{~km}$.
\end{tabular}

\begin{tabular}{|c|c|}
\hline $\begin{array}{l}\text { ACE-FTS }{ }^{4} \text { on } \\
\text { SCISAT-1 }\end{array}$ & $\begin{array}{l}\text { Vertical profiles of } \\
\mathrm{ClONO}_{2}, \mathrm{~N}_{2} \mathrm{O}_{5}, \mathrm{HCl}\end{array}$ \\
\hline
\end{tabular}

ACE-FTS is a solar occultation instrument that flies in a circular orbit at $650 \mathrm{~km}$ at an inclination of $74^{\circ}$ and provides daily vertical profiles for up to 15 sunrises and 15 sunsets with latitudinal coverage exhibiting an annual cycle between $85^{\circ} \mathrm{S}$ to $85^{\circ} \mathrm{N}$. Retrieval version 3 was used in RECONCILE-related studies.

Levelt et al. (2006)

Bernath et al. (2005); Wolff et

al. (2008); Mahieu et al. (2005)

SMR observes the thermal emission from the Earth limb. Stratospheric mode measurements are generally performed in the altitude range from 7 to $70 \mathrm{~km}$ with a vertical resolution of $1.5 \mathrm{~km}$ below $50 \mathrm{~km}$ tangent altitude and 5.5 $\mathrm{km}$ above, normally covering the latitude range between $82.5^{\circ} \mathrm{S}$ and $82.5^{\circ} \mathrm{N}$

$\begin{array}{ll}\mathrm{SMR}^{5} \text { on Odin } & \text { Vertical profiles of } \mathrm{O}_{3}, \\ & \mathrm{~N}_{2} \mathrm{O}, \mathrm{HNO}_{3}\end{array}$
$\begin{array}{lll}\text { MSR }+ & \text { local-noon clear-sky } & \text { The globally gridded }\left(0.5^{\circ} \times 0.5^{\circ}\right) \text { clear-sky } \\ \text { SCIAMACHY } & \text { UV index } & \text { surface UV index data are derived from column }\end{array}$ ozone data (1979-2008: MSR; 2008-2011: SCIAMACHY) and solar zenith angle using an algorithm described by Allaart et al. (2004). The algorithm does not take into account the variability of other parameters affecting surface UV radiation such as clouds, atmospheric aerosol loading, and surface albedo.

\author{
Eskes et al. (2005); van der A et \\ Urban et al. (2009); Murtagh et \\ al. (2002) \\ al. (2010); Allaart et al. (2004)
}

\footnotetext{
1 Cloud-Aerosol Lidar and Infrared Pathfinder Satellite Observation.

2 Microwave Limb Sounder.

3 Ozone Monitoring Instrument.

${ }^{4}$ Atmospheric Chemistry Experiment - Fourier Transform Spectrometer.

5 Sub-Millimetre Radiometer.

6 Multi-Sensor Reanalysis and Scanning Imaging Absorption Spectrometer for Atmospheric CHartographY; the dataset is available from

http://www.temis.nl/uvradiation/UVarchive.html.
} 


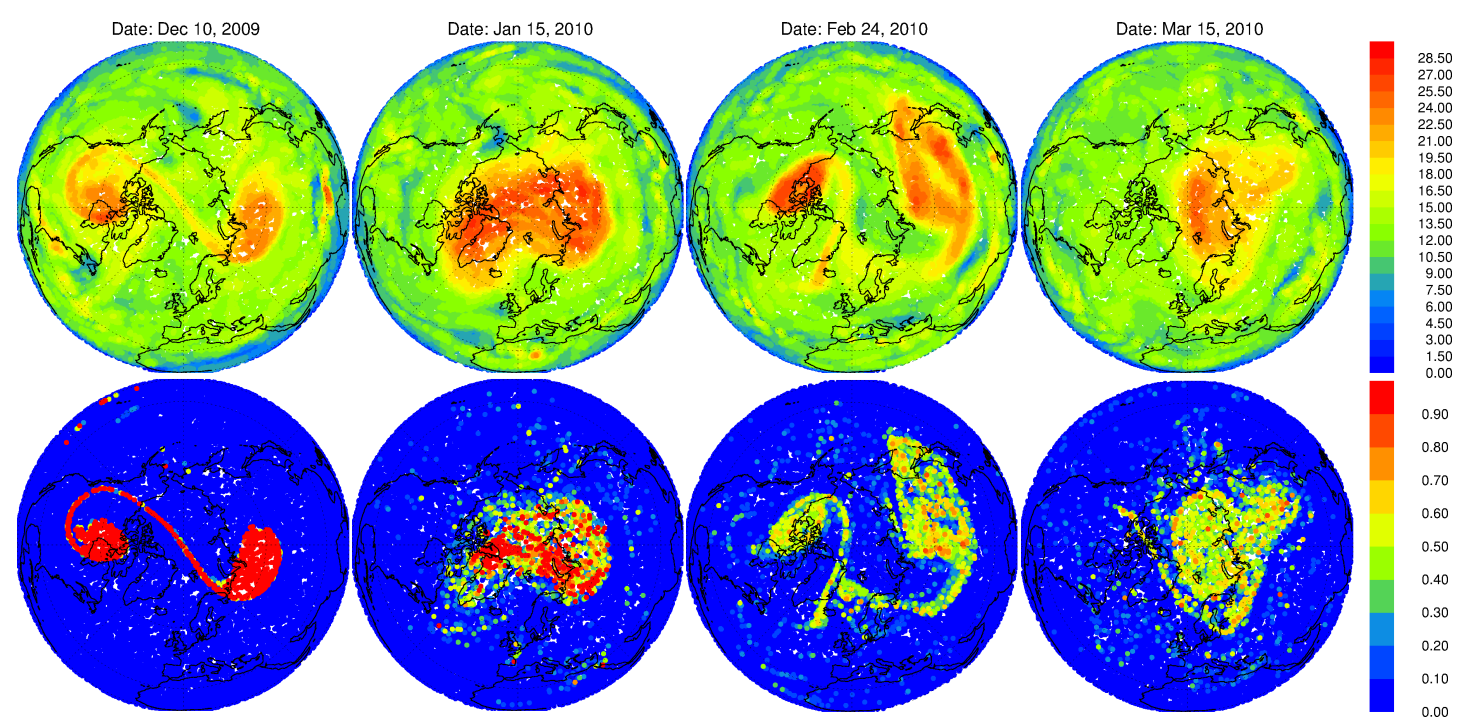

Fig. 2. Modified potential vorticity (PV, given in $10^{-6} \mathrm{~K} \mathrm{~m}^{2} \mathrm{~kg}^{-1} \mathrm{~s}^{-1}$, upper panel) and inert tracer P4 (indicating the relative contribution of air masses that were inside the vortex core at the time of initialisation, lower panel) on $450 \mathrm{~K}$ isentropic level during the first vortex split, after reorganisation of the vortex, during the second vortex split and at the end of the winter (order from left to right).

in terms of PV and simulated tracer fields in Fig. 2 and are briefly summarised below. The evolution of average vortex temperature over the entire winter is displayed in Fig. 1. A climatological analysis revealed that the 2009/10 winter was the third warmest winter in the $21 \mathrm{yr}$ period from 1989 to 2009 measured by the December/January/February mean values of the mean polar cap temperatures at $50 \mathrm{hPa}$ (see Tables in Dörnbrack et al., 2012).

A sequence of tropospheric disturbances and associated planetary wave activity governed the formation and evolution of the polar vortex in late November and early December 2009 (see Fig. 8 in Dörnbrack et al., 2012). As a consequence, the polar vortex split into two lobes of different strength during the first 10 days of December 2009 (Fig. 2, left-hand column). The two lobes rejoined, enclosing midlatitude air in the vortex, and the new vortex cooled gradually through mid-January 2010 (second column in Fig. 2). A period of exceptionally cold temperatures with $T_{\mathrm{MIN}}$ as much as $9 \mathrm{~K}$ below the climatological mean (Fig. 1) followed due to the development of a positive phase of the western Pacific teleconnection pattern in the troposphere, as described by Nishii et al. (2011) and Orsolini et al. (2009). The anomalously cold vortex period was concluded near the end of January 2010 by the onset of a major stratospheric warming (SSW) that was also related to tropospheric features (Ayarzaguena et al., 2011). In early February, the vortex again broke apart into two lobes (third column in Fig. 2), which rejoined again in early March. The new single vortex remained intact throughout March (Fig. 2, right-hand column).

In artificial tracer simulations made using CLaMS (Chemical Lagrangian Model of the Stratosphere; see next section for a short description of the model; the idea behind the artificial tracer simulations and their implementation has been described by Günther et al., 2008), $60 \%$ of vortex air was affected by mixing as a result of the vortex split in December 2009 (Fig. 2, left-hand column). After a reorganisation before January 2010, the vortex stayed coherent with significant mixing only at potential temperatures below $500 \mathrm{~K}$ (Fig. 2, second column). Following the second vortex split, enhanced transport of air from lower latitudes into the reformed vortex occurred (Fig. 2, third column), leading to a heterogeneous origin distribution inside the vortex interior during late winter (Fig. 2, right-hand column). The CLaMS results were validated with observations obtained by the CRISTA-NF (Kalicinsky et al., 2013) and HAGAR (Hösen et al., 2012) instruments (cf. below). Analysis of tracer-tracer correlations observed by HAGAR also indicate ongoing irreversible mixing, directly across the vortex edge, and, in particular, mixing of the enclosed mid-latitude air masses with pre-February split vortex air inside the vortex in March 2010 (Hösen et al., 2012), which is also captured by the CLaMS simulations.

The evolution of PSCs during this winter has been described by Pitts et al. (2011), and is illustrated here with examples of CALIPSO PSC observations in Fig. 3. More PSCs were observed by CALIPSO in the winter 2009/10 than in the previous three Arctic seasons combined. The evolution of PSCs in January 2010 observed by CALIPSO was also seen by ground-based lidar observations near Kiruna (Khosrawi et al., 2011).

The winter of 2009/10 was a moderate one in terms of ozone loss, which was monitored using the Match technique first described by Rex et al. (1999). Thirty-one ozone 

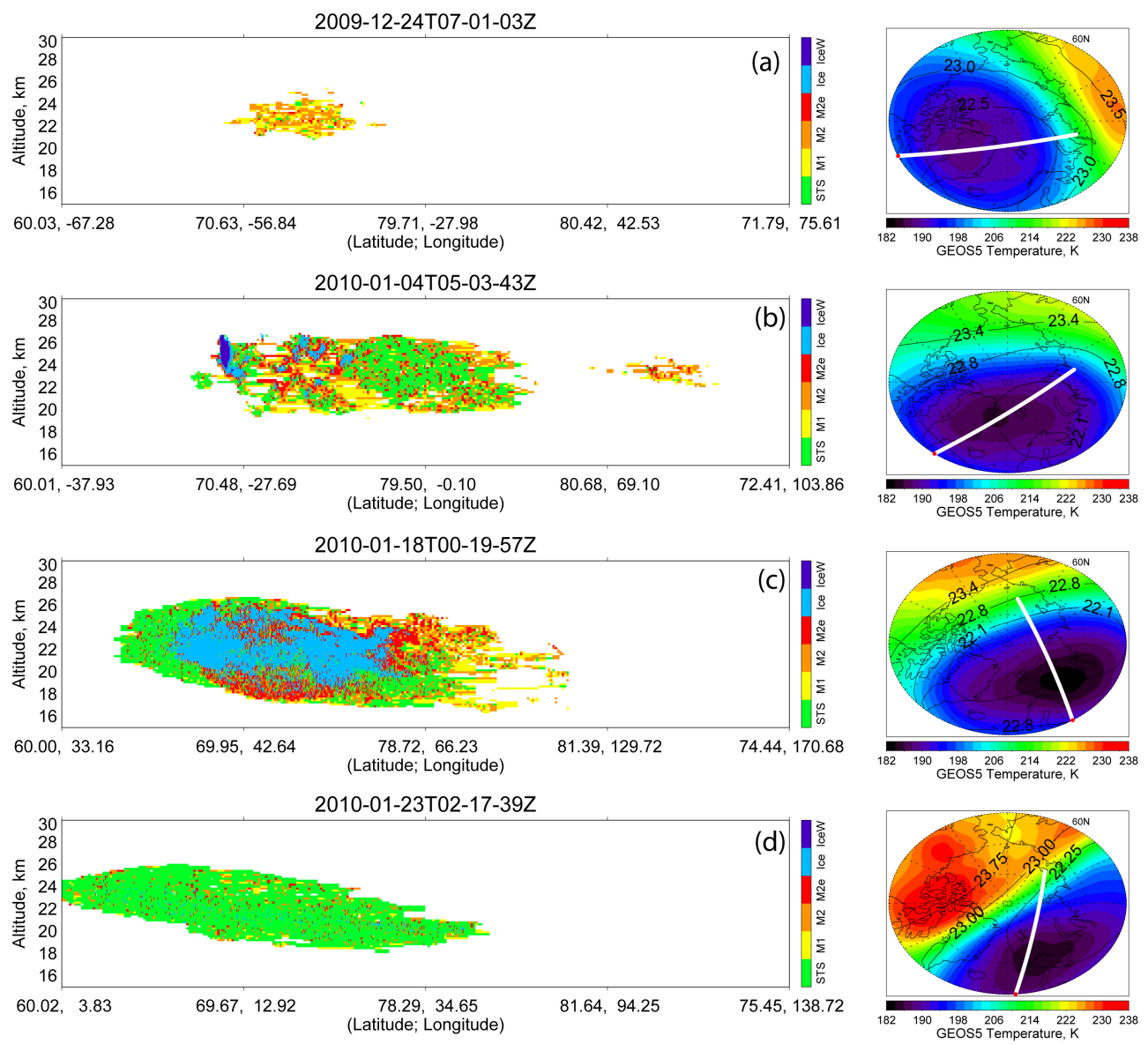

Fig. 3. Examples of CALIPSO PSC composition observations during the 2009-2010 Arctic winter. The panels on the left show CALIPSO PSC composition images for representative orbits from four distinct periods during the winter: (a) 15-30 December, characterised primarily by patchy, tenuous low number density liquid/NAT mixtures and no ice clouds; (b) 31 December-14 January, with frequent mountain wave ice clouds that nucleated widespread NAT particles throughout the vortex; (c) 15-21 January, when synoptic-scale temperatures below the frost point led to a rare outbreak of widespread ice PSCs; and (d) 22-28 January, dominated by STS PSCs possibly containing NAT in low number densities masked from detection by the more abundant STS droplets at colder temperatures. GEOS5 temperature and geopotential height fields at $30 \mathrm{hPa}$ for 12:00 UTC are shown at the right of each panel with the location of the corresponding CALIPSO orbit track indicated by the white line (red dot marks orbit track start).

sounding stations (Fig. 4) participated in the 2010 Match campaign and 573 ozone sondes were launched from 29 of these stations mainly between 5 January and 28 February, when the meteorological conditions for continuing the campaign had deteriorated following the major warming that started in late January. A few coordinated sondes were launched at a later stage into a vortex remnant that returned to Canada and later to the European sector of the Arctic during mid-March to assess whether ozone loss had continued after the end of the Match campaign. Maximum ozone loss rates of the order of $60 \mathrm{ppb}$ per day occurred in mid-February, and an overall column ozone loss of about 66 DU inside the polar vortex was determined. Ozone loss was also inferred from the difference between observed gridded MLS and passively transported ozone fields initialised with EOS MLS and SBUV/2 observations as in Sovde et al. (2011). This method yields a vortex average ozone loss of about $50 \mathrm{DU}$, and about $1.0 \mathrm{ppm}$ ozone loss (corresponding to a relative loss of $26 \%$ ) at the $68 \mathrm{hPa}$ level at the end of March. Both numbers are in fair agreement with estimates based on the in situ aircraft observations (Hösen et al., 2012) and the Match ozone sonde data.

\subsubsection{The Geophysica aircraft campaign}

Twelve RECONCILE flights of the high-altitude aircraft M55-Geophysica totalling 57 flight hours were carried out from Kiruna, Sweden, complemented by one flight of the PremierEX project (Spang et al., 2011). The flights were made during two measurement periods (17 January-2 February and 27 February-10 March 2010), designed to cover early and late winter conditions. 


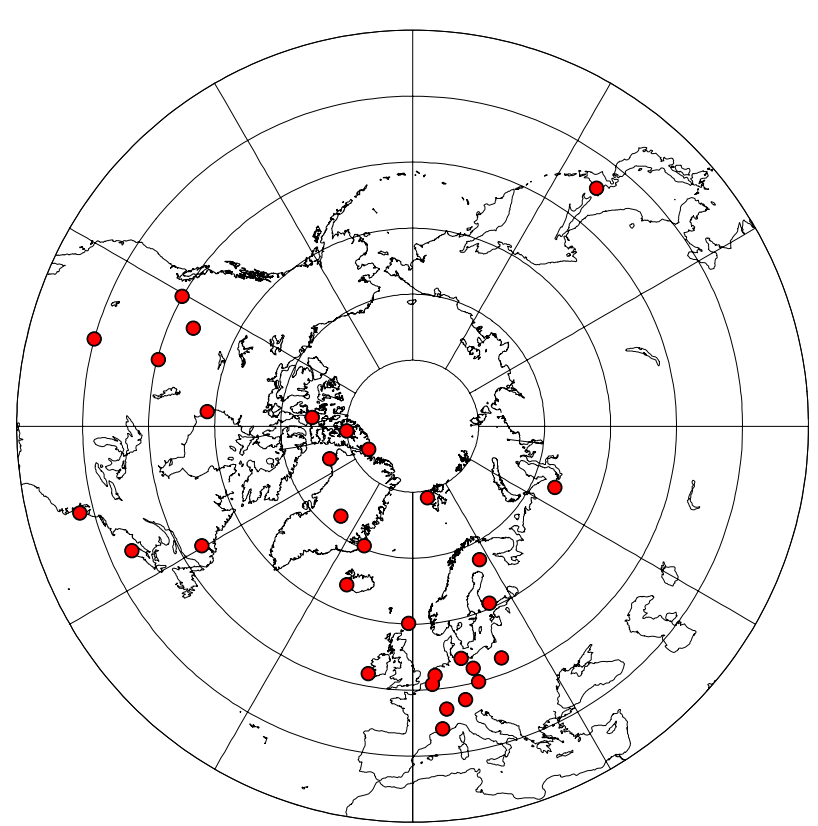

Fig. 4. Network of ozone sounding stations that participated in the RECONCILE Match campaign.

\section{Aircraft and payload}

The Russian M55-Geophysica is a stratospheric research aircraft with a ceiling altitude of $21 \mathrm{~km}$, a total range of about $2500 \mathrm{~km}$ and a maximum payload of about 2.5 metric tons. A more detailed description of the aircraft characteristics and the initial payload configuration when it was first commissioned as a research aircraft is given in Stefanutti et al. (1999). The most recent payload developments prior to RECONCILE are described in Cairo et al. (2010). A complete list of the instruments deployed during the RECONCILE campaign with appropriate references is given in Table 2 .

The payload was tailored towards the RECONCILE objectives. Particularly with respect to PSC processes, it represents the most comprehensive suite of instruments flown on a single aircraft to date. Three in situ cloud particle probes (forward-scattering spectrometer probes FSSP-100, FSSP 300; cloud-imaging probe, CIP) were used to obtain size distributions and shadow images of larger PSC particles (Molleker and al., 2013). The $\mathrm{HNO}_{3}$ content of these particles was measured by the SIOUX (StratospherIc Observation Unit for nitrogen oXides) instrument that is capable of resolving large $\mathrm{NO}_{\mathrm{y}}$-containing particles and also measures gas-phase $\mathrm{NO}_{\mathrm{y}}$ concentration. The forward-looking backscatter probe MAS (Multiwavelength Aerosol Scattersonde), deployed for the first time with a newly implemented range-resolving channel, and the upward- and downwardlooking airborne Miniature Aerosol Lidar (MAL 1 and 2) provided information on the number and types of PSC particles around, above, and below the aircraft. The compre- hensive information on particle distribution and properties together with the measurements of many trace gases - provided the unique opportunity to constrain and improve forward simulations of infrared spectra observed by the IR limb sounders MIPAS-STR and CRISTA-NF (Griessbach et al., 2013). These improvements made it possible to gather information on particle types, shapes, and sizes from these instruments, which was then used in the scientific interpretation of the PSC observations.

Upgrades to the IR limb-sounding instruments were also made with respect to the measurement and retrieval of trace gases. Ungermann et al. (2012) improved the calibration process and retrieval algorithm for CRISTA-NF and achieved unprecedented vertical resolution for several trace gases, making it possible to resolve small-scale features. Woiwode et al. (2012) devised a new retrieval scheme for MIPASSTR suitable for accurate retrievals of temperature and an extended set of trace gases by taking into consideration continuum-like contributions to the spectra.

A miniaturised impactor system placed downstream of the COPAS aerosol inlet was deployed for the first time during RECONCILE. Over a preselected $20 \mathrm{~min}$ time period in each flight, generally at $\Theta>410 \mathrm{~K}$, particles in the submicrometre size range were collected onto boron substrates. Of the 13 samples, six were clearly taken inside the vortex and three outside the vortex (distinguishable based on simultaneous $\mathrm{N}_{2} \mathrm{O}$ tracer observations by HAGAR). Four samples were taken in the vortex edge region; one sample could not be allocated due to the lack of simultaneous HAGAR measurements. Subsequently, the samples were analysed in the laboratory using environmental scanning electron microscopy (ESEM) and energy dispersive X-ray (EDX) analysis to study their morphology and chemical composition (Weigel et al., 2012; Ebert et al., 2013).

\section{Flight planning}

Flight planning was based on results of the Integrated Forecast System (IFS) of the European Centre of MediumRange Weather Forecasts (ECMWF), with innovative flightplanning tools being used for the first time during the RECONCILE aircraft campaign. Different thermo-dynamical fields and derived quantities from the deterministic run were visualised on a website as part of the Mission Support System being developed at the DLR (Deutsches Zentrum für Luft und Raumfahrt, Rautenhaus et al., 2012).

Chemical forecasts were made using a hemispheric CLaMS simulation that started at 1 December 2009 and was run using up-to-date ECMWF analyses and ECMWF forecasts 3 to 4 days into the future. CLaMS represents a hierarchy of models ranging from a box model to a 3-D chemistry transport model (CTM) based on a Lagrangian transport concept (Konopka et al., 2004; McKenna et al., 2002a, b; Grooß et al., 2005). Stratospheric chemistry includes 143 reactions of 45 variable chemical species. CLaMS was used 
Table 2. Instrumental payload of M55 Geophysica during the RECONCILE field campaign.

\begin{tabular}{|c|c|c|c|c|c|c|}
\hline Instrument & Parameter & Time res. & Accuracy & Precision & Technique & References \\
\hline \multicolumn{7}{|c|}{ in situ } \\
\hline FOZAN & $\mathrm{O}_{3}$ & $1 \mathrm{~s}$ & $0.01 \mathrm{ppm}$ & $8 \%$ & Dye chemiluminescence+ECC & $\begin{array}{l}\text { Ulanovsky et al. } \\
\text { (2001); Yushkov et al. } \\
\text { (1999) }\end{array}$ \\
\hline FISH & $\mathrm{H}_{2} \mathrm{O}$ (total) & $1 \mathrm{~s}$ & $0.2 \mathrm{ppm}$ & $4 \%$ & Lyman- $\alpha$ & Zöger et al. (1999) \\
\hline FLASH & $\mathrm{H}_{2} \mathrm{O}$ (gas phase) & $8 \mathrm{~s}$ & $0.2 \mathrm{ppm}$ & $6 \%$ & Lyman- $\alpha$ & Sitnikov et al. (2007) \\
\hline SIOUX & $\begin{array}{l}\mathrm{NO} \\
\mathrm{NO}_{\mathrm{y}} \\
\text { Particle } \mathrm{NO}_{\mathrm{y}}\end{array}$ & $\begin{array}{l}1 \mathrm{~s} \\
1 \mathrm{~s}\end{array}$ & $\begin{array}{l}10 \% \\
15 \%\end{array}$ & $\begin{array}{l}3 \% \\
5 \%\end{array}$ & $\begin{array}{l}\text { Chemiluminescence, } \\
+ \text { Au-converter } \\
+ \text { subisokinetic inlet }\end{array}$ & Voigt et al. (2005) \\
\hline HALOX & $\begin{array}{l}\mathrm{ClO} \\
\mathrm{ClOOCl}\end{array}$ & $\begin{array}{l}10 \mathrm{~s} \\
30 \mathrm{~s}\end{array}$ & $\begin{array}{l}20 \% \\
30 \%\end{array}$ & $\begin{array}{l}5 \% \\
15 \%\end{array}$ & $\begin{array}{l}\text { CCRF } \\
+ \text { thermal dissociation }\end{array}$ & von Hobe et al. (2005) \\
\hline HAGAR & $\begin{array}{l}\mathrm{N}_{2} \mathrm{O}, \mathrm{CFC} 12 \\
\mathrm{CFC} 11 \\
\mathrm{CH}_{4}, \mathrm{H}_{2} \\
\mathrm{SF}_{6} \\
\text { Halon } 1211 \\
\mathrm{CO}_{2}\end{array}$ & $\begin{array}{l}90 \mathrm{~s} \\
90 \mathrm{~s} \\
90 \mathrm{~s} \\
90 \mathrm{~s} \\
90 \mathrm{~s} \\
5 \mathrm{~s}\end{array}$ & $\begin{array}{l}1.3 \% \\
1.6 \% \\
1.8 \% \\
2.3 \% \\
3.0 \% \\
0.1 \%\end{array}$ & $\begin{array}{l}0.3 \% \\
0.6 \% \\
0.8 \% \\
1.3 \% \\
2.0 \% \\
0.05 \%\end{array}$ & $\begin{array}{l}\text { Gas chromatography }(\mathrm{GC}) \\
\text { with electron capture detector } \\
\text { (ECD) } \\
\text { IR absorption }\end{array}$ & $\begin{array}{l}\text { Homan et al. (2010); } \\
\text { Werner et al. (2010) }\end{array}$ \\
\hline COLD & $\mathrm{CO}$ & $5 \mathrm{~s}$ & $9 \%$ & $1 \%$ & TDL & Viciani et al. (2008) \\
\hline COPAS & $\begin{array}{l}\text { Condensation nuclei }(\mathrm{CN} \\
\text { total, } \mathrm{CN} \text { non-volatile) }\end{array}$ & $1 \mathrm{~s}$ & $10 \%$ & $5 \%$ & $\begin{array}{l}\text { 2-channel CN counter, } \\
\text { one inlet heated }\end{array}$ & Weigel et al. (2009) \\
\hline FSSP & $\begin{array}{l}\text { Cloud particle size distrib. } \\
(0.4-47 \mu \mathrm{m})\end{array}$ & $1 \mathrm{~s}$ & $20 \%$ & $10 \%$ & Laser-particle spectrometer & de Reus et al. (2009) \\
\hline $\mathrm{CCP}$ & $\begin{array}{l}\text { Cloud particle size distrib. } \\
(3-47 \mu \mathrm{m})\end{array}$ & $1 \mathrm{~s}$ & $20 \%$ & $10 \%$ & Laser-particle spectrometer & \\
\hline CIP & $\begin{array}{l}\text { Cloud particle size distrib. } \\
(25-1600 \mu \mathrm{m}) \\
\text { Particle Images }\end{array}$ & $1 \mathrm{~s}$ & $20 \%$ & $10 \%$ & Laser-particle spectrometer & $\begin{array}{l}\text { Baumgardner et al. } \\
\text { (2001) }\end{array}$ \\
\hline MAS & Aerosol optical properties & $10 \mathrm{~s}$ & $5 \%$ & $5 \%$ & Multi-wavelength scattering & $\begin{array}{l}\text { Buontempo et al. } \\
(2006)\end{array}$ \\
\hline WAS & $\begin{array}{l}\text { Long-lived trace gases and } \\
\text { isotopo-logues }\end{array}$ & minutes & $5 \%$ & $\begin{array}{l}<2 \% \\
\text { isotopol: } 0.1- \\
2 \%\end{array}$ & $\begin{array}{l}\text { Whole air sampling with lab } \\
\text { GC and MS analysis }\end{array}$ & $\begin{array}{l}\text { Kaiser et al. (2006); } \\
\text { Laube et al. (2010a) }\end{array}$ \\
\hline $\begin{array}{l}\text { Rosemount } \\
\text { probe (TDC) }\end{array}$ & $\begin{array}{l}T, P \\
\text { horizontal wind }\end{array}$ & $\begin{array}{l}0.1 \mathrm{~s} \\
0.1 \mathrm{~s}\end{array}$ & $\begin{array}{l}0.5 \mathrm{~K} \\
1 \mathrm{~m} \mathrm{~s}^{-1}\end{array}$ & $\begin{array}{l}0.1 \mathrm{~K}^{-1} \\
0.1 \mathrm{~m} \mathrm{~s}^{-1}\end{array}$ & $\begin{array}{l}\text { PT100, } \\
\text { 5-hole probe }\end{array}$ & \\
\hline \multicolumn{7}{|c|}{ Remote sensing } \\
\hline MAL $1 \& 2$ & $\begin{array}{l}\text { Remote Aerosol Profile } \\
(2 \mathrm{~km} \text { from aircraft altitude })\end{array}$ & $30-120 \mathrm{~s}$ & $10 \%$ & $10 \%$ & Microjoule lidar & Matthey et al. (2003) \\
\hline miniDOAS & $\mathrm{BrO}, \mathrm{OClO}$ & & & & DOAS & \\
\hline MIPAS-STR & $\begin{array}{l}\text { Cloud index, } \mathrm{T}, \mathrm{HNO}_{3}, \mathrm{O}_{3} \text {, } \\
\mathrm{ClONO}_{2}, \mathrm{CFCs}, \mathrm{H}_{2} \mathrm{O} \text { and } \\
\text { minor species }\end{array}$ & $\begin{array}{l}\text { typ. } 2.4 / 3.8 \\
\text { min for } 1 \text { pro- } \\
\text { file (depends } \\
\text { on sampling } \\
\text { programme) }\end{array}$ & $\begin{array}{l}T<1 \mathrm{~K} / \\
\text { vmr typ. } 10- \\
15 \%\end{array}$ & $\begin{array}{l}T<1 \mathrm{~K} / \\
\text { vmr typ. } 4- \\
12 \%\end{array}$ & FTIR limb sounder & Woiwode et al. (2012) \\
\hline CRISTA-NF & $\begin{array}{l}\mathrm{H}_{2} \mathrm{O}, \mathrm{HNO}_{3}, \mathrm{PAN}, \\
\mathrm{ClONO}_{2}, \mathrm{CFCs}, \mathrm{O}_{3}, \\
\mathrm{CCl}_{4}, \text { information on } \\
\text { clouds + aerosol }\end{array}$ & & & & $\begin{array}{l}\text { MIR emission in limb-viewing } \\
\text { geometry }\end{array}$ & $\begin{array}{l}\text { Hoffmann et al. } \\
\text { (2009); Ungermann et } \\
\text { al. (2012); Weigel et al. } \\
\text { (2010); }\end{array}$ \\
\hline MARSCHALS & $\mathrm{O}_{3}, \mathrm{H}_{2} \mathrm{O}, \mathrm{CO}, \mathrm{HNO}_{3}, \mathrm{~N}_{2} \mathrm{O}$ & & & & $\begin{array}{l}\text { Millimetre wave spectrometer } \\
\text { in limb geometry }\end{array}$ & Moyna et al. (2006) \\
\hline
\end{tabular}

extensively in RECONCILE not only as a flight-planning tool but also in process studies described in Sect. 3. Hemispheric simulations in RECONCILE have been carried out with horizontal resolutions up to $70 \mathrm{~km}$. For the mixing pa- rameterisation, a time step of $24 \mathrm{~h}$ and a critical Lyapunov coefficient of $1.5 \mathrm{day}^{-1}$ were used (see also Riese et al., 2012).

Model forecast tools were complemented with near-realtime satellite data products including the distribution of PSCs and trace gases (cf. Table 1). 
Table 3. Overview of RECONCILE flights. All flights were carried out in 2010; take-off and landing times are in UTC. The corresponding flight tracks are shown in Fig. 5.

\begin{tabular}{lllll}
\hline No. & Date & Take off & Landing & Scientific targets \\
\hline F1 & 17.01. & $11: 20$ & $15: 33$ & PSC characterisation \\
F2 & 20.01. & $08: 13$ & $11: 55$ & PSC characterisation and CALIPSO match \\
F3 & 22.01. & $10: 01$ & $13: 35$ & PSC characterisation \\
F4 & 24.01. & $13: 30$ & $16: 56$ & PSCs and renitrification \\
F5 & 25.01. & $05: 50$ & $09: 19$ & PSCs, de/renitrification, $\mathrm{Cl}$ activation, self-Match experiment \\
F6 & 28.01. & $09: 00$ & $12: 56$ & vortex survey $($ dynamics and mixing) \\
F7 & 30.01. & $06: 36$ & $10: 15$ & self-Match experiment ${ }^{1}, \mathrm{Cl}$ activation, de/renitrification \\
F8 & 02.02. & $10: 01$ & $13: 31$ & Match experiment ${ }^{2}, \mathrm{Cl}$ activation, de/renitrification, $\mathrm{O}_{3}$ loss \\
F9 & 27.02. & $12: 06$ & $15: 41$ & vortex filament \\
F10 & 02.03. & $02: 51$ & $06: 31$ & vortex survey, $\mathrm{Cl}$ deactivation, de/renitrification, $\mathrm{O}_{3}$ loss \\
F11 & 02.03. & $09: 35$ & $13: 35$ & vortex survey, Cl deactivation, de/renitrification, $\mathrm{O}_{3}$ loss \\
F12 $^{3}$ & 05.03. & $15: 05$ & $18: 36$ & vortex filament \\
F13 $^{4}$ & 10.03. & $07: 14$ & $10: 51$ & test of remote sensing instrumentation, $\mathrm{O}_{3}$ loss \\
\hline
\end{tabular}

\footnotetext{
1 The self-match flight is a particularly useful flight pattern to constrain kinetic parameters. Air masses are sampled twice during the same flight (Schofield et al., 2008). The two RECONCILE self-match flights were carried out over sunrise to constrain the ClOOCl photolysis rate $J$ and the $\mathrm{ClO} / \mathrm{ClOOCl}$ thermal equilibrium constant $K_{\mathrm{EQ}}$ (Sumińska-Ebersoldt et al., 2012).

2 Three days after the second self-match flight, the air masses that had been sampled came within reach of the Geophysica again, and a

Match flight was carried out to test the accuracy of trajectory calculations and to check the consistency of observed and simulated

chlorine activation and ozone loss (Wegner et al., 2013).

${ }^{3}$ Flights F10 and 11 were carried out as relay flights with an intermediate stop in Spitsbergen.

${ }^{4}$ Flight 13 was dedicated to testing remote sensing instrumentation under the PremierEx project funded by the ESA.
}

\section{Scientific missions and observations}

An overview of all flights with the respective scientific missions is given in Table 3, and the flight tracks are shown in Fig. 5. Some specific highlights in terms of observations and innovative flight patterns are described below, taking into account coordinated measurements by other platforms where appropriate.

The first five flights took place in a period of low temperatures and extensive PSC occurrence (cf. above), and allowed for the most comprehensive set of PSC observations to date obtained from the airborne PSC instruments described above, the spaceborne lidar CALIPSO, groundbased lidars in Esrange, Kiruna and Ny-Ålesund, and eight launches of the recently developed lightweight, high-powerLED-based aerosol backscatter sonde COBALD (Compact Optical Backscatter and AerosoL Detector, Wienhold, 2012) from Ny-Ålesund in January 2010 (Engel et al., 2013a; Khaykin et al., 2013). Closely matched measurements between CALIPSO and COBALD agree well in their backscatter profiles at PSC levels (Fig. 6), and also the agreement between COBALD and the Ny-Ålesund lidar is convincing at cirrus levels.

The in situ optical particle spectrometers on board the Geophysica FSSP and CIP observed PSCs during the first five RECONCILE flights, and show the existence of socalled NAT rocks up to sizes of roughly $25 \mu \mathrm{m}$ in diameter, confirming earlier observations (Brooks et al., 2003; Fahey et al., 2001; Northway et al., 2002) and theoretical considerations (Salawitch et al., 1989). Figure 7 shows a size distribu- tion averaged over a period of $22 \mathrm{~min}$ that was measured by the FSSP-100 instrument in one of the dense NAT fields. This size distribution is compared to the theoretical size distribution that Fahey et al. (2001) retrieved from their $\mathrm{NO}_{\mathrm{y}}$ measurements made in 2000 . The probably first images of NAT rocks recorded by the greyscale CIP (optical array probe) provide an additional proof of their existence with an optical detection technique other than forward scattering. Those images were observed exclusively when the penetration of NAT fields during a RECONCILE flight was confirmed also by the MAL, MAS, and SIOUX instruments (cf. Table 2). The CIP greyscale image data showed mainly 2-4 pixel features which correspond to particles of roughly 15 to $30 \mu \mathrm{m}$ in diameter. No larger particles were detected. The images recorded during a PSC penetration on 25 January 2010 over a time period of $30 \mathrm{~min}$ amount to a number concentration of about $1 \times 10^{-3} \mathrm{~cm}^{-3}$, which is in the same range as measured by the FSSP. The $\mathrm{NO}_{\mathrm{y}}$ instrument SIOUX generally supports the optical data, including the assumed composition of the particles and consequently the assumption of the refractive index of NAT for the processing of FSSP data. However, size distributions inferred from the SIOUX data show fewer large particles than the particle instruments, very similar to what was observed in 2000 (Brooks et al., 2003; Fahey et al., 2001). Moreover, the high number concentration of large NAT particles observed by the particle instruments amounts to condensed-phase $\mathrm{HNO}_{3}$ concentrations approaching the theoretical limit of available $\mathrm{NO}_{\mathrm{y}}$, and microphysical calculations cannot explain particles larger than about $18 \mu \mathrm{m}$. 

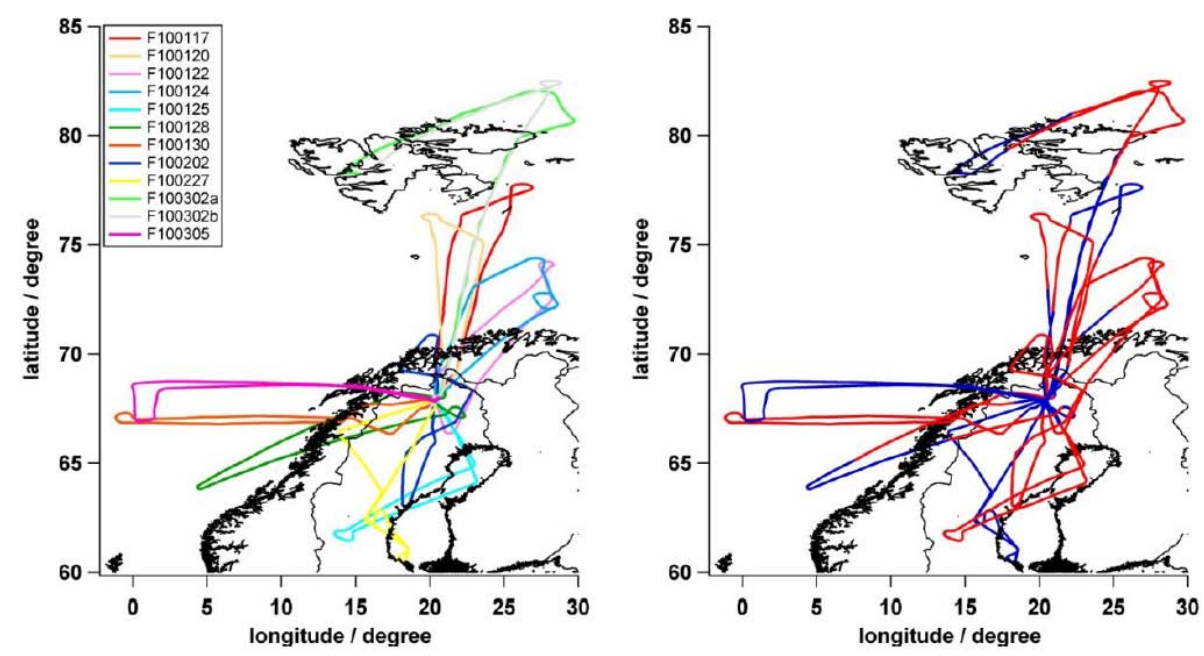

Fig. 5. Geophysica flight paths during RECONCILE. In the left panel, all flights are marked by different colours (referring to flight date, yymmdd). In the right panel, flight sections in vortex air are marked in red; flight sections outside the polar vortex are marked in blue. Two self-match flights were carried out on 25 and 30 January, as well as a Match flight on 2 February (matching the flight on 30 January).

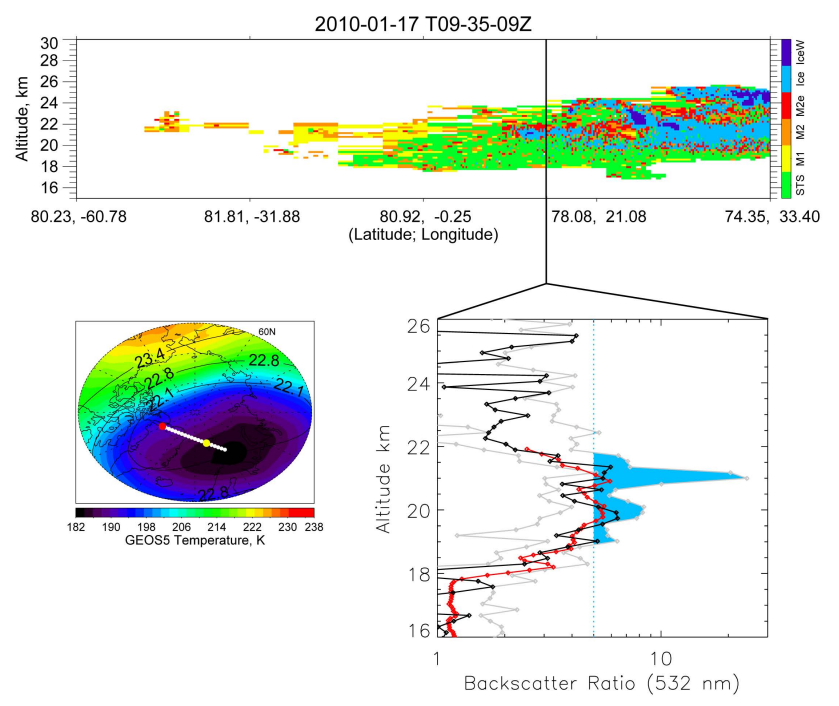

Fig. 6. CALIPSO-COBALD comparison on the 17 January 2010. Upper panel: CALIPSO PSC composition observations. The black line denotes the location of the simultaneously performed COBALD sounding. Lower left panel: GEOS5 temperature and geopotential height fields at $30 \mathrm{hPa}$ for 12:00 UTC, with the location of the corresponding CALIPSO orbit track indicated by the white line and the position of the COBALD sonde by the yellow dot. Lower right panel: profiles of backscatter measurements from COBALD (red) and CALIPSO (black). According to the composition classification by Pitts et al. (2011) and the definition of ice, backscatter ratios larger than 5 are highlighted in blue. Grey profiles show maximum and minimum backscatter values from CALIPSO within a range of $\pm 25 \mathrm{~km}$ around the closest profile indicating the uncertainty between both measurements at $21 \mathrm{~km}$ altitude.

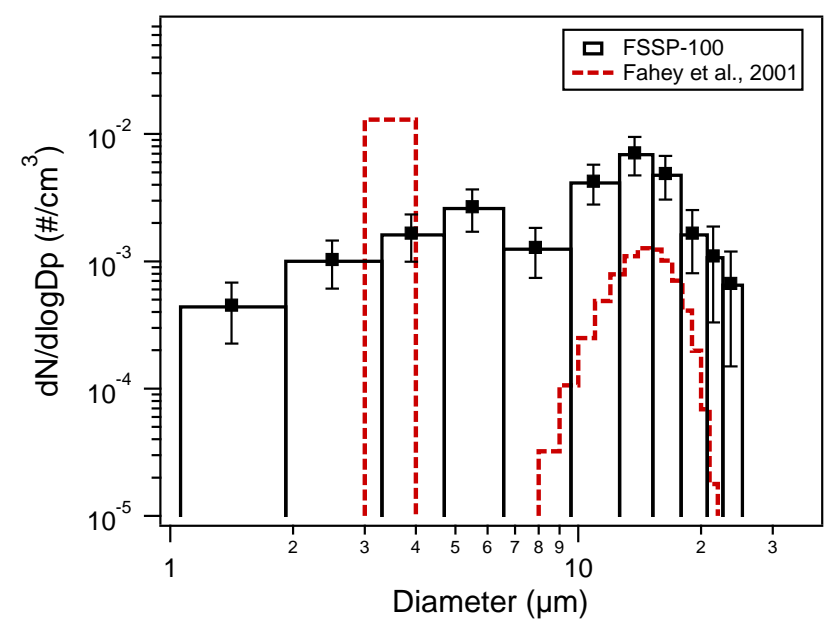

Fig. 7. Particle number size distribution obtained from FSSP-100 measurements during RECONCILE flight on 25 January 2010, averaged over $22 \mathrm{~min}$ (from 07:58 to 08:20 UTC). For comparison, the size distribution retrieved from $\mathrm{NO}_{\mathrm{y}}$ observations in the Arctic winter 2000 by Fahey et al. (2001) is shown in red.

Non-spherical shapes of the NAT particles might contribute to a certain overestimation in the particle size, and therefore in the total volume of the particle phase.

Besides the large NAT particles, the FSSP-300 detected a particle mode around $0.5-1 \mu \mathrm{m}$ that shows volume to temperature behaviour close to the one measured (Dye et al., 1992) and modelled for supersaturated ternary solution STS (Peter, 1997). However, NAT signatures in CRISTA-NF spectra show that at least part of this small particle mode also consists of NAT (Griessbach et al., 2013). Throughout all proven PSC penetration events, the particles larger than about 


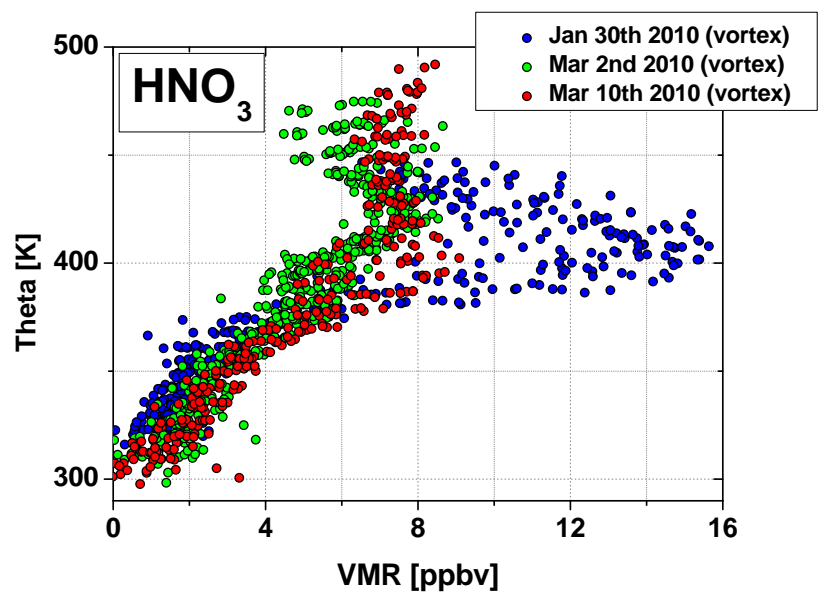

Fig. 8. MIPAS-STR standard retrieval results showing vertical redistribution of $\mathrm{HNO}_{3}$ due to denitrification. A developed layer of excess $\mathrm{HNO}_{3}$ resulting from renitrification is found on 30 January 2010.

$1 \mu \mathrm{m}$ in diameter were detected only at ambient temperatures below the NAT equilibrium temperature $\left(T_{\mathrm{NAT}}\right)$, but mostly well above the frost point ( $T_{\mathrm{ICE}}$ ) so that pure ice particles can most likely be excluded. Only at a few short parts along some of the flight tracks did the ambient air temperature drop to $T_{\text {ICE }}$. There was no indication for the presence of ice from the observations of gas phase and total water by FLASH (FLuorescent Airborne Stratospheric Hygrometer) and FISH (Fast In situ Stratospheric Hygrometer) and in the MAL lidar images. The presence of ice particles at or below the flight altitude is also not supported by the spectral signatures seen by CRISTA-NF. Spectra simulated for in situ measured particle size distributions compare reasonably well with the observed IR limb spectra under the assumption that the large particles consist of NAT (Griessbach et al., 2013; Kalicinsky et al., 2013). Furthermore, comparisons of measured vertical $\mathrm{HNO}_{3}$ redistribution (cf. Fig. 8) with results from dedicated CLaMS simulations (not shown) support the hypothesis of denitrification by NAT particles with reduced settling velocities, possibly due to aspheric particle shape (see Sect. 3.3.3).

The presence of ice above the Geophysica flight altitude throughout much of January detected by CALIPSO (Fig. 3) was confirmed by CRISTA-NF spectra and by the COBALD backscatter profiles. As a consequence of ice PSC formation on synoptic scales, unprecedented evidence of water redistribution in the Arctic stratosphere with irreversible dehydration by up to $1.5 \mathrm{ppm}$ within $20-24 \mathrm{~km}$ altitude range followed by a rehydration in a $2 \mathrm{~km}$ thick layer below was revealed by balloon-borne measurements of water vapour and aerosol acquired within the LAPBIAT-II atmospheric sounding campaign in Sodankylä during the second half of January. The source region and the spatio-temporal evolution of the dehydrated air masses were well established using AURA MLS observations (Khaykin et al., 2013). For the first time, an active phase of ice PSC formation was captured by the simultaneous balloon measurements of water vapour and aerosol on 17 January, providing a unique highresolution snapshot of repartitioning of water vapour into ice particles. This observation, bearing important implications for the PSCs formation thresholds, is analysed in detail by Engel et al. (2013a) using microphysical box modelling (cf. Sect. 3.3.1).

The widespread occurrence of PSCs in January also led to strong and widespread denitrification, observed by the ACEFTS and Odin satellite instruments. The 2009/10 period was the strongest denitrification since the start of the Odin measurement period in 2001; however, this was exceeded in the 2010/11 Arctic winter (Khosrawi et al., 2012). Observations of $\mathrm{NO}_{\mathrm{y}}$ compounds made during the aircraft campaign by SIOUX as well as MIPAS-STR and CRISTA-NF (Woiwode et al., 2012; Ungermann et al., 2012) allowed for a comprehensive investigation of the vertical redistribution of $\mathrm{NO}_{\mathrm{y}}$. Process studies that relate the observed denitrification and renitrification to the earlier PSC observations and help to better parameterise this important process that determines chlorine deactivation, and thus winter ozone loss, are described in Sect. 3.3.4.

A particularly innovative flight pattern was applied to three flights. It was based on the idea of the Match method of probing an individual air parcel multiple times in order to obtain information on the temporal evolution of the concentration of chemical species. A self-match flight, in which air parcels probed during the outbound flight leg are sampled again during the return flight leg, had successfully been carried out before to investigate the temporal evolution of the concentration of chlorine species and deduce information on the kinetics (Schofield et al., 2008). However, this flight in 2003 was characterised by an exceptionally steep gradient in active chlorine $\left(\mathrm{ClO}_{\mathrm{x}}\right)$ at flight altitude and a timing in late afternoon where the reaction system was far from equilibrium or photochemical steady state. During RECONCILE, two selfmatch flights were carried out over sunrise, when the reaction system just starts to come out of thermal equilibrium. The results are described in detail in Sect. 3.1.1. Three days after the second self-match flight, probed air parcels were sampled again, allowing for a detailed case study of uncertainties related to transport in simulating observed tracer concentrations in a region of strong gradients (Wegner et al., 2010). The comparison of mixing ratios of the tracer $\mathrm{N}_{2} \mathrm{O}$ at the start and end points of trajectories connecting the two Match flights on 30 January and 2 February (Fig. 9) revealed that the mean uncertainty of the trajectory calculations (based on high-resolution ECMWF wind fields) over three days was $65 \mathrm{~km}$. Using the HAGAR $\mathrm{N}_{2} \mathrm{O}$ observations in addition to the calculated match radii as a criterion for defining successful matches significantly reduced the number of matches but eliminated matches where obviously very different air masses had been sampled. 


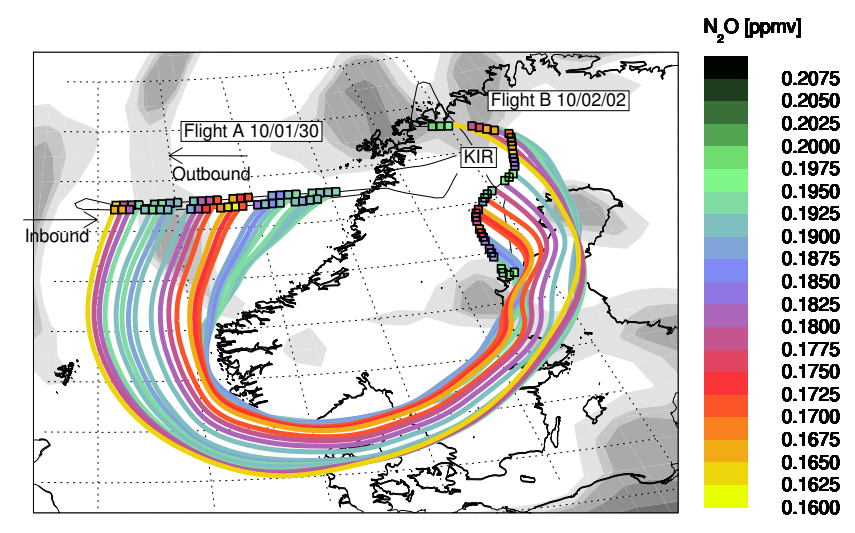

Fig. 9. Flight tracks of the second self-match flight on 30 January and the match flight on 2 February with HAGAR $\mathrm{N}_{2} \mathrm{O}$ measurements along the flight tracks shown by the coloured squares. The trajectories connecting the flights are colour coded according to the $\mathrm{N}_{2} \mathrm{O}$ (in ppb) observed during the first flight. The grey contours in the background show PV from ERA-Interim at the $425 \mathrm{~K}$ level on 30 January 12:00 UTC, with white representing high PV, and darker grey representing areas of low PV pointing to a significant contribution of non-vortex air.

In coordination with the RECONCILE Geophysica flights, a balloon flight with a remote sensing payload consisting of the instruments MIPAS-B (Michelson Interferometer for Passive Atmospheric Sounding - Balloonborne), TELIS (TErahertz and submillimeter LImbSounder) and mini-DOAS was carried out from Esrange, Kiruna, Sweden, on 24 January 2010 (de Lange et al., 2012; Wetzel et al., 2012) to study the diurnal variation of reactive chlorine and nitrogen oxides inside the Arctic vortex from nighttime photochemical equilibrium until local noon covering the full vertical extent of the activated region. Along with $\mathrm{O}_{3}$, $\mathrm{H}_{2} \mathrm{O}$, and tracers, the complete nitrogen and chlorine families were measured, allowing for the study of partitioning and the budgets of these ozone-controlling substances from the tropopause up to about $34 \mathrm{~km}$.

\subsection{The Arctic winter 2010/11: record ozone loss in the Arctic}

In terms of geographical extent and persistence of PSC conditions, 2010/11 was one of the coldest Arctic winters on record (Fig. 1), and measurable ozone loss rates persisted longer into spring than in any previous winter and exceeded the maximum rates previously measured in the Arctic. Based on Aura satellite observations (OMI and MLS) and a second RECONCILE Match campaign with about 270 ozone sondes launched from 13 stations between 12 January 2011 and 27 April 2011, Manney et al. (2011) showed that the vertical loss profile is mostly within the range of Antarctic ozone losses and far outside the range of previous ozone loss in the Arctic (Fig. 10). More than $80 \%$ of ozone was lost at the surface subsiding to $460 \mathrm{~K}$ by late March. Manney et al. (2011) also provided an in-depth investigation of the processes leading to the record ozone loss, highlighting the remarkable degrees of chlorine activation and denitrification. In addition, they presented a comprehensive comparison to the winter 1996/97, which was among the coldest previous Arctic winters. Kuttippurath et al. (2012) also discussed the dynamical situation in both winters and extended the analysis of Manney et al. (2011) by describing the contribution of the $\mathrm{NO}_{\mathrm{x}}$ cycle at higher altitudes.

Balis et al. (2011) and Isaksen et al. (2012) show that dynamics and in particular weak transport from lower latitudes were important in setting the scene for the record low Arctic ozone in 2011, and also that reduced isentropic mixing and lack of transport into the high latitudes by the BrewerDobson circulation played an equally important role as the record high halogen-induced ozone depletion in the ozone deficit in 2011. Note that it is impossible to attribute the peculiar meteorological conditions that led to the 2011 record Arctic ozone depletion event to either climate change or simply natural variability (as discussed in detail by Pommereau et al., 2013). The repetition of such an event during the coming decades cannot be ruled out but presently remains unpredictable.

As a consequence of the strong ozone depletion in 2011, increases in surface UV radiation were observed throughout the Arctic and occasionally at lower latitudes (Bernhard et al., 2012). Von Hobe et al. (2012a) analysed a $30 \mathrm{yr}$ record of surface UV data products from satellite measurements, and showed that for Arctic winters with strong ozone depletion including 2011, UV increases did not reach the extent observed in the Antarctic (this is not surprising: at solar zenith angles typical for polar spring, the change in UV radiation for a given change in column ozone - the so-called radiation amplification factor, cf. Box 2-1 in WMO, 2010 - is higher for the generally lower ozone in the Southern Hemisphere). The largest enhancements in 2011 occurred at high latitudes $\left(>60^{\circ} \mathrm{N}\right)$ in March and early April, when absolute UV levels were still moderate. At lower latitudes, low column ozone due to transport from the subtropics has a stronger effect on surface UV than Arctic ozone loss.

\section{Advances in our understanding of processes relevant to polar ozone loss}

This section summarises key results from RECONCILE in terms of improved understanding of dynamic, microphysical and chemical processes relevant to polar ozone loss. 


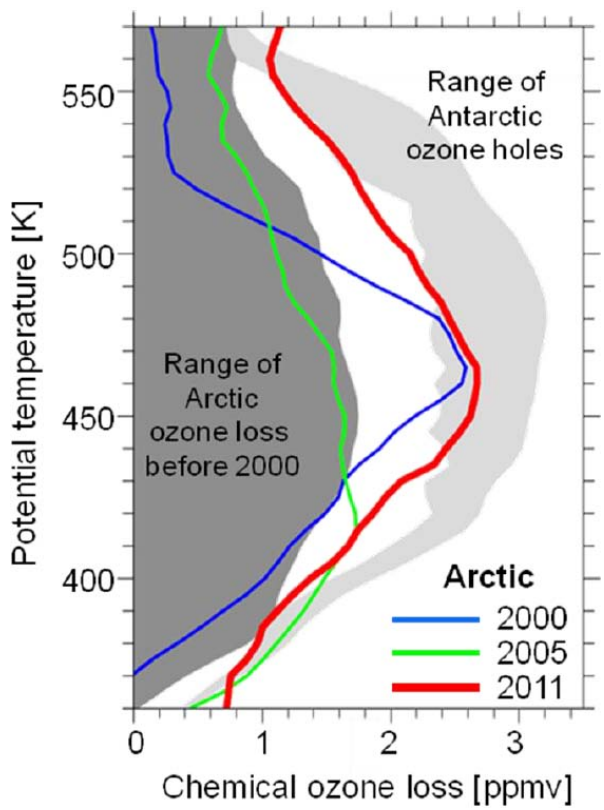

Fig. 10. Vertical profile of chemical ozone loss for 2011 and previous Arctic winters derived from Match ozone sonde measurements. Theta levels are given for end-of-winter conditions. The uncertainty in the data has been estimated to be of the order of $20 \%$.

\subsection{Catalytic ozone destruction by the CIO dimer and CIO-BrO catalytic cycles}

\subsubsection{ClOOCl photolysis rate and $\mathrm{ClOOCl} / \mathrm{ClO}$ equilibrium constant}

Under most conditions, the $\mathrm{ClOOCl}$ photolysis rate $J$ is the rate-limiting step in the $\mathrm{ClO}$ dimer ozone loss cycle. By controlling the abundance of $\mathrm{ClO}$ under daylight conditions, it also indirectly impacts the overall rate of the $\mathrm{ClO}-\mathrm{BrO}$ cycle. $J$ is the wavelength-integrated product of the ClOOCl photolysis cross section $\sigma$ and the actinic flux. The uncertainty in $\sigma$ was particularly large before the start of RECONCILE. A novel laboratory experiment (Pope et al., 2007) stood in obvious contrast to observed or inferred $\mathrm{ClO} / \mathrm{ClOOCl}$ partitioning in the atmosphere (Schofield et al., 2008; Stimpfle et al., 2004; von Hobe, 2007; von Hobe et al., 2007) and had even cast doubt on the $\mathrm{ClO}$ dimer cycle in the form suggested by Molina and Molina (1987) driving catalytic ozone loss (Schiermeier, 2007). It has been one of the primary objectives of RECONCILE to resolve this puzzle - by either proving the Pope et al. (2007) experiment wrong in the laboratory, or by finding new mechanisms in the atmosphere that would explain the observed $\mathrm{ClO} / \mathrm{ClOOCl}$ balance and ozone destruction - and to quantitatively reduce uncertainties in the kinetic parameters governing the $\mathrm{ClO}$ dimer cycle. RECONCILE has addressed this issue in a new laboratory experiment and with observations made during the self-match flights described in Sect. 2.1.2. While this section focuses on results of these activities, they have to be put into the context of the work by many other groups that was also triggered by the Pope et al. (2007) publication. An overview of these efforts (which is beyond the scope of this paper) has been given by Kurylo and Sinnhuber (2009) in a report of a recent SPARC initiative that addressed these issues and established a framework for related research activities.

On the laboratory side, the experiment carried out by Pope et al. (2007) - i.e. purifying $\mathrm{ClOOCl}$ by cold trapping prior to spectral analysis - was repeated using a dual wavelength range spectrometer system that can simultaneously perform single-pass UV absorption spectroscopy (wavelength range $200-350 \mathrm{~nm}$ ) and braodband cavity-enhanced absoprtion spectroscopy (BBCEAS, wavelength range 510$560 \mathrm{~nm}$ ) that offers the possibility to simultaneously monitor and unambiguously subtract the $\mathrm{Cl}_{2}$ contribution to the spectrum, i.e. the impurity that proved to cause major uncertainties in the previous experiment. A detailed description of the experimental setup as well as the UV and visible absorption cross sections of molecular chlorine $\left(\mathrm{Cl}_{2}\right)$ at different temperatures are given in Young et al. (2011). The UV spectrum of $\mathrm{ClOOCl}$ (Young et al., 2013) agrees with spectra reported by von Hobe et al. (2009) and Papanastasiou et al. (2009), and like these two demonstrates that Pope et al. (2007) had overcorrected for the $\mathrm{Cl}_{2}$ impurity, and thus underestimated absorption by $\mathrm{ClOOCl}$. There are visible differences in the spectral shapes between the three studies, although they lie within the combined uncertainties. Papanastasiou et al. (2009) is the only recent study that covers the full spectral range in the UV and gives absolute absorption cross sections (about $15 \%$ higher than previous studies), and it has been adopted for the most recent JPL recommendation (Sander et al., 2011). Absolute cross sections at discrete wavelengths were independently measured by Chen et al. (2009) at 308 and $350 \mathrm{~nm}$, Lien et al. (2009) at 248 and $266 \mathrm{~nm}$, and Jin et al. (2010) at $330 \mathrm{~nm}$. The agreement with Papanastasiou et al. (2009) above $300 \mathrm{~nm}$ is very good, but the cross sections observed at lower wavelengths by Lien et al. (2009) fall another $15 \%$ higher. This raises issues for the scaling of studies measuring only spectral shapes such as the measurement presented here or von Hobe et al. (2009).

Besides contributing to the reconciliation of measurements of the ClOOCl UV spectrum in the atmospherically relevant region between 310 and $350 \mathrm{~nm}$, Young et al. (2013) present the first measurement of the much weaker visible spectrum of $\mathrm{ClOOCl}$. It falls into the range expected from extrapolating the current JPL recommendation. This information will help to constrain the long-wavelength absorption of $\mathrm{ClOOCl}$ and its impact on $\mathrm{ClO}_{\mathrm{x}}$-catalysed polar $\mathrm{O}_{3}$ loss cycles..

The magnitude of $\mathrm{ClOOCl}$ photolysis cross sections that the new studies are converging to agrees favourably with field observations. Older studies (Schofield et al., 2008; Stimpfle et al., 2004; von Hobe et al., 2007) and a very recent one (Kremser et al., 2011) that is also part of this ACP special issue tested the consistency of observed $\mathrm{ClO}$ - and in some 
cases also $\mathrm{ClOOCl}$ - mixing ratios for different combinations of kinetic parameters, most often $J / k_{\mathrm{rec}}$ that is proportional to the ratio of $[\mathrm{ClO}]^{2} /[\mathrm{ClOOCl}]$ under conditions close to photochemical steady state. Sumińska-Ebersoldt et al. (2012) were able to constrain $J$ almost independently of $k_{\text {rec }}$ by looking at $\mathrm{ClO}$ coming out of thermal equilibrium directly after sunrise, which was only possible due to the sunrise self-match flight pattern described in Sect. 2.1.2. The observed increase of $\mathrm{ClO}$ after sunrise is consistent with the $\mathrm{Pa}$ panastasiou et al. (2009) cross sections, and essentially rules out $\mathrm{ClOOCl}$ absorption cross sections lower than the spectrum published by von Hobe et al. (2009) scaled to absolute cross sections near the peak of the spectrum $(246 \mathrm{~nm})$ observed by Lien et al. (2009). The field measurements do not support an additional $\mathrm{ClOOCl}$ absorption band of high atmospheric significance in the visible region of the spectrum, in good agreement with the Young et al. (2013) results.

Remaining uncertainties in the $\mathrm{ClOOCl}$ cross sections influence $J_{\mathrm{ClOOCl}}$ approximately on the same order of magnitude as parameters influencing the actinic flux (Fig. 11). The presence of PSCs can have a particularly strong influence on the actinic flux and photochemistry. Wetzel et al. (2012) showed that, during the balloon flight on 24 January, the onset of $\mathrm{ClO}$ production from $\mathrm{ClOOCl}$ photolysis was delayed by about $45 \mathrm{~min}$ after sunrise in the stratosphere due to the occurrence of stratospheric clouds.

The thermal equilibrium constant $K_{\mathrm{EQ}}$ reported by Plenge et al. (2005) is supported by HALOX ClO and preliminary $\mathrm{ClOOCl}$ observations made before sunrise during two RECONCILE Geophysica flights (Stroh et al., 2012). The higher $K_{\mathrm{EQ}}$ currently recommended by JPL (Sander et al., 2011) would imply unrealistically high total stratospheric chlorine $\left(\mathrm{Cl}_{\mathrm{y}}\right)$ around $5 \mathrm{ppb}$ to be consistent with the $\mathrm{ClO}$ observations (Sumińska-Ebersoldt et al., 2012).

Table 4 provides parameterisations for $\mathrm{ClO}_{\mathrm{x}}$ kinetics that consistently and reasonably accurately simulate atmospheric observations of $\mathrm{ClO}_{x}$ partitioning and ozone loss. No indication was found for alternative $\mathrm{ClO}_{\mathrm{x}}$ chemistry that was suggested during the time of the RECONCILE proposal (e.g. Salawitch et al., 2009; Vogel et al., 2006).

\subsubsection{Bromine chemistry}

Of the kinetic parameters governing the $\mathrm{ClO} / \mathrm{BrO}$ catalytic cycle, significant uncertainties exist for the $\mathrm{ClO}+\mathrm{BrO}$ reaction and its branching ratio (Kawa et al., 2009). However, the most critical uncertainties with respect to the ozone loss rate by this cycle lie in the concentrations of $\mathrm{ClO}$ and $\mathrm{BrO}$. The former is governed by the available $\mathrm{ClO}_{\mathrm{x}}$ (i.e. the degree of chlorine activation) and by the kinetic parameters governing the partitioning of $\mathrm{ClO}$ and $\mathrm{ClOOCl}$ as described above. With respect to $\mathrm{BrO}$, uncertainties exist for both the total available stratospheric bromine content $\mathrm{Br}_{\mathrm{y}}$ and the partitioning between $\mathrm{BrO}$ and the main inorganic bromine reservoir in the polar stratosphere, $\mathrm{BrONO}_{2}$. The amount of $\mathrm{Br}_{\mathrm{y}}$ has been

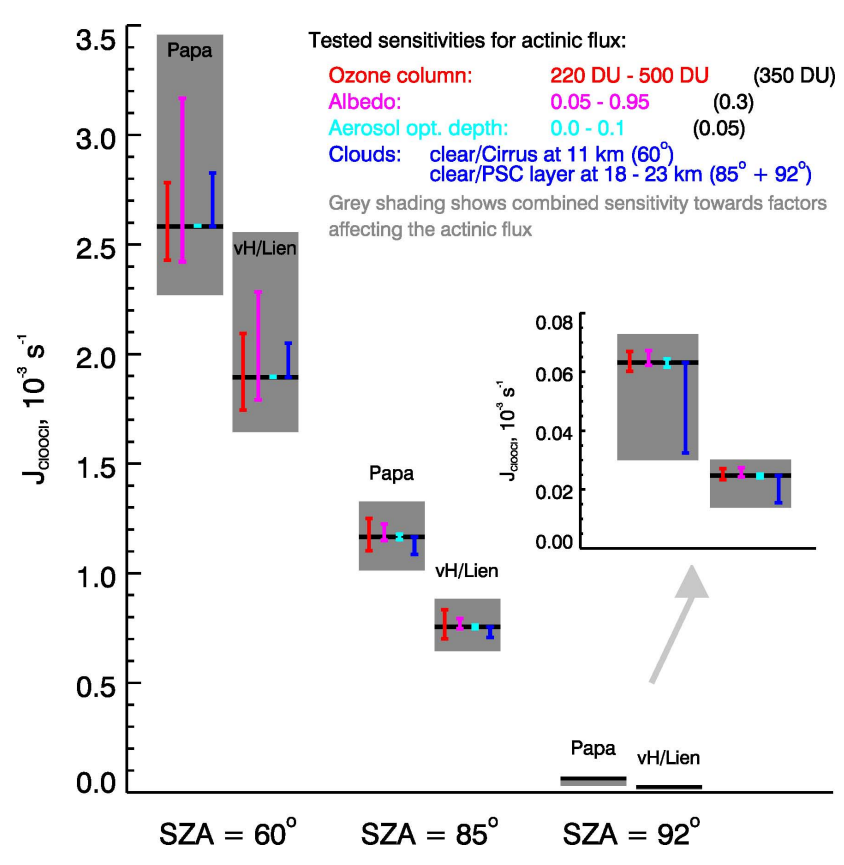

Fig. 11. $\mathrm{ClOOCl}$ photolysis rate, $J_{\mathrm{ClOOCl}}$, at different solar zenith angles for two different $\mathrm{ClOOCl}$ cross sections: Papa: determined by Papanastasiou et al. (2009) and currently recommended by JPL; vH/Lien: spectrum measured by von Hobe et al. (2009) scaled to the absolute measurement by Lien et al. (2009) at $248 \mathrm{~nm}$ wavelength. The grey area represents uncertainty due to variability in the actinic flux, with the black lines denoting a baseline scenario and the coloured error bars showing the sensitivities towards individual parameters affecting the actinic flux. This plot summarises a study by von Hobe et al. (2012b). Actinic fluxes were calculated using the radiative transfer model MYSTIC (Monte Carlo code for the phYsically correct Tracing of photons in Cloudy atmospheres, Mayer, 2009) in fully spherical geometry (Emde and Mayer, 2007) with the ALIS (absorption lines importance sampling) method to perform the high-spectral-resolution calculations efficiently (Emde et al., 2011). MYSTIC is part of the libRadtran radiative transfer package (Mayer and Kylling, 2005; see also http://www.libradtran.org).

identified as a very critical parameter for ozone loss in models (Frieler et al., 2006), and in spite of intensive research efforts in the past decade it is still ill constrained, mainly due to the possible contribution from very short lived species (VSLS) to the stratospheric bromine budget (WMO, 2011, and references therein). Inventories of their sources are not sufficiently accurate to be used in bottom-up estimates of $\mathrm{Br}_{\mathrm{y}}$ (the so-called "organic bromine method"), while top-down approaches to estimate $\mathrm{Br}_{\mathrm{y}}$ from $\mathrm{BrO}$ in aged air (termed "inorganic bromine method") suffer from both $\mathrm{BrO}$ measurement uncertainty and uncertainties in the partitioning between $\mathrm{BrO}$ and $\mathrm{Br}_{\mathrm{y}}$ (most notably in the partitioning between $\mathrm{BrO}$ and $\mathrm{BrONO}_{2}$; Dorf et al., 2006; WMO, 2011). 
Table 4. Kinetic and photochemical parameters for the $\mathrm{ClO}$-dimer cycle that are most consistent with the experiments and observations made within RECONCILE. Clearly, it does not represent a comprehensive evaluation of kinetic parameters determined in laboratory experiments such as given by Sander et al. (2011).

$\begin{array}{ll}\text { ClOOCl production } & \text { (Nickolaisen et al., 1994) } \\ \text { rate constant } k_{\mathrm{f}}^{*} & 2.1 \times 10^{-32} \cdot(T / 300)^{-3.01}\end{array}$

$\mathrm{ClOOCl}$ production $2.1 \times 10^{-32} \cdot(T / 300)^{-3.01}$
This is up to $30 \%$ lower than the current JPL recommendation (Sander et al., 2011) at stratospheric temperatures, but gives the best fit to field measurements of $\mathrm{ClO}$ made during the RECONCILE field campaign in 2010 (Sumińska-Ebersoldt et al., 2012), and can be rationalised based on theoretical chemistry calculations (von Hobe et al., 2007).

\begin{tabular}{lll}
\hline $\begin{array}{l}\mathrm{ClO} / \mathrm{ClOOCl} \\
\text { equilibrium constant }\end{array}$ & $\begin{array}{l}\text { (Plenge et al., 2005) } \\
K_{\mathrm{eq}}\end{array}$ & $\begin{array}{l}\text { Field measurements of ClO before sunrise in air masses that } \\
\text { were shown to be in thermal equilibrium rule out parameterisa- } \\
\text { tions that give higher values for } K_{\text {eq }} \text { (Sumińska-Ebersoldt et al., } \\
\text { 2012). Again, this is in good agreement with theoretical consid- } \\
\text { erations by von Hobe et al. (2007) }\end{array}$ \\
\hline $\begin{array}{l}\mathrm{ClOOCl} \text { absorption } \\
\text { cross sections } \sigma_{\mathrm{ClOOCl}}\end{array}$ & (Papanastasiou et al., 2009) & $\begin{array}{l}\text { These published cross sections are consistent with the ones } \\
\text { measured in the laboratory as part of RECONCILE and also } \\
\text { with ClO observations made during the RECONCILE aircraft } \\
\text { campaign. }\end{array}$ \\
\end{tabular}

* We only consider the low-pressure limit for $k_{\mathrm{f}}$, which is much more relevant for stratospheric conditions than the high-pressure limit.
During the RECONCILE period, the bromine budget and photochemistry - important for the rate of the $\mathrm{ClO}-\mathrm{BrO}$ cycle - was investigated by aircraft and balloon observations. First, on 7 and 8 September 2009, the stratospheric photochemistry of bromine, in particular of the $\mathrm{BrO} / \mathrm{BrONO}_{2} \mathrm{ra}-$ tio, was probed for the high-latitude summer-to-winter circulation turnover, where in the stratosphere major reactive bromine species are $\mathrm{BrO}$ at daytime and $\mathrm{BrONO}_{2}$ at night (Kreycy et al., 2013). Here the transition between $\mathrm{BrO}$ and $\mathrm{BrONO}_{2}$ was observed at dusk and dawn using direct-sun solar occultation and time-dependent limb spectroscopy of stratospheric $\mathrm{NO}_{2}$ and $\mathrm{BrO}$ as well as proxies for actinic fluxes (i.e the amount of direct solar radiation and the radiance in the sky's limb direction). The major advantage of this study as compared to previous studies on stratospheric bromine came with the detailed insight gained into the kinetics of stratospheric $\mathrm{BrO}$ and $\mathrm{BrONO}_{2}$ obtained from observing their time-dependent concentrations at different altitudes and changing illumination. With support from radiative transfer and photochemical modelling, the Kreycy et al. (2013) study indicates that the ratio of the $\mathrm{BrONO}_{2}$ photolysis rate, $J_{\mathrm{BrONO}_{2}}$, to the three-body formation reaction $\left(\mathrm{BrO}+\mathrm{NO}_{2}+\mathrm{M} \rightarrow \mathrm{BrONO}_{2}\right)$ rate coefficient, $k_{\mathrm{BrO}+\mathrm{NO}_{2}}$, i.e. $J_{\mathrm{BrONO}_{2}} / k_{\mathrm{BrO}+\mathrm{NO}_{2}}$, is by a factor of 1.70 $(+0.51 /-0.32)$ larger than recommended by the most recent JPL-2011 compilation (Sander et al., 2011). Major consequences of the findings for the stratosphere are that (1) recent assessments of total stratospheric bromine $\left(\mathrm{Br}_{\mathrm{y}}\right)$ using the inorganic method for high stratospheric $\mathrm{NO}_{\mathrm{x}}$ loadings may have overestimated the necessary correction for the $\mathrm{BrO}$ to $\mathrm{Br}_{\mathrm{y}}$ ratio (cf. for this flight, $\mathrm{Br}_{\mathrm{y}}$ should be $1.4 \mathrm{ppt}$ or $6.8 \%$ of the total lower using the revised $J_{\mathrm{BrONO}_{2}} / k_{\mathrm{BrO}+\mathrm{NO}_{2}}$ ratio as compared to the JPL-2011 recommendations), and (2) a larger $J_{\mathrm{BrONO}_{2}} / k_{\mathrm{BrO}+\mathrm{NO}_{2}}$ ratio may cause a small increase in the bromine-mediated ozone loss in the stratosphere (maximum $-0.8 \%$, see Fig. 12).

The trend of total stratospheric bromine (Fig. 1.21 in WMO, 2011) was also continued with data collected during RECONCILE, during auxiliary field campaigns performed, for example, in 2008 in the tropics, at high latitudes in autumn 2009, in winter 2010 and spring 2011, and lately during the SHIVA project (Stratospheric Ozone: Halogen Impacts in a Varying Atmosphere) in the western Pacific in autumn 2011. The collected data indicate that, from its peak in the early $2000 \mathrm{~s}, \mathrm{Br}_{\mathrm{y}}$ continues to decrease by about $10 \%$ per decade and may now have reached about $19 \mathrm{ppt}$ in $4 \mathrm{yr}$ old air. Together with the finding of Kreycy et al. (2013) the collected field data, in particular during SHIVA, indicate that the contribution of VSLS inferred using the inorganic stratospheric method may be lower than stated in WMO (2011), i.e. $4 \pm 2.5$ ppt instead of 6 (range $3-8$ ) ppt. The new estimate is also in better agreement with past and recent estimates of VSLS based on the organic bromine method, which indicate $[\mathrm{VSLS}]=2.25 \pm 0.25 \mathrm{ppt}$, where $90 \%$ is due to contributions from $\mathrm{CH}_{2} \mathrm{Br}_{2}$ and $\mathrm{CHBr}_{3}$ (e.g. Brinckmann et al., 2012). The apparent agreement between the two methods suggests that injection by other VSLS and product gases is indeed small.

\subsection{Heterogeneous chlorine activation}

As expected, the cold vortex temperatures and extensive PSC coverage in December 2009 and January 2010 led to substantial chlorine activation. A broad activated layer of enhanced $\mathrm{ClO}$ between 16 and $26 \mathrm{~km}$ altitude was detected by MIPASB on 24 January (Wetzel et al., 2012), corresponding nicely 
to the vertical extent of PSCs/cold temperatures observed by MIPAS-B in the same dataset, as well as CALIPSO (Pitts et al., 2011) and ground-based lidars (Khosrawi et al., 2011) in the time period preceding the flight. $\mathrm{ClONO}_{2}$ observations indicate no or very little activation in the air masses below and above this layer. Based on the observations in 2009/10 as well as aircraft data from earlier winters and satellite observations, studies were carried out to better quantify the role of cold binary aerosol in chlorine activation.

\subsubsection{CTM studies on chlorine activation}

Using CLaMS along 7-day backward trajectories (with chemistry initialised from a hemispheric CLaMS simulation) from RECONCILE flight tracks, which had observed temperatures expected to lead to chlorine activation, Wegner et al. (2012) found virtually no difference in chlorine activation between simulations that employed the full PSC scheme with the aerosol surface area density (SAD) increasing with STS, NAT, and ice formation and simulations that kept the SAD at background levels for the case considered. Both simulations produce the same amount of $\mathrm{ClO}_{\mathrm{x}}$ and are consistent with HALOX observations along the corresponding flight tracks (Fig. 13). Unfortunately, temperatures in late winter were too warm to repeat such simulations under sunlit conditions, where chlorine activation would have to compete with deactivation.

Wohltmann et al. (2013) carried out sensitivity runs with ATLAS to examine the impact of known uncertainties in heterogeneous chemistry and PSC microphysics. ATLAS is based on the same Lagrangian approach as CLaMS, and includes a stratospheric chemistry module comprising 47 species and more than 180 reactions, detailed heterogeneous chemistry on PSCs, and a particle-based Lagrangian denitrification module (Wohltmann et al., 2010; Wohltmann and Rex, 2009). The simulations were compared to MLS and ACE-FTS observations and in situ measurements on board the Geophysica during the aircraft campaign. In agreement with Wegner et al. (2012), chlorine activation on liquid ternary aerosols alone and even on the binary background aerosol was sufficient to explain the observed order of magnitude and morphology of the abundances of chlorine, reservoir gases, and ozone (Fig. 14). Assuming default values for NAT number density and supersaturation, runs with different rates for the heterogeneous reactions $\mathrm{ClONO}_{2}+\mathrm{HCl}$ and $\mathrm{ClONO}_{2}+\mathrm{H}_{2} \mathrm{O}$ on liquid aerosols (Hanson and Ravishankara, 1994; Shi et al., 2001) and on NAT (Carslaw and Peter, 1997; Carslaw et al., 1997; based on laboratory studies by Abbatt and Molina, 1992; Hanson and Ravishankara, 1993) produce very similar results. Only if an appreciable NAT surface area density is assumed and the reactions are not dominated by liquid aerosols, the rate and degree of chlorine activation becomes significantly smaller with the rates based on Abbatt and Molina (1992). Despite differences of up to $30 \%$ in chlorine activation between sensitivity runs, the as-

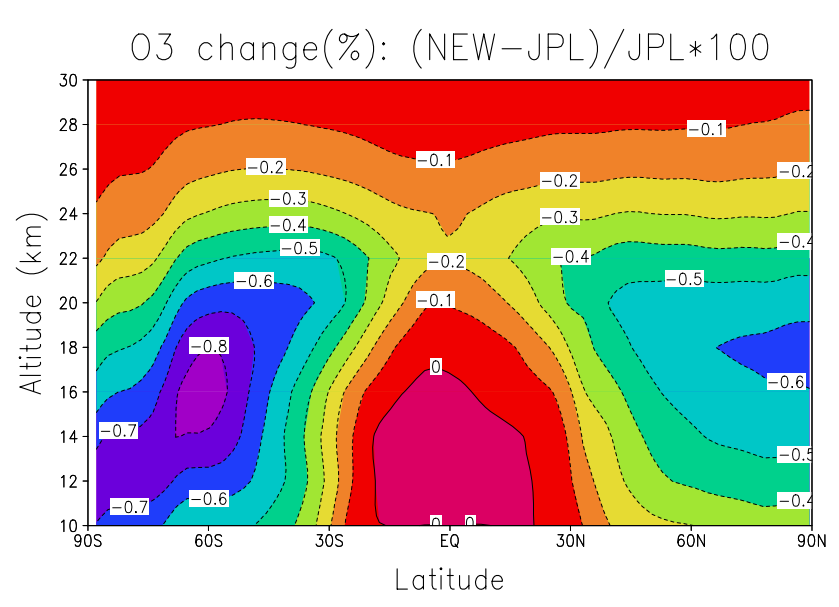

Fig. 12. Difference in zonal mean annual mean ozone from a simulation of the SLIMCAT 3-D CTM with scaled $J_{\mathrm{BrONO}_{2}}$ (times 1.27) and $k_{\mathrm{BrO}+\mathrm{NO}_{2}}$ (times 0.75 ) compared to a run with standard JPL kinetics (from Kreycy et al., 2013).

sumptions with respect to heterogeneous chlorine activation have a negligible impact on ozone loss. In general, ozone loss is a surprisingly robust quantity with regard to changes in the microphysical assumptions with column ozone loss never varying more than $10 \%$ in all sensitivity runs (Fig. 14, right panel). This hints that at least in the Arctic winter 2009/10 with its early major warming and breakup of the polar vortex, the processes investigated in the sensitivity studies are not the factors determining total winter ozone loss.

Both RECONCILE winter (2009/10) case studies demonstrate that in the models, at sufficiently low temperatures in January, heterogeneous chemistry on the cold binary background aerosol is sufficient to produce the same amount of active chlorine as the full PSC scheme. However, this may not hold true for the cold, sunlit conditions when there is a fine balance between chlorine activation and deactivation and when most of the ozone loss occurs. Also, in the RECONCILE winter, PSCs were shown to be present and the realworld contributions of binaries and PSCs to chlorine activation cannot be quantified. This is different for another case study for an episode in March 2004/5 presented by Wegner et al. (2012). Significant chlorine activation was produced by CLaMS along $96 \mathrm{~h}$ trajectories leading up to a flight on 7 March 2005 (von Hobe et al., 2006) with the resulting $\mathrm{ClO}_{\mathrm{x}}$ levels comparing well to the observations. Temperatures were low enough for chlorine activation to occur, but significant denitrification probably prevented the formation of NAT and STS so that chlorine activation occurred to a very large extent on cold background binary aerosol.

\subsubsection{Climatological analysis}

Wegner et al. (2012) corroborate the conclusions of their CLaMS investigations by an analysis of Aura-MLS observations for seven Arctic winters (2004/5-2010/11), focusing on 

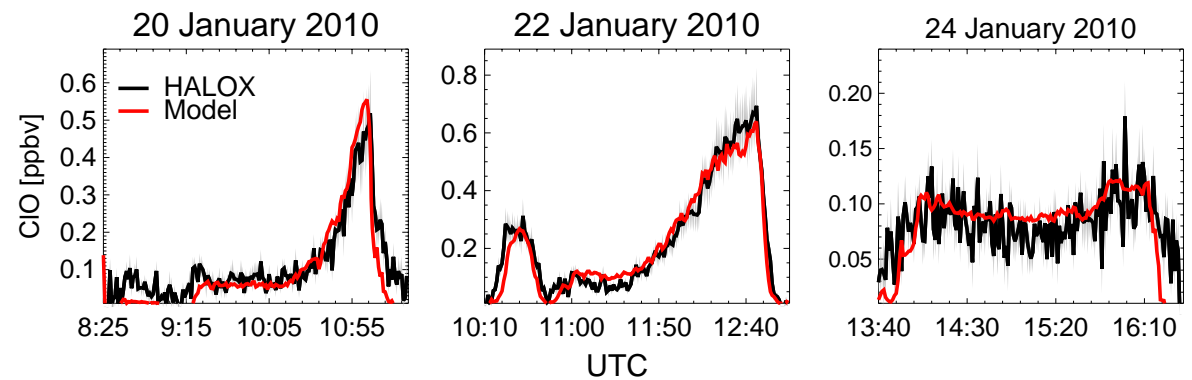

Fig. 13. Comparison of $\mathrm{ClO}$ simulated by CLaMS and observed by HALOX with measurement uncertainties shown in grey. Adapted from Wegner et al. (2012).
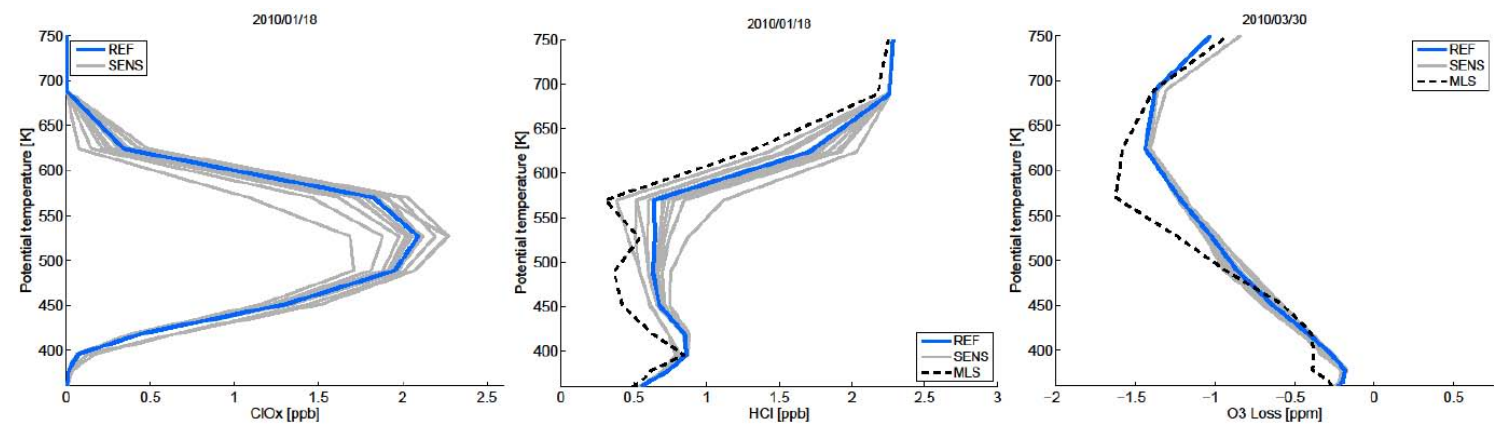

Fig. 14. Results of ATLAS model runs, showing the reference (blue) and sensitivity (grey) runs for vortex-averaged $\mathrm{ClO}_{\mathrm{x}}$ (left) and $\mathrm{HCl}$ (middle) for 18 January 2010, as well as ozone loss for 30 March 2010 as a function of potential temperature (right). For comparison, HCl observed by MLS and ozone loss inferred from MLS measurements (subtracting observed ozone measurements from the passive ozone tracer) are shown as black dashed lines in the respective panels. The panels are simplified versions of Figs. 4, 5, and 9 in Wohltmann et al. (2013).

$\mathrm{HCl}$ as an indicator for chlorine activation and $\mathrm{HNO}_{3}$ as an indicator for the formation of PSC particles. Below $550 \mathrm{~K}$ potential temperature, the vortex average removal rates of gasphase $\mathrm{HCl}$ and $\mathrm{HNO}_{3}$ are not correlated. By 1 January, the vortex average shows that for all considered winters, $\mathrm{HCl}$ has been removed from the gas phase to a similar extent, while $\mathrm{HNO}_{3}$ shows great inter-annual variability. This indicates that at these altitudes the additional surface area provided by PSCs does not directly influence the rate of chlorine activation in early winter. However, at higher altitudes, where the background aerosol begins to thin out, ice PSCs may play an important role. Between 600 and $650 \mathrm{~K}$, the maximum $\mathrm{HCl}$ depletion is observed in the winter 2009/10, which was unique in terms of occurrence of ice PSCs. Different from the Arctic, $\mathrm{HCl}$ depletion cannot be used as an indicator for chlorine activation in the cold vortex core of the Antarctic, where condensation of $\mathrm{HCl}$ into STS presents a viable pathway to sequester $\mathrm{HCl}$ from the gas phase. This has been demonstrated by Wegner et al. (2013a), who argue that, during the polar night, a major part of $\mathrm{HCl}$ is dissolved in STS particles, because heterogeneous reactions, especially with $\mathrm{ClONO}_{2}$, cannot explain the observed loss of gas-phase $\mathrm{HCl}$ due to shortage of $\mathrm{NO}_{\mathrm{x}}$ even if the photolysis of con- densed phase $\mathrm{HNO}_{3}$ is taken into account as a potential additional $\mathrm{NO}_{\mathrm{x}}$ source.

\subsubsection{Minimum ozone mixing ratios in Antarctica}

The amount of active chlorine is not only determined by temperature and available surface area on PSC and/or aerosol particles driving heterogeneous chemistry but often depends on a fine balance between heterogeneous and gas-phase chemistry. This has been nicely illustrated by Grooß et al. (2011), who presented a CLaMS investigation to explain the extremely low ozone mixing ratios reaching values as low as $10 \mathrm{ppb}$ observed by ozone sondes in Antarctic spring (Solomon et al., 2005). While in principle the mechanisms of ozone depletion are known, it was not clear what controls the ozone and chlorine chemistry causing such low ozone concentrations and what determines the lowest ozone values that can be reached. The ozone observations since the 1990s show a very similar behaviour from year to year; that is, a minimum value changing with the time of year. This lower envelope of the observations reaches a minimum in late September and increases again in October and November. It is obvious that such low ozone mixing ratios can only be achieved when temperatures are low enough for rapid 
activation (note that temperatures were well below $T_{\mathrm{NAT}}$, and PSCs were present to drive the heterogeneous chemistry). However, under these conditions, the interaction between gas-phase and heterogeneous chemistry is particularly complex. To correctly simulate the behaviour of the ozone observations, it is necessary to include the oxidation chains of $\mathrm{CO}$ and $\mathrm{CH}_{4}$, starting with the decomposition of $\mathrm{CO}$ by $\mathrm{OH}$ and the decomposition of $\mathrm{CH}_{4}$ by $\mathrm{OH}, \mathrm{O}\left({ }^{1} \mathrm{D}\right)$, or $\mathrm{Cl}$. The reaction of the methyl peroxy radical $\mathrm{CH}_{3} \mathrm{O}_{2}$ with $\mathrm{ClO}$ (Crutzen et al., 1992) is especially important here. It was shown that rapid ( $\sim 1$ day) deactivation halting ozone depletion occurs when the $\mathrm{Cl} / \mathrm{ClO}$ ratio reaches high enough values.

\subsection{PSC formation and denitrification}

While heterogeneous chlorine activation will almost certainly take place without the presence of PSCs if the temperature is sufficiently low, the formation of PSCs is a prerequisite for denitrification by sedimenting particles. Without denitrification, chlorine would rapidly deactivate into $\mathrm{ClONO}_{2}$ as soon as there is sunlight present and temperatures become too warm for efficient heterogeneous activation, and the ozone loss season would be shorter in both hemispheres. A correct representation of denitrification has been identified as critical to simulate ozone loss over an entire winter (e.g. Tabazadeh et al., 2000), and this depends on the correct simulation of the occurrence and abundance of PSCs. This section describes important advances in our understanding of PSCs and denitrification made by RECONCILE.

\subsubsection{A revised PSC formation scheme}

To understand STS, NAT, and ice formation in the Arctic stratosphere, the Zurich Optical and Microphysical box Model (ZOMM) is used. ZOMM has been described previously by Luo et al. (2003) and Meilinger et al. (1995), and has been applied very recently in detailed cirrus modelling (Brabec et al., 2012). Along the lines of previous understanding of PSC formation (Peter, 1997), the pre-RECONCILE version of the PSC model focussed on simulating kinetic growth of STS by simultaneous uptake of $\mathrm{H}_{2} \mathrm{O}$ and $\mathrm{HNO}_{3}$, homogeneous nucleation of ice in these solution droplets (Koop et al., 1995), and heterogeneous nucleation of NAT on pre-existing ice particles (Carslaw et al., 1998) along air parcel trajectories.

For every distinct PSC period defined by Pitts et al. (2011) and described in Sect. 2.1.1, optical parameters simulated with ZOMM were compared to selected CALIPSO PSC observations. The best agreement between model results and observations is achieved by (1) allowing for NAT and ice to nucleate heterogeneously on pre-existing solid particles (with a linear relationship between the number densities of these "foreign nuclei" and resulting PSC particles), and (2) superimposing small-scale temperature fluctuations (e.g. Murphy and Gary, 1995; Bacmeister et al., 1999; Gary, 2006)

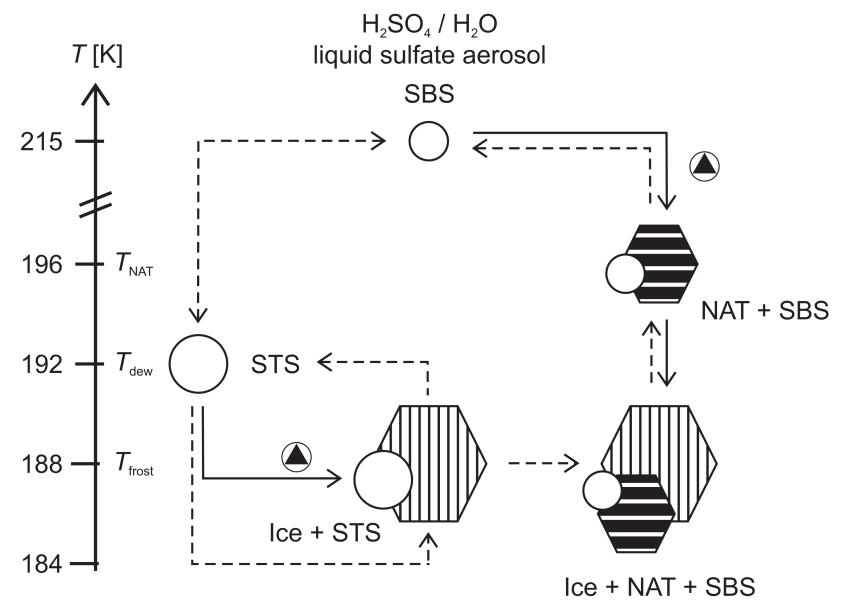

Fig. 15. PSC formation pathways as implemented into ZOMM with SBS standing for supercooled binary solution $\left(\mathrm{H}_{2} \mathrm{SO}_{4} / \mathrm{H}_{2} \mathrm{O}\right)$; STS, supercooled ternary solution $\left(\mathrm{HNO}_{3} / \mathrm{H}_{2} \mathrm{SO}_{4} / \mathrm{H}_{2} \mathrm{O}\right)$; NAT, nitric acid trihydrate $\left(\mathrm{HNO}_{3} \cdot 3 \mathrm{H}_{2} \mathrm{O}\right)$; and $\boldsymbol{\Delta}=$ solid inclusion, e.g. meteoritic dust. Dashed arrows denote pathways included in previous schemes describing PSC formation pathways (going back to Peter, 1997). Solid arrows show the heterogeneous nucleation pathways of NAT and ice on pre-existing solid particles supported by the new laboratory and field observations. The figure is adopted from Hoyle et al. (2013) and Engel et al. (2013b), where the new PSC scheme is described in detail.

onto the trajectories (which otherwise remain unresolved along the ECMWF trajectories). Only the combination of both effects can provide good agreement in particle types and captures the backscatter and depolarisation ratios measured by CALIPSO (Hoyle et al., 2013; Engel et al., 2013b).

In a revised scheme of PSC formation and phase transitions shown in Fig. 15, the heterogeneous nucleation pathways of NAT are allowed to compete with the accepted pathway of NAT formation via homogeneous nucleation of ice, which typically requires cold localised pools in mountainwave-driven temperature fluctuations (Carslaw et al., 1998; Peter, 1997). In the absence of better knowledge of the nucleation properties, immersion freezing of NAT and ice is assumed to occur on active sites much like heterogeneous ice nucleation on Arizona test dust demonstrated in previous laboratory experiments (Marcolli et al., 2007).

At first sight the new results appear to be at odds with the previous laboratory-based understanding of NAT nucleation - namely that ice would be the first solid, nucleating homogeneously within liquid aerosol particles (Koop et al., 1995), and that NAT nucleated only subsequently on ice (Carslaw et al., 1998). In these days, direct heterogeneous NAT nucleation on pre-existing solid particles was deemed to be unlikely by Biermann et al. (1996), who reported an upper bound for freezing rates of six different ternary $\mathrm{H}_{2} \mathrm{SO}_{4} / \mathrm{HNO}_{3} / \mathrm{H}_{2} \mathrm{O}$-solutions with immersed micrometeorites under stratospheric conditions. Using a differential 
scanning calorimeter (DSC) (e.g. Koop and Zobrist, 2009; Marcolli et al., 2007; Zobrist et al., 2008), new bulk experiments, similar to those from Bogdan et al. (2003b, a), were carried out on fragments of the meteorites Orgueil and Murchison with radii varying between 100 and $500 \mathrm{~nm}$ (provided by Centre de Spectrométrie Nucléaire et de Spectrométrie de Masse, Paris, France). Preliminary results corroborate the early results of Biermann et al. (1996), but also seem to suggest that the heterogeneous NAT nucleation rate may indeed reach the upper limits specified by Biermann and colleagues. With today's new insights into low number density NAT clouds, as observed by CALIPSO in December 2009, and NAT rocks, described by Fueglistaler et al. (2002), nuclei consisting of coagulated meteoritic smoke particles or micrometeorites become favourable candidates to explain those observations.

\subsubsection{Characterisation of background aerosol}

The abundance and nature of condensation nuclei in the polar vortex was also investigated. Measurements with the COndensation PArticle counting System (COPAS, Weigel et al., 2009) during the RECONCILE winter agree well with the data from Curtius et al. (2005). While outside the polar vortex the fraction of non-volatile (at $250{ }^{\circ} \mathrm{C}$ ) particles remains nearly constant with altitude, it increases noticeably with altitude inside the vortex, reaching up to $80 \%$ of detected submicron refractory particles deeply inside the Arctic vortex $(\Theta \approx 470 \mathrm{~K})$.

Nevertheless, the hypothesis by Curtius et al. (2005) that the enhanced non-volatile aerosol in the polar vortex mainly consists of meteoritic smoke particles needs further refinements. Ebert et al. (2013) present a detailed chemical analysis of the refractory aerosol material from particle samples collected using the impactor system introduced in Sect. 2.1.2. Three of the six particle samples, which were taken well inside the vortex, mainly contained spheres and aggregates of globules (like "a bunch of grapes", Bigg et al., 1970) in the diameter range $500 \mathrm{~nm}-2 \mu \mathrm{m}$, chemically dominated by metallic aerosol species composed of $\mathrm{Al}, \mathrm{Cr}, \mathrm{Mn}, \mathrm{Fe}$, or $\mathrm{Ni}$. On samples that were taken well outside the polar vortex, also fractured alumosilicate particles, showing the character of crustal material, were found in the large particle size range. For smaller particles with $\mathrm{dp}<500 \mathrm{~nm}$, besides some metallic and alumosilicate spheres, mostly soot and leadbearing particles were found. Overall, the results show that the refractory material in the stratosphere can neither exclusively nor unambiguously be attributed to meteoritic origin. In particular the chemical composition together with the morphology information of the refractory material indicates that also crustal material as well as contributions of anthropogenic sources (including "space debris") are present. The complete results and their interpretation will soon be published (Weigel et al., 2012; Ebert et al., 2013).
Based on these results, meteoritic ablation is not the only source of refractory aerosol material in the polar winter stratosphere. Also space debris and in particular crustal aerosol material and anthropogenic particles were found in the air masses over the Arctic in winter. This new finding indicates efficient transport pathways for aerosol particles to reach elevated atmospheric altitude, i.e. the stratosphere, to re-enter the lowermost stratosphere due to the developing polar vortex.

\subsubsection{Properties of NAT rocks and role in denitrification}

Significant $\mathrm{HNO}_{3}$ enhancements attributed to renitrification processes were observed by MIPAS-STR and CRISTA-NF in the polar vortex after the end of the PSC phase in the Arctic winter 2009/10. Standard retrieval results from MIPASSTR showing vertical distributions of $\mathrm{HNO}_{3}$ versus potential temperature are presented in Fig. 8 for the flight on 30 January and for two flights in March (vortex air identified by measured tracer distributions). A significant $\mathrm{HNO}_{3}$ maximum peaking around $405 \mathrm{~K}$ potential temperature (about $16.5 \mathrm{~km}$ altitude at this flight) is identified for the flight in January directly after the PSC phase of this winter. Using MIPAS-STR measurements of $\mathrm{HNO}_{3}$ and CLaMS simulations, a dedicated study was carried out, aiming at explaining the unexpected large sizes of potential NAT particles derived from in situ observations (see Fig. 7). The study was based on the assumption that (i) compact aspheric NAT particles (i.e. platelets or needles) and/or (ii) approximately spherical NAT particles with low mass densities (i.e. "flake-like" particles) might explain the in situ observations. Such particles would grow faster to large sizes due to consuming less $\mathrm{HNO}_{3}$ compared to compact spherical particles, which are usually assumed for simplification. In particular, such particles were characterised by reduced settling velocities, altering the vertical redistribution of $\mathrm{HNO}_{3}$. The results of the study show that considering settling speeds reduced by a factor of 0.7 for the simulated NAT particles results in an improved agreement with the observed $\mathrm{HNO}_{3}$ redistribution. This factor of settling speed reduction would correspond to significantly aspheric compact particles (cf. Westbrook, 2008) with maximum dimensions (diameter or length, respectively) that might explain the particle sizes derived from the in situ observations (Woiwode, 2013).

\subsubsection{Vertical redistribution of $\mathrm{NO}_{\mathrm{y}}$}

The parameterisation of PSCs by a simple equilibrium scheme usually causes models to overestimate the magnitude, spatial extent, and duration of chlorine activation (Santee et al., 2008), which has a significant impact on ozone depletion. This was investigated in detail in a recent paper by Feng et al. (2011) that is also part of the special issue.

The observations in the Arctic winter 2009/10 with its extensive PSC formation leading to substantial denitrification 
(Sect. 2.1.2) provided a good opportunity to study this in detail. Box model simulations together with Odin/SMR, AuraMLS, and CALIPSO observations of $\mathrm{HNO}_{3}$, water vapour, and PSC particles respectively show that the strong denitrification observed in mid-January 2010 is linked to an unusually strong synoptic cooling event in mid-January with ice particle formation on NAT as a possible formation mechanism. The denitrification in the beginning of January was more likely caused by the sedimentation of NAT particles that formed on mountain wave ice clouds (Khosrawi et al., 2011).

One critical parameter determining the rate and extent of vertical $\mathrm{HNO}_{3}$ redistribution in the polar vortex is the nucleation rate for NAT particle formation. The simulation of denitrification by CLaMS is performed using particle trajectories that follow individual NAT particles. Previous simulations (Grooß et al., 2005) that assumed globally constant nucleation rates for all locations with $T<T_{\mathrm{NAT}}$ produced reasonable results for the winter 2002/3 using a nucleation rate of $7.8 \times 10^{-6} \mathrm{~cm}^{-3} \mathrm{~h}^{-1}$. Using the same nucleation rate, the observed vertical $\mathrm{NO}_{\mathrm{y}}$ redistribution in the winter 2009/10 was underestimated, suggesting faster NAT nucleation. In CLaMS simulations with the new nucleation rate parameterisation based on the active site model described in Holye et al. (2013), the vertical redistribution of $\mathrm{NO}_{\mathrm{y}}$ compares better to the $\mathrm{NO}_{\mathrm{y}}$ observations, but cannot fully resolve the smallscale structures of denitrification and renitrification (Grooß et al., 2013).

\subsection{Stability of the Arctic polar vortex}

Our understanding of the processes governing the stability and persistence of the Arctic vortex is still far from being complete. These processes are not confined to the polar vortex, and thus were not comprehensively addressed in RECONCILE (cf. Sect. 5). However, advancements were made.

For the first time, the ensemble prediction system has been analysed to investigate the forecast skill of the ECMWF Integrated Forecast System (Dörnbrack et al., 2012). It was shown that the 10-day forecasts provide a reliable means to predict the onset and the process of the SSW. The false alarm rate was low, and almost all members of the ensemble predicted the correct evolution. However, after the warming happened, the ensemble predictions deviated significantly, leading to a high ensemble spread.

A comprehensive analysis of SSWs in past Arctic winters suggests profound tropospheric forcing for the observed major SSWs (Kuttippurath and Nikulin, 2012). The authors also present a statistical analysis for the past 17 Arctic winters showing that ozone loss is closely correlated to the intensity and timing of major warmings in each winter, early warmings in December-January leading to minimal ozone loss. It is further argued that a particularly high frequency of major warmings observed in recent Arctic winters could have significant implications for stratospheric ozone trends in the Northern Hemisphere.

Equally, a better characterisation of the tropospheric patterns preceding polar stratospheric coolings are needed to understand ozone trends and potential ozone depletion in a changing climate. Both during the cold episode of January 2010 (Dörnbrack et al., 2012) and during the first part of the winter 2010/11, pronounced polar stratospheric coolings and vortex intensification were a response to the weakened planetary wave flux from the troposphere into the stratosphere. The lessening of the wave flux seemed to originate from the interaction of a blocking high in the North Pacific with the planetary wave trough over the Far East. This evolution follows the typical amplification of the positive phase of the western Pacific teleconnection pattern (Nishii et al., 2011; Orsolini et al., 2009). Recent modelling studies (Hurwitz et al., 2011) further indicate the important role of sea surface temperatures and circulation anomalies over the North Pacific in modulating polar stratospheric temperatures.

Major stratospheric warmings also lead to strong exchange between the vortex and the surrounding mid-latitudes with profound effects on vortex composition. For the major warming in February 2010, these effects could be investigated in great detail using tracer observations on board the M55 Geophysica, including remote sensing measurements with unprecedented vertical and horizontal resolution by CRISTANF (Kalicinsky et al., 2013) and highly resolved in situ measurements by HAGAR (Hösen et al., 2012). These measurements, along with Lagrangian transport simulations by the CLaMS CTM show that, following the split of the vortex, mid-latitude air masses were entrained when the vortex reformed, and subsequently mixed inside the vortex (cf. Sect. 2.1.1). The detailed case studies following the February 2010 warming event and the good ability of the CLaMS CTM to capture the associated transport and mixing corroborate our understanding of the effects of major warmings on the chemical composition of the vortex.

\subsection{Trends in ozone and ozone-depleting substances}

Besides the process studies described above, which have been the primary focus of the RECONCILE project, two investigations looked at trends in ozone and ozone-depleting substances. The latter may lead to revised forcing parameters of CCM, and thereby contribute to improved predictions of future ozone and climate trends.

\subsubsection{Antarctic ozone recovery}

Using two regression methods (piece-wise linear trend and effective equivalent stratospheric chlorine functions) on three different datasets (ground-based, TOMS/OMI, and multisensor reanalysis data) for the 2000-2010 period that have not been used together for estimating of Antarctic ozone trends before, Kuttippurath et al. (2013) have revealed a clear 
signature of Antarctic ozone recovery, in agreement with a study by Salby et al. (2011) based on TOMS/OMI data over the 1979-2009 period. They show a September-November trend of about $-4.6 \mathrm{DU} \mathrm{yr}^{-1}$ over the period 1979-1999, and of $+1 \mathrm{DU} \mathrm{yr}^{-1}$ or $+2.6 \mathrm{DU} \mathrm{yr}^{-1}$ (depending on the regression method used) for the 2000-2010 period. Kuttippurath et al. (2013) also go beyond the Salby et al. (2011) work and other previous Antarctic ozone trend studies (WMO, 2011, and references therein) by applying three different vortex definitions to diagnose the strength of the recovery signal and also testing the significance of the recovery signal with respect to the changes in the Antarctic meteorology. This makes their trend estimates of Antarctic ozone more robust than in these previous studies, and adds confidence to the observed ozone recovery signal.

\subsubsection{Ozone depletion potentials, lifetimes, and GHG potentials of CFCs and HCFCs}

A number of important long-lived brominated and chlorinated source gases (i.e. the the three major CFCs and HCFCs, the two major halons, $\mathrm{CCl}_{4}$ and $\mathrm{CH}_{3} \mathrm{CCl}_{3}$ ) were sampled by the whole air sampler (WAS) on board the Geophysica and subsequently analysed in the laboratory. Together with age-of-air measurements inferred from $\mathrm{SF}_{6}$, the results have been used for a re-evaluation of the stratospheric lifetimes of these compounds as well as their fractional release (i.e. the fraction that has released its halogens) and ozone depletion potentials (ODPs), all of which are policy-relevant quantities. As outlined in Laube et al. (2013), there are indications for considerably smaller fractional release resulting in a $22 \%$ reduction in the equivalent chlorine released from these gases at a mean age of $3 \mathrm{yr}$. The differences to earlier studies also illustrate the dependency of fractional release on the variability of the mean stratospheric transit times as well as changes in tropospheric source gas abundances. Moreover, the derived ratios between the stratospheric lifetimes of these compounds also indicate slower decomposition. In combination with the reduced fractional release this leads to smaller ODPs in many cases. Therefore these findings have the potential to significantly delay the recovery of the ozone layer. In addition, WAS measurements of other strong greenhouse gases (i.e. the CFC replacement HFC-227ea as well as the very long-lived $\mathrm{c}-\mathrm{C}_{4} \mathrm{~F}_{8}, \mathrm{C}_{4} \mathrm{~F}_{10}, \mathrm{C}_{5} \mathrm{~F}_{12}, \mathrm{C}_{6} \mathrm{~F}_{14}$, and $\mathrm{C}_{7} \mathrm{~F}_{16}$ ) have improved the knowledge of their atmospheric distributions (Laube et al., 2010b, 2012; Oram et al., 2012).

\section{Progress in global chemistry-climate modelling}

The main objective of the global modelling activity in RECONCILE is to assess the impact of results from the process studies described in the previous section on predictions of polar stratospheric ozone loss in a global CCM. This section describes the LMDz-Reprobus model used in RECON-
CILE and the implementation of process study results in this model, compares ensemble simulations with the upgraded model to the standard version and to observational records, and exhibits the changes in global spectral properties and temporal correlations of the time series produced by the model of improved chemistry module.

In addition to the studies with LMDz-Reprobus described below, scientific findings from the RECONCILE project have been incorporated in the Whole Atmosphere Community Climate Model (WACCM). PSC processes have been improved in WACCM to give a better representation of mixed PSCs, and the formation threshold for ice PSCs has been modified to agree with observations (Wegner et al., 2013b).

\subsection{The LMDz-Reprobus model and the RECONCILE upgrades}

LMDz-Reprobus (Marchand et al., 2012; Jourdain et al., 2008) couples the LMDZ general circulation model (Hourdin et al., 2013) and the Reprobus stratospheric chemistry package (Lefèvre et al., 1998, 1994). The configuration used in RECONCILE extends from the ground up to $65 \mathrm{~km}$ on 39 hybrid pressure vertical levels, and the horizontal resolution is $3.75^{\circ}$ in longitude and $1.875^{\circ}$ in latitude. The chemical package is comprehensive and includes the usual set of gas-phase and heterogeneous reaction rates - already including those on binaries (cf. Sect. 3.2) - recommended by the JPL evaluation (Sander et al., 2011). For the treatment of polar stratospheric clouds, the pre-RECONCILE version uses a simple equilibrium scheme that predicts the existence of liquid (binary $\mathrm{H}_{2} \mathrm{O} / \mathrm{H}_{2} \mathrm{SO}_{4}$ or ternary $\mathrm{H}_{2} \mathrm{O} / \mathrm{H}_{2} \mathrm{SO}_{4} / \mathrm{HNO}_{3}$ solutions) and solid (NAT or $\mathrm{H}_{2} \mathrm{O}$ ice) aerosols from the local thermodynamic conditions in each model grid box. As for all equilibrium schemes, the scheme has no memory of the temperature history of the air mass, and the particles are not transported separately from one time step to the other. This usual treatment of PSCs in CCMs is computationally cheap but cannot represent properly the slow growth of large solid particles (such as NAT rocks) and their consequences on denitrification and ozone loss. However, even this simple scheme includes one small $(r=0.5 \mu \mathrm{m})$ and one large $(r=6.5 \mu \mathrm{m})$ mode of NAT particles, allowing for a basic treatment of NAT rocks that is usually absent in current CCMs.

In RECONCILE, the following updates were implemented in the LMDz-Reprobus CCM:

- Based on the results described in Sect. 3.1, no new reactions driving catalytic ozone loss were included, and $\mathrm{ClO}_{\mathrm{x}}$ parameterisations were adopted from Table 4 . $\mathrm{ClOOCl}$ photolysis cross sections that are in very close agreement with the RECONCILE findings were already included in the standard version because they had been updated in Sander et al. (2011) compared to older evaluations as a result of the international research activities described in Sect. 3.1. Therefore, the only changes compared to the reference model were 
in $k_{\mathrm{f}}$ and $K_{\text {eq }}$. Both adaptations slightly shift the $\mathrm{ClO}_{\mathrm{x}}$ equilibrium towards $\mathrm{ClO}$. This is not expected to have a significant impact on the overall rate of catalytic ozone loss, but may enlarge the relative importance of the $\mathrm{ClO}-\mathrm{BrO}$ cycle compared to the $\mathrm{ClO}$ dimer cycle in the model.

- A more realistic PSC parameterisation has been developed based on the results described in Sect. 3.3. The new PSC scheme takes into account a tracer keeping the memory of the time spent under $T_{\mathrm{NAT}}$, allowing for a more realistic slow growth of NAT particles. Heterogeneous nucleation of NAT is now allowed above the ice frost point, but one week of temperatures continuously below $T_{\mathrm{NAT}}$ is required in a given air mass to grow a PSC particle of $r=7.5 \mu \mathrm{m}$. This is in contrast with the previous equilibrium scheme for which NAT rocks were formed as soon as temperatures dropped below $T_{\mathrm{NAT}}$.

\subsection{Ensemble simulations of past and future ozone depletion}

Three transient CCM simulations have been integrated over the period 1960-2050: the reference simulation (REF) with the equilibrium NAT scheme and standard kinetics, a "corrected temperature" simulation (TC) with the same equilibrium NAT scheme but with polar temperatures corrected from their past bias relative to ERA-Interim, and a "RECONCILE" simulation (NMP) with corrected temperatures and improved microphysics and kinetics. External forcings (such as greenhouse gases or ozone-depleting substances) used in all simulations are those prescribed in the CCMVal-2 international project of evaluation of chemistry-climate models (SPARC, 2010).

Figure 16 shows that correcting the cold bias in the LMDzReprobus CCM is not sufficient to reproduce properly the past ozone loss over the Antarctic. In this region the new RECONCILE PSC scheme and $\mathrm{ClO}_{\mathrm{x}}$ kinetic parameters have a clear positive impact on the results. Due to large interannual variability this effect is not identified in the Arctic.

Regarding future trends, the RECONCILE parameters have in general little impact on the results, indicating that the degree of future ozone loss is more sensitive to other parameters than the ones investigated here. In the Antarctic spring, differences between the three runs decrease with time, which is expected in a future atmosphere where PSCs and chlorine should play a lesser chemical role. The stable return to preozone-hole October values does not occur before 2050 for all simulations, in good agreement with previous CCM predictions (SPARC, 2010). Results in the Arctic are more difficult to evaluate due to the chaotic nature of the dynamics. There are, however, occurrences of very low March ozone values ( 300 DU) before 2020 in the REF and TC simulations. These episodes of strong ozone depletion are not ob- served in the RECONCILE run. After 2020, the three simulations show a similar long-term positive $\mathrm{O}_{3}$ trend. The March ozone level of 1970s is crossed towards 2030. This result is also in line with previous CCM studies (SPARC, 2010). A full analysis of the CCM runs carried out within the RECONCILE framework that includes the impact on trends for global, mid-latitude, and tropical ozone will be presented in a future paper.

\subsection{Model evaluation by spectral weight and detrended fluctuation analyses}

While the last big cross-validation project CCMVal-2 (Eyring et al., 2010; Gillett et al., 2011; SPARC, 2010) provided comprehensive bias estimates for several models, we extended the methodology by comparing dynamical features of empirical data and time series obtained by the LMDzReprobus simulations. The main focus was on a global analysis of spectral properties, two-point correlations determined by detrended fluctuation analysis (DFA, e.g. Derby, 2004), and detecting higher order correlations by the spectral surrogate method (Kantz and Schreiber, 2004).

Spectral properties were evaluated by extracting the spectral weights (relative strength) of semi-annual, annual, and quasi-biennial oscillations (QBO) with respect to the integrated power spectra. The spectral weight in a given frequency band provides information about the variance of the original signal, e.g. about the variance explained by an annual oscillation. The method of detrended fluctuation analysis (DFA) has become a standard tool in time series analysis (e.g. Derby, 2004) for quantifying two-point correlations in non-stationary signals, because the autocorrelation function or the power spectrum can erroneously indicate longrange correlations in the absence of strict stationarity. Higher order correlations were tested by computing the time reversal asymmetry statistics (it is essentially based on timelagged third moments) for the original and surrogate datasets where only two-point correlations are preserved (Kantz and Schreiber, 2004).

In a preparatory study, Homonnai et al. (2013) have tested the methodology by a global statistical analysis of total column ozone records obtained from satellite measurements (Bodeker Scientific, http://www.bodekerscientific.com/) and from two CCMs, the original version of LMDz-Reprobus and the model of the Meteorological Research Institute, Tsukuba, Japan (MRI). The latter was chosen because its dynamical core is very similar to $\mathrm{LMDz}$ with a seemingly important difference of producing QBO signal along the equator. The comparison revealed some anomalies in the model representations at each spectral component. The tails of the spectra demonstrate that both models underestimate high-frequency (daily) ozone variability. Furthermore, the DFA analysis of ozone anomaly time series (climatic mean values are removed) revealed that both models reproduce the characteristic geographic dependence of correlation strength in the 


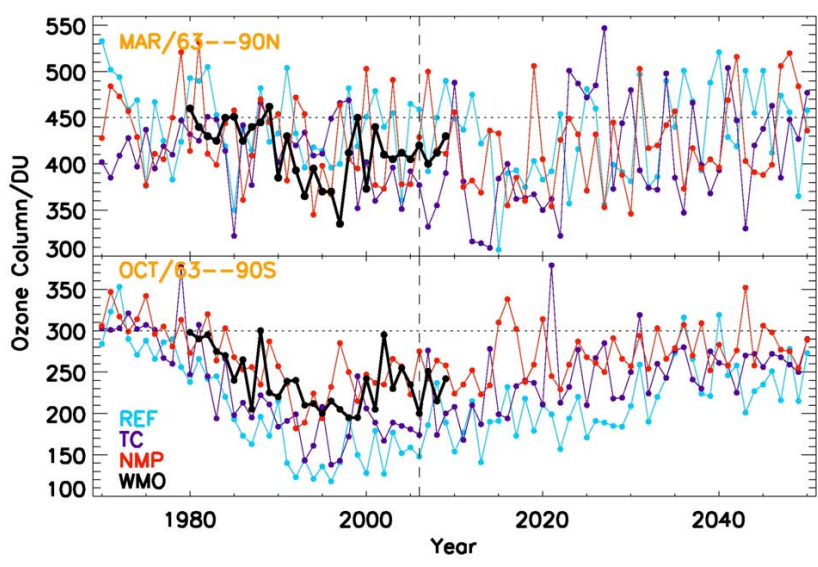

Fig. 16. Springtime total ozone values (DU) calculated by the LMDz CCM in polar regions from 1970 to 2050 for the three simulations (see main text for details). TOMS/OMI/SBUV merged satellite data (WMO) from 1980 to 2010 are shown for comparison. Top: March, Northern Hemisphere 63-90 N. Bottom: October, Southern Hemisphere 63-90 $\mathrm{S}$.

overlapping area with measurements (latitude band between $60^{\circ} \mathrm{S}$ and $60^{\circ} \mathrm{N}$ ). The values of precise correlation exponents are hard to obtain over regions where QBO or other strong nonstationarities (ozone hole) are present; however, the missing QBO component in the LMDz-Reprobus data has no demonstrable effects away from the narrow equatorial band. In spite of all the numerical difficulties, significant long-range correlations are detected for total ozone over all geographic locations (Homonnai et al., 2013). The results on higher order nonlinear correlations will be reported elsewhere.

The three new runs described above (REF, TC, and NMP) are evaluated by the same methodology. Here we show characteristic examples of the results; details will be published in a subsequent paper. Figure 17a shows the difference in the spectral weights of the annual peak (area under the peak normalised by the integrated total power) between the results of NMP and REF runs. The geographic distribution of the differences is far from being random noise; the changes appear over large coherent regions. The patterns clearly demonstrate that all the sub-processes in the CCM models are in interaction with each other, and thus a change in the chemical species distribution like ozone can induce changes in the radiative calculation and also on the dynamics and transport. There is no established methodology to clearly separate and identify the different impacts. Figure 17b illustrates the zonal mean values of the DFA-3 exponents (third-order polynomial local detrending) for the three runs of LMDz-Reprobus. The differences are small but significant over the Northern Hemisphere. The pattern reproduces the behaviour of the same quantity obtained for measured data (Homonnai et al., 2013), i.e. increased correlation strength over the equatorial and polar regions. All numerical values are larger than 0.5 every- where, suggesting the presence of long-range correlations. Note that measured data are scarce during the polar nights, and therefore correlation analysis is not possible poleward of $60^{\circ}$ latitude. The purpose of our validation procedure was to get a stronger confidence of CCM results for polar locations where spectral methods work only with a restricted temporal coverage.

\section{Conclusions}

Besides providing the foundation for the advancement of our understanding of processes involved in polar ozone depletion - the overall objective of RECONCILE - the data obtained during the aircraft and Match campaigns have been useful in several ways. The Match sonde data from 2011 have contributed to the quantification of the record-breaking ozone loss in this unusual winter. Measurements of a large number of ODPs made during the Geophysica campaign were used for assessing the trends and lifetimes of these compounds. The dataset is placed at the disposal of the larger scientific community for further scientific exploitation. $\mathrm{Fu}$ ture stratospheric campaigns will benefit from technological advances made in the framework of the field campaigns such as enhanced flight-planning tools and the deployment of the novel impactor to collect non-volatile stratospheric aerosol for laboratory analysis. Improvements to the interpretation of IR limb-sounding data including an enhanced resolution of trace gas distributions and novel methods to quantify and discriminate particle types may also improve the analysis of space-borne versions of such instruments. Two novel laboratory experiments addressed the issues of $\mathrm{ClO}$ dimer kinetics and NAT nucleation.

The results from laboratory studies and field observations from the RECONCILE campaigns, related missions, and satellites were used in scientific studies that have substantially advanced our understanding of the processes destroying ozone in the polar vortex. In concert with efforts made by others, the uncertainty of the $\mathrm{ClOOCl}$ photolysis rate has been reduced to about $20 \%$ and reconciliation of kinetic parameters governing $\mathrm{ClO}_{\mathrm{x}}$-catalysed polar ozone loss has been achieved at least to the degree relevant for global models. The set of kinetic parameters in best agreement with observations at least in the RECONCILE studies was incorporated into the LMDz-Reprobus CCM. The novel constraint on the $J_{\mathrm{BrONO}_{2}} / k_{\mathrm{BrO}+\mathrm{NO}_{2}}$ ratio leads to a reduced estimate of total stratospheric $\mathrm{Br}_{\mathrm{y}}$ using the inorganic method, and consequently to a smaller (and tighter) estimate on the contribution of VSLS to total stratospheric bromine, i.e. $4 \pm 2.5 \mathrm{ppt}$ instead of 6 (range 3-8) ppt reported in WMO (2011). A chemical analysis of the non-volatile fraction of the background aerosol confirmed the expected presence of meteoritic material, but other components including crustal material and particles of anthropogenic origin were also found. The role of heterogeneous nucleation on such particles for 

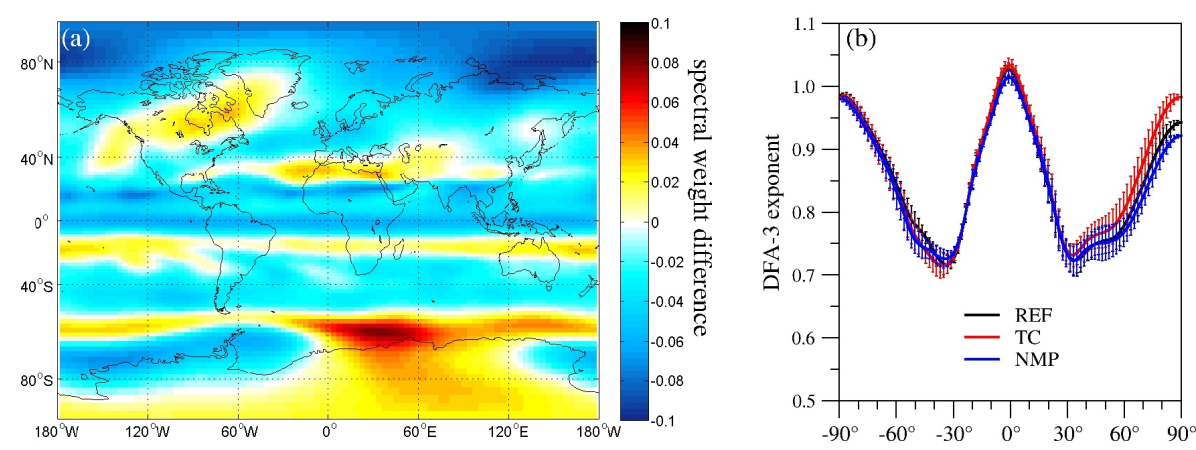

Fig. 17. (a) Geographic distribution of the difference of spectral weights (colour coded) between the NMP and REF results. (b) Zonal mean values of the DFA-3 exponents for the three runs.

PSC formation has been unequivocally demonstrated, and an advanced scheme of PSC formation and processing has been developed. This was adapted into the LMDz-Reprobus CCM. The importance of a correct representation of PSCs for accurately simulating the degree of denitrification - and thus polar ozone loss - has been demonstrated in models on all scales, including the CCM simulations that are doing a better job in reproducing observed ozone losses over Antarctica with the upgraded non-equilibrium PSC scheme. Under cold conditions, rates of heterogeneous chlorine activation on binary aerosols from earlier laboratory studies are sufficiently fast to drive chlorine activation. For the overall rate of heterogeneous activation, the increase of activation rates with decreasing temperature is relatively more important than the increase due to enhanced surface area provided by PSCs compared to binary aerosol. While it was not possible to quantify how much heterogeneous activation takes place on each particle type, there is evidence that in early winter and under denitrified conditions, cold binaries contribute substantially to the observed chlorine activation. Because, under most circumstances, PSCs are present when temperatures are low enough for efficient heterogeneous chemistry, the effect of cold binaries on ozone loss is probably limited. In any case, the abundance of NAT PSCs is an important factor in determining the degree of ozone depletion in any particular winter due to the role of denitrification described above. Low sensitivity of ozone loss to parameterisations of microphysical and chemical processes in the polar vortex was observed in CTM studies for the relatively warm winter $2009 / 10$ as well as in the long-term CCM simulations, suggesting that the interannual variability in Arctic ozone depletion is largely driven by dynamic processes determining the stability of the polar vortex.

Reduced uncertainties and more realistic process parameterisations - particularly with respect to PSC processes resulting from RECONCILE enhance the robustness of the LMDz-Reprobus CCM and increase confidence in future ozone trends calculated by this model. Hopefully, the improved understanding of some details on polar ozone deple- tion will also find its way into other models. But besides representing an important step towards closure with respect to some existing uncertainties, some of the RECONCILE results also raised new questions. The observation of the coldest Arctic winter on record in 2010/11, prompting an unprecedented degree of Arctic ozone loss and related increases in UV radiation and the lack of prognostic tools that could have predicted such an event, made it evident that efforts to understand exactly what drives cold Arctic winters and the development of predictive capabilities are imperative. The observation of non-volatile particles of meteoritic, crustal, and anthropogenic origin inside the Arctic vortex challenges some of our presumptions on how materials, and especially aerosols, are transported to and distributed through the stratosphere. This is particularly important if we want to understand and model how climate change might affect the composition of the stratosphere in the future.

These questions concern the preconditions for Arctic ozone depletion rather than the actual ozone destruction process. For a full understanding of the whole problem a more global view is required, including also the tropics as the main source of stratospheric trace gases and particles (e.g. Fueglistaler et al., 2009). Both the Brewer-Dobson circulation and the mixing between troposphere and stratosphere will likely strengthen in a changing climate (Butchart and Scaife, 2001; Fomichev et al., 2007) with possible influences on the global distribution of trace species, and thereby on ozone depletion at high latitudes. For these processes wave activity in the tropics and extratropics plays a key role (e.g. Zhou et al., 2012). Interactions between the tropics and high latitudes also have influence on the stability of the polar vortex (e.g. Garfinkel et al., 2012; Holton and Tan, 1980), and it is indicated that, in a changing climate, major stratospheric warmings will shift towards late winter (e.g. Naoe and Shibata, 2012) with potentially important consequences for ozone loss in the Arctic. For predicting how climate change will affect the ozone layer in future, it will also be necessary to quantify the contribution of GHG forcing to current and future trends in the atmospheric conditions. 
Investigations into these issues will be needed to complement the work done in RECONCILE and further advance our understanding of Arctic ozone depletion.

Acknowledgements. RECONCILE is funded by the European Commission under the grant number RECONCILE-226365-FP7ENV-2008-1. This funding enabled the scientific findings described in this paper, and is greatly appreciated. We are also grateful to the EC scientific officers Claus Brüning and Franz Immler for their support. We also acknowledge important contributions from institutional funding, and thank the involved scientists and administrative and technical stuff at the partner institutions who supported the project work in many ways. We thank MDB and in particular the M55-Geophysica pilots Oleg Shepetkov and Oleg Kononenko and the ground crew led by G. Belyaev for their fantastic work during the aircraft campaign. For invaluable support with logistics, flight permissions, and many other aspects of the aircraft campaign, we thank Rolf Maser and Harald Franke from ENVISCOPE, Heinz Finkenzeller from FINKCAS, Kurt Mäki and the Kiruna airport crew, and the Longyearbyen airport crew. Support for M. C. Pitts is provided under the auspices of the NASA CALIPSO/CloudSat Science Team. Support for L. R. Poole is provided under NASA contract NNL11AA10D. Work at the Jet Propulsion Laboratory, California Institute of Technology, was done under contract with the National Aeronautics and Space Administration. The Atmospheric Chemistry Experiment (ACE), also known as SCISAT, is a Canadian-led mission mainly supported by the Canadian Space Agency. Work at the University of East Anglia was made possible through funding from the UK Natural Environment Research Council (research fellowships NE/F015585/1 \& NE/I021918/1). The atmospheric sounding campaign at FMI Sodankylä was supported by the EU through the Lapland Atmosphere-Biosphere Facility (LAPBIAT2) project. The Geophysica flight on 10 March 2010 was funded by the ESA under the PremierEx project. The PremierEx project also funded two Geophysica flights in autumn 2009 from Oberpfaffenhofen, Germany, that provided an invaluable opportunity for instrument testing prior to the Kiruna activities. We thank Bodeker Scientific for the total column ozone data and ECMWF for providing forecast, analysis and reanalysis data. Some of these data were available through the special project "Effect of non-hydrostatic gravity waves on the stratosphere above Scandinavia" by one of the authors (A.D.). Finally, we thank Susan Solomon, Jean-Pierre Pommereau, Rob MacKenzie, and Ross Salawitch for constructive reviews and valuable comments that helped to improve the manuscript and greatly enhanced the value of this paper.

The service charges for this open access publication have been covered by a Research Centre of the Helmholtz Association.

Edited by: D. Knopf

\section{References}

Abbatt, J. P. D. and Molina, M. J.: Heterogeneous interactions of $\mathrm{ClONO} 2$ and $\mathrm{HCl}$ on nitric acid trihydrate at $202 \mathrm{~K}$, J. Phys. Chem., 96, 7674-7679, 1992.

Allaart, M., van Weele, M., Fortuin, P., and Kelder, H.: An empirical model to predict the UV-index based on solar zenith angles and total ozone, Meteorol. Appl., 11, 59-65, 2004.

Anderson, J. G., Wilmouth, D. M., Smith, J. B., and Sayres, D. S.: UV Dosage Levels in Summer: Increased Risk of Ozone Loss from Convectively Injected Water Vapor, Science, 337, 835-839, 2012.

Ayarzaguena, B., Langematz, U., and Serrano, E.: Tropospheric forcing of the stratosphere: A comparative study of the two different major stratospheric warmings in 2009 and 2010,, J. Geophys. Res, 116, D18114, doi:10.1029/2010JD015023, 2011.

Bacmeister, J. T., Eckermann, S. D., Tsias, A., Carslaw, K. S., and Peter, T.: Mesoscale temperature fluctuations induced by a spectrum of gravity waves: a comparison of parameterizations and their impact on stratospheric microphysics, J. Atmos. Sci., 56, 1913-1924, doi:10.1175/15200469(1999)056<1913:MTFIBA>2.0.CO;2, 1999.

Balis, D., Isaksen, I. S. A., Zerefos, C., Zyrichidou, I., Eleftheratos, K., Tourpali, K., Bojkov, R., Rognerud, B., Stordal, F., Søvde, O. A., and Orsolini, Y.: Observed and modelled record ozone decline over the Arctic during winter/spring 2011, Geophys. Res. Lett., 38, L23801, doi:10.1029/2011gl049259, 2011.

Baumgardner, D., Jonsson, H., Dawson, W., O'Connor, D., and Newton, R.: The cloud, aerosol and precipitation spectrometer: a new instrument for cloud investigations, Atmos. Res., 59, 251264, 2001.

Bernath, P. F., McElroy, C. T., Abrams, M. C., Boone, C. D., Butler, M., Camy-Peyret, C., Carleer, M., Clerbaux, C., Coheur, P. F., Colin, R., DeCola, P., DeMazière, M., Drummond, J. R., Dufour, D., Evans, W. F. J., Fast, H., Fussen, D., Gilbert, K., Jennings, D. E., Llewellyn, E. J., Lowe, R. P., Mahieu, E., McConnell, J. C., McHugh, M., McLeod, S. D., Michaud, R., Midwinter, C., Nassar, R., Nichitiu, F., Nowlan, C., Rinsland, C. P., Rochon, Y. J., Rowlands, N., Semeniuk, K., Simon, P., Skelto, R., Sloan, J. J., Soucy, M. A., Strong, K., Tremblay, P., Turnbull, D., Walker, K. A., Walkty, I., Wardle, D. A., Wehrle, V., Zander, R., and Zou, J.: Atmospheric Chemistry Experiment (ACE): Mission overview, Geophys. Res. Lett., 32, L15S01, doi:10.1029/2005GL022386, 2005.

Bernhard, G., Manney, G., Fioletov, V., Grooß, J.-U., Heikkilä, A., Johnsen, B., Koskela, T., Lakkala, K., Müller, R., Myhre, C. L., and Rex, M.: Arctic Ozone and UV radiation, B. Am. Meteor. Soc., 93, S129-S132, doi:10.1175/2012BAMSStateoftheClimate.1, 2012.

Biermann, U. M., Presper, T., Koop, T., Mossinger, J., Crutzen, P. J., and Peter, T.: The unsuitability of meteoritic and other nuclei for polar stratospheric cloud freezing, Geophys. Res. Lett., 23, 1693-1696, 1996.

Bigg, E. K., Ono, A., and Thompson, W. J.: Aerosols at altitudes between 20 and $37 \mathrm{~km}$, Tellus, 22, 550-563, 1970.

Bogdan, A., Kulmala, M., MacKenzie, A. R., Laaksonen, A., Molina, M. J., and Avramenko, A.: The study of finely divided aqueous systems as a clue to understanding the formation mechanisms of polar stratospheric clouds: $2 . \mathrm{HCl} / \mathrm{H}_{2} \mathrm{O}$ and $\mathrm{HNO}_{3} / \mathrm{HCl} / \mathrm{H}_{2} \mathrm{O}$ systems, J. Geophys. Res, 108, 4303, 
doi:10.1029/2002JD002606, 2003a.

Bogdan, A., Kulmala, M., MacKenzie, A. R., Laaksonen, A., Molina, M. J., and Avramenko, A.: The study of finely divided aqueous systems as a clue to understanding the formation mechanisms of polar stratospheric clouds: $1 . \mathrm{HNO}_{3} / \mathrm{H} 2 \mathrm{O}$ and $\mathrm{H} 2 \mathrm{SO} 4 / \mathrm{H} 2 \mathrm{O}$ systems, J. Geophys. Res, 108, 4302, doi:10.1029/2002JD002605, 2003b.

Brabec, M., Wienhold, F. G., Luo, B. P., Vömel, H., Immler, F., Steiner, P., Hausammann, E., Weers, U., and Peter, T.: Particle backscatter and relative humidity measured across cirrus clouds and comparison with microphysical cirrus modelling, Atmos. Chem. Phys., 12, 9135-9148, doi:10.5194/acp-12-9135-2012, 2012.

Brasseur, G. P.: Creating Knowledge from the Confrontation of Observations and Models: The Case of Stratospheric Ozone, in: Climate Variability and Extremes During the Past 100 Years, edited by: Brönnimann, S., Luterbacher, J., Ewen, T., Diaz, H. F., Stolarski, R. S., and Neu, U., Springer, 303-316, 2008.

Brinckmann, S., Engel, A., Bönisch, H., Quack, B., and Atlas, E.: Short-lived brominated hydrocarbons - observations in the source regions and the tropical tropopause layer, Atmos. Chem. Phys., 12, 1213-1228, doi:10.5194/acp-12-1213-2012, 2012.

Brooks, S. D., Baumgardner, D., Gandrud, B., Dye, J. E., Northway, M. J., Fahey, D. W., Bui, T. P., Toon, O. B., and Tolbert, M. A.: Measurements of large stratospheric particles in the Arctic polar vortex, J. Geophys. Res., 108, 4652, doi:10.1029/2002JD003278, 2003.

Buontempo, C., Cairo, F., Di Donfrancesco, G., Morbidini, R., Viterbini, M., and Adriani, A.: Optical measurements of atmospheric particles from airborne platforms: in situ and remote sensing instruments for balloons and aircrafts, Ann. Geophys., 49, 57-64, 2006,

http://www.ann-geophys.net/49/57/2006/.

Butchart, N. and Scaife, A. A.: Removal of chlorofluorocarbons by increased mass exchange between the stratosphere and troposphere in a changing climate, Nature, 410, 799-802, 2001.

Cairo, F., Pommereau, J. P., Law, K. S., Schlager, H., Garnier, A., Fierli, F., Ern, M., Streibel, M., Arabas, S., Borrmann, S., Berthelier, J. J., Blom, C., Christensen, T., D'Amato, F., Di Donfrancesco, G., Deshler, T., Diedhiou, A., Durry, G., Engelsen, O., Goutail, F., Harris, N. R. P., Kerstel, E. R. T., Khaykin, S., Konopka, P., Kylling, A., Larsen, N., Lebel, T., Liu, X., MacKenzie, A. R., Nielsen, J., Oulanowski, A., Parker, D. J., Pelon, J., Polcher, J., Pyle, J. A., Ravegnani, F., Rivière, E. D., Robinson, A. D., Röckmann, T., Schiller, C., Simões, F., Stefanutti, L., Stroh, F., Some, L., Siegmund, P., Sitnikov, N., Vernier, J. P., Volk, C. M., Voigt, C., von Hobe, M., Viciani, S., and Yushkov, V.: An introduction to the SCOUT-AMMA stratospheric aircraft, balloons and sondes campaign in West Africa, August 2006: rationale and roadmap, Atmos. Chem. Phys., 10, 2237-2256, doi:10.5194/acp-10-2237-2010, 2010.

Carslaw, K. S. and Peter, T.: Uncertainties in reactive uptake coefficients for solid stratospheric particles. 1. Surface chemistry, Geophys. Res. Lett., 24, 1743-1746, 1997.

Carslaw, K. S., Peter, T., and Müller, R.: Uncertainties in reactive uptake coefficients for solid stratospheric particles. 2. Effect on ozone depletion, Geophys. Res. Lett., 24, 1747-1750, 1997.

Carslaw, K. S., Wirth, M., Tsias, A., Luo, B. P., Dörnbrack, A., Leutbecher, M., Volkert, H., Renger, W., Bacmeister, J. T.,
Reimer, E., and Peter, T.: Increased stratospheric ozone depletion due to mountain-induced atmospheric waves, Nature, 391, 675-678, 1998.

Chen, H. Y., Lien, C. Y., Lin, W. Y., Lee, Y. T., and Lin, J. J.: UV Absorption Cross Sections of $\mathrm{ClOOCl}$ Are Consistent with Ozone Degradation Models, Science, 324, 781-784, 2009.

Chubachi, S. and Kajiwara, R.: Total Ozone Variations at Syowa, Antarctica, Geophys. Res. Lett., 13, 1197-1198, 1986.

Cox, R. A., MacKenzie, A. R., Müller, R. H., Peter, T., and Crutzen, P. J.: Activation of stratospheric chlorine by reactions in liquid sulphuric acid, Geophys. Res. Lett., 21, 1439-1442, doi:10.1029/93gl03073, 1994.

Crutzen, P. J.: Albedo enhancement by stratospheric sulfur injections: A contribution to resolve a policy dilemma?, Climatic Change, 77, 211-219, 2006.

Crutzen, P. J., Müller, R., Brühl, C., and Peter, T.: On the Potential Importance of the Gas-Phase Reaction $\mathrm{CH}_{3} \mathrm{O}_{2}+\mathrm{ClO} \rightarrow \mathrm{ClOO}$ $+\mathrm{CH}_{3} \mathrm{O}$ and the Heterogeneous Reaction $\mathrm{HOCl}+\mathrm{HCl} \rightarrow \mathrm{H}_{2} \mathrm{O}$ $+\mathrm{Cl}_{2}$ in Ozone Hole Chemistry, Geophys. Res. Lett., 19, 11131116, 1992.

Curtius, J., Weigel, R., Vössing, H.-J., Wernli, H., Werner, A., Volk, C.-M., Konopka, P., Krebsbach, M., Schiller, C., Roiger, A., Schlager, H., Dreiling, V., and Borrmann, S.: Observations of meteoric material and implications for aerosol nucleation in the winter Arctic lower stratosphere derived from in situ particle measurements, Atmos. Chem. Phys., 5, 3053-3069, doi:10.5194/acp-5-3053-2005, 2005.

Dameris, M. and Baldwin, M. P.: Impact of Climate Change on the Stratospheric Ozone Layer, in: Stratospheric Ozone Depletion and Climate Change, edited by: Müller, R., RSC Publishing, Cambridge, 214-252, 2012.

Dameris, M., Wirth, M., Renger, W., and Grewe, V.: Definition of the polar vortex edge by LIDAR data of the stratospheric aerosol: A comparison with values of potential vorticity, Beitr. Phys. Atmos., 68, 113-119, 1995.

de Lange, A., Birk, M., de Lange, G., Friedl-Vallon, F., Kiselev, O., Koshelets, V., Maucher, G., Oelhaf, H., Selig, A., Vogt, P., Wagner, G., and Landgraf, J.: $\mathrm{HCl}$ and $\mathrm{ClO}$ in activated Arctic air; first retrieved vertical profiles from TELIS submillimetre limb spectra, Atmos. Meas. Tech., 5, 487-500, doi:10.5194/amt5-487-2012, 2012.

Derby, N. B.: Assessing the Detrended Fluctuation Analysis Method of Estimating the Hurst Coefficient, University of Washington, Seattle, WA, USA, 2004.

de Reus, M., Borrmann, S., Bansemer, A., Heymsfield, A. J., Weigel, R., Schiller, C., Mitev, V., Frey, W., Kunkel, D., Kürten, A., Curtius, J., Sitnikov, N. M., Ulanovsky, A., and Ravegnani, F.: Evidence for ice particles in the tropical stratosphere from in-situ measurements, Atmos. Chem. Phys., 9, 6775-6792, doi:10.5194/acp-9-6775-2009, 2009.

Deshler, T., Peter, T., Müller, R., and Crutzen, P.: The lifetime of leewave-induced ice particles in the Arctic stratosphere: I. Balloonborne observations, Geophys. Res. Lett., 21, 1327-1330, doi:10.1029/93gl03228, 1994.

Dorf, M., Butler, J. H., Butz, A., Camy-Peyret, C., Chipperfield, M. P., Kritten, L., Montzka, S. A., Simmes, B., Weidner, F., and Pfeilsticker, K.: Long-term observations of stratospheric bromine reveal slow down in growth, Geophys. Res. Lett., 33, L24803, doi:10.1029/2006gl027714, 2006. 
Dörnbrack, A., Leutbecher, M., Volkert, H., and Wirth, M.: Mesoscale forecasts of stratospheric mountain waves, Meteorol. Appl., 5, 117-126, 1998.

Dörnbrack, A., Leutbecher, M., Kivi, R., and Kyrö, E.: Mountain wave induced record low stratospheric temperatures above Northern Scandinavia, Tellus, 51A, 951-963, 1999.

Dörnbrack, A., Pitts, M. C., Poole, L. R., Orsolini, Y. J., Nishii, K., and Nakamura, H.: The 2009-2010 Arctic stratospheric winter general evolution, mountain waves and predictability of an operational weather forecast model, Atmos. Chem. Phys., 12, 36593675, doi:10.5194/acp-12-3659-2012, 2012.

Drdla, K. and Müller, R.: Temperature thresholds for chlorine activation and ozone loss in the polar stratosphere, Ann. Geophys., 30, 1055-1073, doi:10.5194/angeo-30-1055-2012, 2012

Drdla, K., Schoeberl, M. R., and Browell, E. V.: Microphysical modeling of the 1999-2000 Arctic winter: 1. Polar stratospheric clouds, denitrification, and dehydration, J. Geophys. Res., 108, 8312, doi:10.1029/2001JD000782, 2003.

Dye, J. E., Baumgardner, D., Gandrud, B. W., Kawa, S. R., Kelly, K. K., Loewenstein, M., Ferry, G. V., Chan, K. R., and Gary, B. L.: Particle Size Distributions in Arctic Polar Stratospheric Clouds, Growth and Freezing of Sulfuric Acid Droplets, and Implications for Cloud Formation, J. Geophys. Res., 97, 8015-8034, 1992.

Ebert, M., Weigel, R., Kandler, K., Günther, G., Grooß, J.-U., Weinbruch, S., and Borrmann, S.: Chemical composition and morphology of refractory aerosols sampled at stratospheric altitudes of the Arctic Winter Vortex, to be submitted to Atmos. Chem. Phys. Discuss., 2013.

Emde, C. and Mayer, B.: Simulation of solar radiation during a total eclipse: a challenge for radiative transfer, Atmos. Chem. Phys., 7, 2259-2270, doi:10.5194/acp-7-2259-2007, 2007.

Emde, C., Buras, R., and Mayer, B.: ALIS: An efficient method to compute high spectral resolution polarized solar radiances using the Monte Carlo approach, J. Quant. Spectrosc. Ra., 112, 16221631, doi:10.1016/j.jqsrt.2011.03.018, 2011.

Engel, I., Luo, B. P., Khaykin, S., Wienhold, F. G., Vömel, H., Kivi, R., Pitts, M. C., Grooß, J.-U., Hoyle, C. R., Lykov, A., and Peter, T.: Arctic Stratospheric Dehydration - Part 2: Microphysical Modeling, in preparation, 2013a.

Engel, I., Luo, B. P., Pitts, M. C., Poole, L. R., Hoyle, C. R., Grooß, J.-U., Dörnbrack, A., and Peter, T.: Heterogeneous formation of polar stratospheric clouds - Part 2: Nucleation of ice on synoptic scales, Atmos. Chem. Phys. Discuss., 13, 8831-8872, doi:10.5194/acpd-13-8831-2013, 2013 b.

Eskes, H. J., van der A, R. J., Brinksma, E. J., Veefkind, J. P., de Haan, J. F., and Valks, P. J. M.: Retrieval and validation of ozone columns derived from measurements of SCIAMACHY on Envisat, Atmos. Chem. Phys. Discuss., 5, 44294475, doi:10.5194/acpd-5-4429-2005, 2005.

Eyring, V., Cionni, I., Bodeker, G. E., Charlton-Perez, A. J., Kinnison, D. E., Scinocca, J. F., Waugh, D. W., Akiyoshi, H., Bekki, S., Chipperfield, M. P., Dameris, M., Dhomse, S., Frith, S. M., Garny, H., Gettelman, A., Kubin, A., Langematz, U., Mancini, E., Marchand, M., Nakamura, T., Oman, L. D., Pawson, S., Pitari, G., Plummer, D. A., Rozanov, E., Shepherd, T. G., Shibata, K., Tian, W., Braesicke, P., Hardiman, S. C., Lamarque, J. F., Morgenstern, O., Pyle, J. A., Smale, D., and Yamashita, Y.: Multimodel assessment of stratospheric ozone return dates and ozone recovery in CCMVal-2 models, Atmos. Chem. Phys., 10, 9451-
9472, doi:10.5194/acp-10-9451-2010, 2010.

Fahey, D. W., Gao, R. S., Carslaw, K. S., Kettleborough, J., Popp, P. J., Northway, M. J., Holecek, J. C., Ciciora, S. C., McLaughlin, R. J., Thompson, T. L., Winkler, R. H., Baumgardner, D. G., Gandrud, B., Wennberg, P. O., Dhaniyala, S., McKinney, K., Peter, T., Salawitch, R. J., Bui, T. P., Elkins, J. W., Webster, C. R., Atlas, E. L., Jost, H., Wilson, J. C., Herman, R. L., Kleinbohl, A., and von Konig, M.: The detection of large $\mathrm{HNO}_{3}$-containing particles in the winter arctic stratosphere, Science, 291, 1026-1031, 2001.

Farman, J. C., Gardiner, B. G., and Shanklin, J. D.: Large Losses of total Ozone in Antarctica Reveal Seasonal ClOx/NOx Interaction, Nature, 315, 207-210, 1985

Feng, W., Chipperfield, M. P., Davies, S., Mann, G. W., Carslaw, K. S., Dhomse, S., Harvey, L., Randall, C., and Santee, M. L.: Modelling the effect of denitrification on polar ozone depletion for Arctic winter 2004/2005, Atmos. Chem. Phys., 11, 6559-6573, doi:10.5194/acp-11-6559-2011, 2011.

Fomichev, V. I., Jonsson, A. I., De Grandpre, J., Beagley, S. R., McLandress, C., Semeniuk, K., and Shepherd, T. G.: Response of the middle atmosphere to $\mathrm{CO}(2)$ doubling: Results from the Canadian Middle Atmosphere Model, J. Climate, 20, 11211144, 2007.

Frieler, K., Rex, M., Salawitch, R. J., Canty, T., Streibel, M., Stimpfle, R. M., Pfeilsticker, K., Dorf, M., Weisenstein, D. K., and Godin-Beekmann, S.: Toward a better quantitative understanding of polar stratospheric ozone loss, Geophys. Res. Lett., 33, L10812, doi:10.1029/2005GL025466, 2006.

Froidevaux, L., Jiang, Y. B., Lambert, A., Livesey, N. J., Read, W. G., Waters, J. W., Fuller, R. A., Marcy, T. P., Popp, P. J., Gao, R. S., Fahey, D. W., Jucks, K. W., Stachnik, R. A., Toon, G. C., Christensen, L. E., Webster, C. R., Bernath, P. F., Boone, C. D., Walker, K. A., Pumphrey, H. C., Harwood, R. S., Manney, G. L., Schwartz, M. J., Daffer, W. H., Drouin, B. J., Cofield, R. E., Cuddy, D. T., Jarnot, R. F., Knosp, B. W., Perun, V. S., Snyder, W. V., Stek, P. C., Thurstans, R. P., and Wagner, P. A.: Validation of Aura Microwave Limb Sounder $\mathrm{HCl}$ measurements, J. Geophys. Res., 113, D15S25, doi:10.1029/2007JD009025, 2008.

Fueglistaler, S., Luo, B. P., Voigt, C., Carslaw, K. S., and Peter, Th.: NAT-rock formation by mother clouds: a microphysical model study, Atmos. Chem. Phys., 2, 93-98, doi:10.5194/acp-293-2002, 2002.

Fueglistaler, S., Dessler, A. E., Dunkerton, T. J., Folkins, I., Fu, Q., and Mote, P. W.: Tropical tropopause layer, Rev. Geophys., 47, RG1004, doi:10.1029/2008rg000267, 2009.

Garfinkel, C. I., Shaw, T. A., Hartmann, D. L., and Waugh, D W.: Does the Holton-Tan Mechanism Explain How the QuasiBiennial Oscillation Modulates the Arctic Polar Vortex?, J. Atmos. Sci., 69, 1713-1733, doi:10.1175/jas-d-11-0209.1, 2012.

Gary, B. L.: Mesoscale temperature fluctuations in the stratosphere, Atmos. Chem. Phys., 6, 4577-4589, doi:10.5194/acp-6-45772006, 2006.

Gernandt, H.: The vertical ozone distribution above the GDR research base, Antarctica in 1985, Geophys. Res. Lett., 14, 84-86, 1987.

Gillett, N. P. and Son, S.-W.: Impact of Polar Ozone Loss on the Troposphere, in: Stratospheric Ozone Depletion and Climate Change, edited by: Müller, R., RSC Publishing, Cambridge, 190$213,2012$. 
Gillett, N. P., Akiyoshi, H., Bekki, S., Braesicke, P., Eyring, V., Garcia, R., Karpechko, A. Yu., McLinden, C. A., Morgenstern, O., Plummer, D. A., Pyle, J. A., Rozanov, E., Scinocca, J., and Shibata, K.: Attribution of observed changes in stratospheric ozone and temperature, Atmos. Chem. Phys., 11, 599609, doi:10.5194/acp-11-599-2011, 2011.

Griessbach, S., Kalicinsky, C., Spang, R., Hoffmann, L., Müller, R., Olschewski, F., Woiwode, W., Oelhaf, H., Riese, M., Schiller, C., Frey, W., Molleker, S., Borrmann, S., Mitev, V., Volk, C. M., Hösen, E., Genco, S., and Von Hobe, M.: Radiative transfer simulations of PSC signatures measured by CRISTA-NF during the RECONCILE campaign in winter 2009/2010, in: Geophysical Research Abstracts, EGU General Assembley, Vienna, Austria, 2013, EGU2013-2715, 2013.

Grooß, J.-U., Günther, G., Müller, R., Konopka, P., Bausch, S., Schlager, H., Voigt, C., Volk, C. M., and Toon, G. C.: Simulation of denitrification and ozone loss for the Arctic winter 2002/2003, Atmos. Chem. Phys., 5, 1437-1448, doi:10.5194/acp-5-14372005, 2005.

Grooß, J.-U., Brautzsch, K., Pommrich, R., Solomon, S., and Müller, R.: Stratospheric ozone chemistry in the Antarctic: what determines the lowest ozone values reached and their recovery?, Atmos. Chem. Phys., 11, 12217-12226, doi:10.5194/acp11-12217-2011, 2011.

Grooß, J.-U., Engel, I., Borrmann, S., Frey, W., Günther, G., Hoyle, C. R., Kivi, R., Luo, B. P., Molleker, S., Peter, T., Pitts, M. C., Schlager, H., Stiller, G., Vömel, H., Walker, K. A., and Müller, R.: NAT nucleation and denitrification in the Arctic stratosphere, Atmos. Chem. Phys. Discuss., 13, 22107-22150, doi:10.5194/acpd-13-22107-2013, 2013.

Günther, G., Müller, R., von Hobe, M., Stroh, F., Konopka, P., and Volk, C. M.: Quantification of transport across the boundary of the lower stratospheric vortex during Arctic winter 2002/2003, Atmos. Chem. Phys., 8, 3655-3670, doi:10.5194/acp-8-36552008, 2008.

Hanson, D. R. and Ravishankara, A. R.: Reaction of $\mathrm{ClONO}_{2}$ with $\mathrm{HCl}$ on NAT, NAD and frozen sulfuric acid and hydrolysis of $\mathrm{N}_{2} \mathrm{O}_{5}$ and $\mathrm{ClONO}_{2}$ on frozen sulfuric acid, J. Geophys. Res., 98, 22931-22936, 1993.

Hanson, D. R. and Ravishankara, A. R.: Reactive uptake of ClONO2 onto sulfuric acid due to reaction with $\mathrm{HCl}$ and $\mathrm{H}_{2} \mathrm{O}, \mathrm{J}$. Phys. Chem., 98, 5728-5735, 1994.

Hanson, D. R., Ravishankara, A. R., and Solomon, S.: Heterogeneous reactions in sulfuric acid aerosols: A framework for model calculations, J. Geophys. Res., 99, 3615-3629, doi:10.1029/93jd02932, 1994.

Harris, N. R. P., Lehmann, R., Rex, M., and von der Gathen, P.: A closer look at Arctic ozone loss and polar stratospheric clouds, Atmos. Chem. Phys., 10, 8499-8510, doi:10.5194/acp-10-84992010, 2010.

Harvey, V. L., Pierce, R. B., and Hitchman, M. H.: A climatology of stratospheric polar vortices and anticyclones, J. Geophys. Res., 107, 4442, doi:10.1029/2001JD001471, 2002.

Hoffmann, L., Weigel, K., Spang, R., Schroeder, S., Arndt, K., Lehmann, C., Kaufmann, M., Ern, M., Preusse, P., Stroh, F., and Riese, M.: CRISTA-NF measurements of water vapor during the SCOUT-O3 Tropical Aircraft Campaign, Adv. Space Res., 43, 74-81, doi:10.1016/j.asr.2008.03.018, 2009.
Hofmann, D. J. and Solomon, S.: Ozone destruction through heterogeneous chemistry following the eruption of El Chichón, J. Geophys. Res., 94, 5029-5041, doi:10.1029/JD094iD04p05029, 1989.

Holton, J. R. and Tan, H.-C.: The Influence of the Equatorial QuasiBiennial Oscillation on the Global Circulation at $50 \mathrm{mb}$, J. Atmos. Sci., 37, 2200-2208, 1980.

Homan, C. D., Volk, C. M., Kuhn, A. C., Werner, A., Baehr, J., Viciani, S., Ulanovski, A., and Ravegnani, F.: Tracer measurements in the tropical tropopause layer during the AMMA/SCOUTO3 aircraft campaign, Atmos. Chem. Phys., 10, 3615-3627, doi:10.5194/acp-10-3615-2010, 2010.

Homonnai, V., Jánosi, I. M., Lefèvre, F., and Marchand, M.: Comparative Spectral Analysis and Correlation Properties of Observed and Simulated Total Column Ozone Records, Atmosphere, 4, 198-213, doi:10.3390/atmos4020198, 2013.

Hösen, E., Volk, C. M., vom Scheidt, M., Wintel, J., Ulanovsky, A., Ravegnani, F., Grooß, J. U., Günther, G., and Walker, K. A.: Transport, mixing and ozone loss in the 2010 Arctic vortex region from in-situ tracer observations during RECONCILE, EGU General Assembly, Vienna, 2012.

Hourdin, F., Foujols, M.-A., Codron, F., Guemas, V., Dufresne, J.L., Bony, S., Denvil, S., Guez, L., Lott, F., Ghattas, J., Braconnot, P., Marti, O., Meurdesoif, Y., and Bopp, L.: Impact of the LMDZ atmospheric grid configuration on the climate and sensitivity of the IPSL-CM5A coupled model, Climate Dynamics, 40, $2167-$ 2192, doi:10.1007/s00382-012-1411-3, 2013.

Hoyle, C. R., Engel, I., Luo, B. P., Pitts, M. C., Poole, L. R., Grooß, J.-U., and Peter, T.: Heterogeneous formation of polar stratospheric clouds - Part 1: Nucleation of nitric acid trihydrate (NAT), Atmos. Chem. Phys. Discuss., 13, 7979-8021, doi:10.5194/acpd-13-7979-2013, 2013.

Hurwitz, M. M., Newman, P. A., and Garfinkel, C. I.: The Arctic vortex in March 2011: a dynamical perspective, Atmos. Chem. Phys., 11, 11447-11453, doi:10.5194/acp-11-11447-2011, 2011.

IPCC: Climate Change 2007 - The Physical Science Basis: Working Group I Contribution to the Fourth Assessment Report of the IPCC, Cambridge University Press9780521705967, 2007.

Isaksen, I. S. A., Zerefos, C., Wang, W.-C., Balis, D., Eleftheratos, K., Rognerud, B., Stordal, F., Berntsen, T. K., LaCasce, J. H., Søvde, O. A., Olivié, D., Orsolini, Y. J., Zyrichidou, I., Prather, M., and Tuinder, O.: Attribution of Arctic ozone loss in March 2011, Geophys. Res. Lett., 39, L24810, doi:10.1029/2012GL053876, 2012.

Jin, B., Chen, I. C., Huang, W. T., Lien, C. Y., Guchhait, N., and Lin, J. J.: Photodissociation Cross Section of $\mathrm{ClOOCl}$ at $330 \mathrm{~nm}$, Journal Of Physical Chemistry A, 114, 4791-4797, doi:10.1021/jp909374k, 2010.

Jourdain, L., Bekki, S., Lott, F., and Lefèvre, F.: The coupled chemistry-climate model LMDz-REPROBUS: description and evaluation of a transient simulation of the period 1980-1999, Ann. Geophys., 26, 1391-1413, doi:10.5194/angeo-26-13912008, 2008.

Kaiser, J., Engel, A., Borchers, R., and Röckmann, T.: Probing stratospheric transport and chemistry with new balloon and aircraft observations of the meridional and vertical $\mathrm{N}_{2} \mathrm{O}$ isotope distribution, Atmos. Chem. Phys., 6, 3535-3556, doi:10.5194/acp6-3535-2006, 2006. 
Kalicinsky, C., Grooß, J.-U., Günther, G., Ungermann, J., Blank, J., Höfer, S., Hoffmann, L., Knieling, P., Olschewski, F., Spang, R., Stroh, F., and Riese, M.: Small-scale transport structures in the Arctic winter 2009/2010, Atmos. Chem. Phys. Discuss., 13, 10463-10498, doi:10.5194/acpd-13-10463-2013, 2013.

Kantz, H. and Schreiber, T.: Nonlinear Time Series Analysis, Cambridge University Press, Cambridge, UK, 2004.

Kawa, S. R., Stolarski, R. S., Newman, P. A., Douglass, A. R., Rex, M., Hofmann, D. J., Santee, M. L., and Frieler, K.: Sensitivity of polar stratospheric ozone loss to uncertainties in chemical reaction kinetics, Atmos. Chem. Phys., 9, 8651-8660, doi:10.5194/acp-9-8651-2009, 2009.

Khaykin, S. M., Engel, I., Vömel, H., Formanyuk, I. M., Kivi, R., Korshunov, L. I., Krämer, M., Lykov, A. D., Meier, S., Naebert, T., Pitts, M. C., Santee, M. L., Spelten, N., Wienhold, F. G., Yushkov, V. A., and Peter, T.: Arctic stratospheric dehydration - Part 1: Unprecedented observation of vertical redistribution of water, Atmos. Chem. Phys. Discuss., 13, 14249-14295, doi:10.5194/acpd-13-14249-2013, 2013.

Khosrawi, F., Urban, J., Pitts, M. C., Voelger, P., Achtert, P., Kaphlanov, M., Santee, M. L., Manney, G. L., Murtagh, D., and Fricke, K.-H.: Denitrification and polar stratospheric cloud formation during the Arctic winter 2009/2010, Atmos. Chem. Phys., 11, 8471-8487, doi:10.5194/acp-11-8471-2011, 2011.

Khosrawi, F., Urban, J., Pitts, M. C., Voelger, P., Achtert, P., Santee, M. L., Manney, G. L., and Murtagh, D.: Denitrifcation and polar stratospheric cloud formation during the Arctic winter 2009/2010 and 2010/2011 in comparison, in: Eur. Space Agency Spec. Publ., Advances in Atmospheric Science and Application, Bruges, Belgium, 2012,

Konopka, P., Steinhorst, H. M., Grooß, J.-U., Günther, G., Müller, R., Elkins, J. W., Jost, H. J., Richard, E., Schmidt, U., Toon, G., and McKenna, D. S.: Mixing and Ozone Loss in the 1999-2000 Arctic Vortex: Simulations with the 3-dimensional Chemical Lagrangian Model of the Stratosphere (CLaMS), J. Geophys. Res., 109, D02315, doi:10.1029/2003JD003792, 2004.

Koop, T. and Zobrist, B.: Parameterizations for ice nucleation in biological and atmospheric systems, Phys. Chem. Chem. Phys., 11, 10839-10850, 2009.

Koop, T., Biermann, U. M., Raber, W., Luo, B. P., Crutzen, P. J., and Peter, T.: Do Stratospheric Aerosol Droplets Freeze above the Ice Frost Point, Geophys. Res. Lett., 22, 917-920, 1995.

Kremser, S., Schofield, R., Bodeker, G. E., Connor, B. J., Rex, M., Barret, J., Mooney, T., Salawitch, R. J., Canty, T., Frieler, K., Chipperfield, M. P., Langematz, U., and Feng, W.: Retrievals of chlorine chemistry kinetic parameters from Antarctic $\mathrm{ClO}$ microwave radiometer measurements, Atmos. Chem. Phys., 11, 5183-5193, doi:10.5194/acp-11-5183-2011, 2011.

Kreycy, S., Camy-Peyret, C., Chipperfield, M. P., Dorf, M., Feng, W., Hossaini, R., Kritten, L., Werner, B., and Pfeilsticker, K.: Atmospheric test of the $\mathrm{J}(\mathrm{BrONO} 2) / k_{\mathrm{BrO}+\mathrm{NO}_{2}}$ ratio: implications for total stratospheric Bry and bromine-mediated ozone loss, Atmos. Chem. Phys., 13, 6263-6274, doi:10.5194/acp-136263-2013, 2013.

Kurylo, M. J. and Sinnhuber, B.-M.: The Role of Halogen Chemistry in Polar Stratospheric Ozone Depletion, SPARC, 2009.

Kuttippurath, J. and Nikulin, G.: A comparative study of the major sudden stratospheric warmings in the Arctic winters 2003/2004-2009/2010, Atmos. Chem. Phys., 12, 8115-8129, doi:10.5194/acp-12-8115-2012, 2012.

Kuttippurath, J., Godin-Beekmann, S., Lefèvre, F., Nikulin, G., Santee, M. L., and Froidevaux, L.: Record-breaking ozone loss in the Arctic winter 2010/2011: comparison with 1996/1997, Atmos. Chem. Phys., 12, 7073-7085, doi:10.5194/acp-12-70732012, 2012.

Kuttippurath, J., Lefèvre, F., Pommereau, J.-P., Roscoe, H. K., Goutail, F., Pazmiño, A., and Shanklin, J. D.: Antarctic ozone loss in 1979-2010: first sign of ozone recovery, Atmos. Chem. Phys., 13, 1625-1635, doi:10.5194/acp-13-1625-2013, 2013.

Lambert, A., Read, W. G., Livesey, N. J., Santee, M. L., Manney, G. L., Froidevaux, L., Wu, D. L., Schwartz, M. J., Pumphrey, H. C., Jimenez, C., Nedoluha, G. E., Cofield, R. E., Cuddy, D. T., Daffer, W. H., Drouin, B. J., Fuller, R. A., Jarnot, R. F., Knosp, B. W., Pickett, H. M., Perun, C. S., Snyder, W. V., Stek, P. C., Thurstans, R. P., Wagner, P. A., Waters, J. W., Jucks, K. W., Toon, G. C., Stachnik, R. A., Bernath, P. F., Boone, C. D., Walker, K. A., Urban, J., Murtagh, D., Elkins, J. W., and Atlas, E.: Validation of the Aura Microwave Limb Sounder middle atmosphere water vapor and nitrous oxide measurements, J. Geophys. Res, 112, D24S36, doi:10.1029/2007JD008724, 2007.

Laube, J. C., Engel, A., Bönisch, H., Möbius, T., Sturges, W. T., Braß, M., and Röckmann, T.: Fractional release factors of long-lived halogenated organic compounds in the tropical stratosphere, Atmos. Chem. Phys., 10, 1093-1103, doi:10.5194/acp10-1093-2010, 2010a.

Laube, J. C., Martinerie, P., Witrant, E., Blunier, T., Schwander, J., Brenninkmeijer, C. A. M., Schuck, T. J., Bolder, M., Röckmann, T., van der Veen, C., Bönisch, H., Engel, A., Mills, G. P., Newland, M. J., Oram, D. E., Reeves, C. E., and Sturges, W. T.: Accelerating growth of HFC-227ea (1,1,1,2,3,3,3-heptafluoropropane) in the atmosphere, Atmos. Chem. Phys., 10, 5903-5910, doi:10.5194/acp-10-5903-2010, 2010b.

Laube, J. C., Hogan, C., Newland, M. J., Mani, F. S., Fraser, P. J., Brenninkmeijer, C. A. M., Martinerie, P., Oram, D. E., Röckmann, T., Schwander, J., Witrant, E., Mills, G. P., Reeves, C. E., and Sturges, W. T.: Distributions, long term trends and emissions of four perfluorocarbons in remote parts of the atmosphere and firn air, Atmos. Chem. Phys., 12, 4081-4090, doi:10.5194/acp12-4081-2012, 2012.

Laube, J. C., Keil, A., Bönisch, H., Engel, A., Röckmann, T., Volk, C. M., and Sturges, W. T.: Observation-based assessment of stratospheric fractional release, lifetimes, and ozone depletion potentials of ten important source gases, Atmos. Chem. Phys., 13, 2779-2791, doi:10.5194/acp-13-2779-2013, 2013.

Lefèvre, F., Brasseur, G. P., Folkins, I., Smith, A. K., and Simon, P.: Chemistry of the 1991-1992 stratospheric winter: Threedimensional model simulations, J. Geophys. Res., 199, 81838195, doi:10.1029/93JD03476, 1994.

Lefèvre, F., Figarol, F., Carslaw, K. S., and Peter, T.: The 1997 Arctic ozone depletion quantified from three-dimensional model simulations, Geophys. Res. Lett., 25, 2425-2428, 1998.

Levelt, P. F., Van den Oord, G. H. J., Dobber, M. R., Malkki, A., Huib, V., de Vries, J., Stammes, P., Lundell, J. O. V., and Saari, H.: The ozone monitoring instrument, Geoscience and Remote Sensing, IEEE Transactions on, 44, 1093-1101, doi:10.1109/tgrs.2006.872333, 2006. 
Li, F., Stolarski, R. S., and Newman, P. A.: Stratospheric ozone in the post-CFC era, Atmos. Chem. Phys., 9, 2207-2213, doi:10.5194/acp-9-2207-2009, 2009.

Lien, C. Y., Lin, W. Y., Chen, H. Y., Huang, W. T., Jin, B., Chen, I. C., and Lin, J. J.: Photodissociation cross sections of $\mathrm{ClOOCl}$ at 248.4 and $266 \mathrm{~nm}, \mathrm{~J}$. Chem. Phys., 131, 174301, doi:10.1063/1.3257682, 2009.

Livesey, N. J., Read, W. G., Froidevaux, L., Lambert, A., Manney, G. L., Pumphrey, H. C., Santee, M. L., Schwartz, M. J., Wang, S., Cofeld, R. E., Cuddy, D. T., Fuller, R. A., Jarnot, R. F., Jiang, J. H., Knosp, B. W., Stek, P. C., Wagner, P. A., and Wu, D. L.: Version 3.3 Level 2 data quality and description document, Jet Propulsion Laboratory, Pasadena, California, USA, 2012.

Luo, B. P., Voigt, C., Fueglistaler, S., and Peter, T.: Extreme NAT supersaturations in mountain wave ice PSCs: A clue to NAT formation, J. Geophys. Res., 108, 4441, doi:10.1029/2002JD003104, 2003.

Mahieu, E., Zander, R., Duchatelet, P., Hannigan, J. W., Coffey, M. T., Mikuteit, S., Hase, F., Blumenstock, T., Wiacek, A., Strong, K., Taylor, J. R., Mittermeier, R. L., Fast, H., Boone, C. D., McLeod, S. D., Walker, K. A., Bernath, P. F., and Rinsland, C. P.: Comparison between ACE-FTS and groundbased measurements of stratospheric $\mathrm{HCl}$ and $\mathrm{ClONO} \$ 2 \$$ loadings at northern latitudes, Geophys. Res. Lett., 32, L15S08, doi:10.1029/2005GL022396, 2005.

Manney, G. L., Santee, M. L., Rex, M., Livesey, N. J., Pitts, M. C., Veefkind, P., Nash, E. R., Wohltmann, I., Lehmann, R., Froidevaux, L., Poole, L. R., Schoeberl, M. R., Haffner, D. P., Davies, J., Dorokhov, V., Gernandt, H., Johnson, B., Kivi, R., Kyro, E., Larsen, N., Levelt, P. F., Makshtas, A., McElroy, C. T., Nakajima, H., Concepcion Parrondo, M., Tarasick, D. W., von der Gathen, P., Walker, K. A., and Zinoviev, N. S.: Unprecedented Arctic ozone loss in 2011, Nature, 478, 469-475, doi:10.1038/nature10556, 2011.

Marchand, M., Keckhut, P., Lefebvre, S., Claud, C. C., D., Hauchecorne, A., Lefèvre, F., Lefebvre, M.-P., Jumelet, J., Lott, F., Hourdin, F., Thuillier, G., Poulain, V., Bossay, S., Lemennais, P., David, C., and Bekki, S.: Dynamical amplification of the stratospheric solar response simulated with the ChemistryClimate model LMDz-Reprobus, J. Atmos. Solar-Terrest. Phys., 75-76, 147-160, doi:10.1016/j.jastp.2011.11.008, 2012.

Marcolli, C., Gedamke, S., Peter, T., and Zobrist, B.: Efficiency of immersion mode ice nucleation on surrogates of mineral dust, Atmos. Chem. Phys., 7, 5081-5091, doi:10.5194/acp-7-50812007, 2007.

Matthey, R., Cacciani, M., Fiocco, G., Martinez, A. A., Martucci, G., Mitev, V., Pace, G., and Stefanutti, L.: Observations of aerosol and clouds with the ABLE and MAL lidars during the mid-latitude and arctic ENVISAT validation campaigns, in: 16th ESA Symposium on European Rocket and Balloon Programmes and Related Research, Proceedings, ESA Special Publications, 579-584, 2003.

Mayer, B.: Radiative transfer in the cloudy atmosphere, Eur. Phys. J. Conf., 1, 75-99, doi:10.1140/epjconf/e2009-00912-1, 2009.

Mayer, B. and Kylling, A.: Technical note: The libRadtran software package for radiative transfer calculations - description and examples of use, Atmos. Chem. Phys., 5, 1855-1877, doi:10.5194/acp-5-1855-2005, 2005.
McElroy, M. B., Salawitch, R. J., Wofsy, S. C., and Logan, J. A.: Reductions of Antarctic Ozone Due to Synergistic Interactions of Chlorine and Bromine, Nature, 321, 759-762, 1986.

McIntyre, M. E.: On the Antarctic Ozone Hole, J. Atmos. Terr. Phys., 51, 29-43, 1989.

McKenna, D. S., Grooß, J. U., Günther, G., Konopka, P., Müller, R., Carver, G., and Sasano, Y.: A new Chemical Lagrangian Model of the Stratosphere (CLaMS) - 2. Formulation of chemistry scheme and initialization, J. Geophys. Res., 107, 42564269, doi:10.1029/2000JD000113, 2002a.

McKenna, D. S., Konopka, P., Grooß, J. U., Günther, G., Müller, R., Spang, R., Offermann, D., and Orsolini, Y.: A new Chemical Lagrangian Model of the Stratosphere (CLaMS) - 1. Formulation of advection and mixing, J. Geophys. Res., 107, 4309, doi:10.1029/2000JD000114, 2002b.

Meilinger, S. K., Koop, T., Luo, B. P., Huthwelker, T., Carslaw, K. S., Krieger, U., Crutzen, P. J., and Peter, T.: Size-Dependent Stratospheric Droplet Composition in Lee Wave TemperatureFluctuations and Their Potential Role in PSC Freezing, Geophys. Res. Lett., 22, 3031-3034, 1995.

Molina, L. T. and Molina, M. J.: Production of $\mathrm{Cl} 2 \mathrm{O} 2$ From the Self-Reaction of the ClO Radical, J. Phys. Chem., 91, 433-436, 1987.

Molleker, S., Borrmann, S., Schlager, H., Frey, W., Weigel, R., Klingebiel, M., Luo, B., Peter, T., and Spelten, N.: Micophysical properties of synoptic scale polar stratospheric clouds: In-situ measurements from the 2010 and 2011 Arctic winters, in preparation, 2013.

Moyna, B. P., Oldfield, M. L., Goizel, A. S., Gerber, D., Siddans, R., Reburn, W. J., Matheson, D. N., Kerridge, B. J., De Maagt, P. J. I., Langen, J., and Klein, U.: MARSCHALS: Airborne simulator of a future space instrument to observe millimetre-wave limb emission from the upper troposphere and lower stratosphere, in: Sensors, Systems, and Next-Generation Satellites X, Proceedings of the Society of Photo-Optical Instrumentation Engineers (Spie), U75-U86, 2006.

Müller, R.: A brief history of stratospheric ozone research, Meteorol. Z., 18, 3-24, 2009.

Murphy, D. M. and Gary, B. L.: Mesosclae temperature fluctuations and polar stratospheric clouds, J. Atmos. Sci., 52, 1753-1760, doi:10.1175/1520-0469(1995)052<1753:MTFAPS>2.0.CO;2, 1995.

Murtagh, D. P., Frisk, U., Merino, F., Ridal, M., Jonsson, A., Stegman, J., Witt, G., Eriksson, P., Jimenez, C., Megie, G., de la Noe, J., Ricaud, P., Baron, P., Pardo, J. R., Hauchcorne, A., Llewellyn, E. J., Degenstein, D. A., Gattinger, R. L., Lloyd, N. D., Evans, W. F. J., McDade, I. C., Haley, C. S., Sioris, C., von Savigny, C., Solheim, B. H., McConnell, J. C., Strong, K., Richardson, E. H., Leppelmeier, G. W., Kyrola, E., Auvinen, H., and Oikarinen, L.: An overview of the Odin atmospheric mission, Can. J. Phys., 80, 309-319, 2002.

Naoe, H. and Shibata, K.: Future changes in the influence of the quasi-biennial oscillation on the northern polar vortex simulated with an MRI chemistry climate model, J. Geophys. Res., 117, D03102, doi:10.1029/2011JD016255, 2012.

Nash, E. R., Newman, P. A., Rosenfield, J. E., and Schoeberl, M. R.: An objective determination of the polar vortex using Ertel's potential vorticity, J. Geophys. Res., 101, 9471-9478, 1996. 
Nickolaisen, S. L., Friedl, R. R., and Sander, S. P.: Kinetics and Mechanism of the $\mathrm{ClO}+\mathrm{ClO}$ Reaction - Pressure and Temperature Dependences of the Bimolecular and Termolecular Channels and Thermal-Decomposition of Chlorine Peroxide, J. Phys. Chem., 98, 155-169, 1994.

Nishii, K., Nakamura, H., and Orsolini, Y. J.: Geographical dependence observed in blocking high influence on the stratospheric variability through enhancement and suppression of upward planetary-wave propagation, J. Climate, 24, 6408-6423, doi:10.1175/JCLI-D-10-05021.1, 2011.

Northway, M. J., Gao, R. S., Popp, P. J., Holecek, J. C., Fahey, D. W., Carslaw, K. S., Tolbert, M. A., Lait, L. R., Dhaniyala, S., Flagan, R. C., Wennberg, P. O., Mahoney, M. J., Herman, R. L., Toon, G. C., and Bui, T. P.: An analysis of large $\mathrm{HNO}_{3}-$ containing particles sampled in the Arctic stratosphere during the winter of 1999/2000, J. Geophys. Res., 107, 8298-8319, doi:10.1029/2001JD001079, 2002.

Oram, D. E., Mani, F. S., Laube, J. C., Newland, M. J., Reeves, C. E., Sturges, W. T., Penkett, S. A., Brenninkmeijer, C. A. M., Röckmann, T., and Fraser, P. J.: Long-term tropospheric trend of octafluorocyclobutane (c- $\mathrm{C}_{4} \mathrm{~F}_{8}$ or PFC-318), Atmos. Chem. Phys., 12, 261-269, doi:10.5194/acp-12-261-2012, 2012.

Orsolini, Y. J., Karpechko, A. Y., and Nikulin, G.: Variability of the Northern Hemisphere polar stratospheric cloud potential: The role of North Pacific disturbances, Q. J. Roy. Meteor. Soc., 135, 1020-1029, doi:10.1002/qj.409, 2009.

Pagan, K. L., Tabazadeh, A., Drdla, K., Hervig, M. E., Eckermann, S. D., Browell, E. V., Legg, M. J., and Foschi, P. G.: Observational evidence against mountain-wave generation of ice nuclei as a prerequisite for the formation of three solid nitric acid polar stratospheric clouds observed in the Arctic in early December 1999, J.Geophys. Res., 109, D04312, doi:10.1029/2003JD003846, 2004.

Papanastasiou, D. K., Papadimitriou, V. C., Fahey, D. W., and Burkholder, J. B.: UV Absorption Spectrum of the ClO Dimer $(\mathrm{Cl}(2) \mathrm{O}(2))$ between 200 and $420 \mathrm{~nm}$, J. Phys. Chem., 113, 13711-13726, doi:10.1021/jp9065345, 2009.

Peter, T.: Microphysics and Heterogeneous Chemistry of Polar Stratospheric Clouds, Annu. Rev. Phys. Chem., 48, 785-822, 1997.

Pitts, M. C., Poole, L. R., and Thomason, L. W.: CALIPSO polar stratospheric cloud observations: second-generation detection algorithm and composition discrimination, Atmos. Chem. Phys., 9, 7577-7589, doi:10.5194/acp-9-7577-2009, 2009.

Pitts, M. C., Poole, L. R., Dörnbrack, A., and Thomason, L. W.: The 2009-2010 Arctic polar stratospheric cloud season: a CALIPSO perspective, Atmos. Chem. Phys., 11, 2161-2177, doi:10.5194/acp-11-2161-2011, 2011.

Plenge, J., Kühl, S., Vogel, B., Müller, R., Stroh, F., von Hobe, M., Flesch, R., and Rühl, E.: Bond strength of chlorine peroxide, J. Phys. Chem., 109, 6730-6734, 2005.

Pommereau, J.-P., Goutail, F., Lefèvre, F., Pazmino, A., Adams, C., Dorokhov, V., Eriksen, P., Kivi, R., Stebel, K., Zhao, X., and van Roozendael, M.: Why unprecedented ozone loss in the Arctic in 2011 ? Is it related to climate change?, Atmos. Chem. Phys., 13, 5299-5308, doi:10.5194/acp-13-5299-2013, 2013.

Poole, L. R. and McCormick, M. P.: Polar stratospheric clouds and the Antarctic ozone hole, J. Geophys. Res., 93, 8423-8430, doi:10.1029/JD093iD07p08423, 1988.
Pope, F. D., Hansen, J. C., Bayes, K. D., Friedl, R. R., and Sander, S. P.: Ultraviolet absorption spectrum of chlorine peroxide, ClOOCl, J. Phys. Chem., 111, 4322-4332, 2007.

Pope, F. D., Braesicke, P., Grainger, R. G., Kalberer, M., Watson, I. M., Davidson, P. J., and Cox, R. A.: Stratospheric aerosol particles and solar-radiation management, Nature Climate Change, 2, 713-719, 2012.

Prather, M. J. and Rodriguez, J. M.: Antarctic ozone: Meteoric control of $\mathrm{HNO}_{3}$, Geophys. Res. Lett., 15, 1-4, doi:10.1029/GL015i001p00001, 1988.

Proffitt, M. H., Powell, J. A., Tuck, A. F., Fahey, D. W., Kelly, K. K., Krueger, A. J., Schoeberl, M. R., Gary, B. L., Margitan, J. J., Chan, K. R., Loewenstein, M., and Podolske, J. R.: A Chemical Definition of the Boundary of the Antarctic Ozone Hole, J. Geophys. Res., 94, 11437-11448, 1989.

Rautenhaus, M., Bauer, G., and Dörnbrack, A.: A web service based tool to plan atmospheric research flights, Geosci. Model Dev., 5, 55-71, doi:10.5194/gmd-5-55-2012, 2012.

Rex, M., Von Der Gathen, P., Braathen, G. O., Harris, N. R. P., Reimer, E., Beck, A., Alfier, R., Krüger-Carstensen, R., Chipperfield, M., De Backer, H., Balis, D., O'Connor, F., Dier, H., Dorokhov, V., Fast, H., Gamma, A., Gil, M., Kyrö, E., Litynska, Z., Mikkelsen, I. S., Molyneux, M., Murphy, G., Reid, S. J., Rummukainen, M., and Zerefos, C.: Chemical Ozone Loss in the Arctic Winter 1994/95 as Determined by the Match Technique, J. Atmos. Chem., 32, 35-59, doi:10.1023/a:1006093826861, 1999.

Rex, M., Salawitch, R. J., von der Gathen, P., Harris, N. R. P., Chipperfield, M. P., and Naujokat, B.: Arctic ozone loss and climate change, Geophys. Res. Lett., 31, L04116, doi:10.1029/2003GL018844, 2004.

Rex, M., Salawitch, R. J., Deckelmann, H., von der Gathen, P., Harris, N. R. P., Chipperfield, M. P., Naujokat, B., Reimer, E., Allaart, M., Andersen, S. B., Bevilacqua, R., Braathen, G. O., Claude, H., Davies, J., De Backer, H., Dier, H., Dorokhov, V., Fast, H., Gerding, M., Godin-Beekmann, S., Hoppel, K., Johnson, B., Kyroe, E., Litynska, Z., Moore, D., Nakane, H., Parrondo, M. C., Risley, A. D., Jr., Skrivankova, P., Stuebi, R., Viatte, P., Yushkov, V., and Zerefos, C.: Arctic winter 2005: Implications for stratospheric ozone loss and climate change, Geophys. Res. Lett., 33, L23808, doi:10.1029/2006GL026731, 2006.

Riese, M., Ploeger, F., Rap, A., Vogel, B., Konopka, P., Dameris, M., and Forster, P.: Impact of uncertainties in atmospheric mixing on simulated UTLS composition and related radiative effects, J. Geophys. Res., 117, D16305, doi:10.1029/2012JD017751, 2012.

Salawitch, R., Canty, T., Stimpfle, R., Wilmouth, D., Anderson, J. G., von Hobe, M., Stroh, F., Rex, M., Schofield, R., Santee, M., Kinnison, D. E., Kurylo, M. J., and Sinnhuber, B. M.: Impact of recent laboratory measurements of the $\mathrm{ClOOCl}$ cross section on our understanding of polar ozone chemistry, Abstr. Pap. Am. Chem. Soc., 237, 363-363, 2009.

Salawitch, R. J., Gobbi, G. P., Wofsy, S. C., and McElroy, M. B.: Denitrification in the Antarctic stratosphere, Nature, 339, 525527, 1989.

Salawitch, R. J., Weisenstein, D. K., Kovalenko, L. J., Sioris, C. E., Wennberg, P. O., Chance, K., Ko, M. K. W., and McLinden, C. A.: Sensitivity of ozone to bromine in the lower stratosphere, Geophys. Res. Lett., 32, L05811, doi:10.1029/2004GL021504, 2005. 
Salby, M., Titova, E., and Deschamps, L.: Rebound of Antarctic ozone, Geophys. Res. Lett., 38, L09702, doi:10.1029/2011GL047266, 2011.

Sander, S. P., Abbatt, J., Barker, J. R., Burkholder, J. B., Friedl, R. R., Golden, D. M., Huie, R. E., Kolb, C. E., Kurylo, M. J., Moortgat, G. K., Orkin, V. L., and Wine, P. H.: Chemical Kinetics and Photochemical Data for Use in Atmospheric Studies, Jet Propulsion Laboratory, Pasadena10-6, 2011.

Santee, M. L., Lambert, A., Read, W. G., Livesey, N. J., Cofield, R. E., Cuddy, D. T., Daffer, W. H., Drouin, B. J., Froidevaux, L., Fuller, R. A., Jarnot, R. F., Knosp, B. W., Manney, G. L., Perun, V. S., Snyder, W. V., Stek, P. C., Thurstans, R. P., Wagner, P. A., Waters, J. W., Muscari, G., de Zafra, R. L., Dibb, J. E., Fahey, D. W., Popp, P. J., Marcy, T. P., Jucks, K. W., Toon, G. C., Stachnik, R. A., Bernath, P. F., Boone, C. D., Walker, K. A., Urban, J., and Murtagh, D.: Validation of the Aura Microwave Limb Sounder $\mathrm{HNO}_{3}$ measurements, J. Geophys. Res., 112, D24S40 doi:10.1029/2007JD008721, 2007a.

Santee, M. L., Lambert, A., Read, W. G., Livesey, N. J., Manney, G. L., Cofield, R. R., Cuddy, D. T., Daffer, W. H., Froidevaux, L., Fuller, R. A., Jarnot, R. F., Knosp, B. W., Perun, V. S., Snyder, W. V., Stek, P. C., Thurstans, R. P., Wagner, P. A., Waters, J. W., Connor, B., Urban, J., Murtagh, D., Ricaud, P., Barret, B., Kleinböhl, A., J, K., Kullmann, H., von Hobe, M., Toon, G. C., and Stachnik, R. A.: Validation of the Aura Microwave Limb Sounder ClO measurements, J. Geophys. Res, 113, D15S22, doi:10.1029/2007JD008762, 2007b.

Santee, M. L., MacKenzie, I. A., Manney, G. L., Chipperfield, M. P., Bernath, P. F., Walker, K. A., Boone, C. D., Froidevaux, L., Livesey, N. J., and Waters, J. W.: A study of stratospheric chlorine partitioning based on new satellite measurements and modeling, J. Geophys. Res., 113, D12307, doi:10.1029/2007jd009057, 2008.

Schiermeier, Q.: Chemists poke holes in ozone theory, Nature, 449, 382-383, 2007.

Schofield, R., Frieler, K., Wohltmann, I., Rex, M., von Hobe, M., Stroh, F., Koch, G., Peter, T., Canty, T., Salawitch, R., and Volk, C. M.: Polar stratospheric chlorine kinetics from a selfmatch flight during SOLVE-II/EUPLEX, Geophys. Res. Lett., 35, L01807, doi:10.1029/2007GL031740, 2008.

Shi, Q., Jayne, J. T., Kolb, C. E., Worsnop, D. R., and Davidovits, P.: Kinetic model for reaction of $\mathrm{ClONO}_{2}$ with $\mathrm{H}_{2} \mathrm{O}$ and $\mathrm{HCl}$ and $\mathrm{HOCl}$ with $\mathrm{HCl}$ in sulfuric acid solutions, J. Geophys. Res., 106, 24259-24274, 2001.

Sitnikov, N. M., Yushkov, V. A., Afchine, A. A., Korshunov, L. I., Astakhov, V. I., Ulanovskii, A. E., Kraemer, M., Mangold, A., Schiller, C., and Ravegnani, F.: The FLASH instrument for water vapor measurements on board the high-altitude airplane, Instrum. Exp.Techn., 50, 113-121, 2007.

Solomon, S.: Stratospheric ozone depletion: A review of concepts and history, Rev. Geophys., 37, 275-316, 1999.

Solomon, S.: Interactive comment on "Temperature thresholds for polar stratospheric ozone loss" by K. Drdla and R. Müller, Atmos. Chem. Phys. Discuss., 10, C11119-C11124, 2010.

Solomon, S., Garcia, R. R., Rowland, F. S., and Wuebbles, D. J.: On the Depletion of Antarctic Ozone, Nature, 321, 755-758, 1986.

Solomon, S., Portmann, R. W., Sasaki, T., Hofmann, D. J., and Thompson, D. W. J.: Four decades of ozonesonde measurements over Antarctica, J. Geophys. Res., 110, D21311,
doi:10.1029/2005JD005917, 2005.

Sovde, O. A., Orsolini, Y. J., Jackson, D. R., Stordal, F., Isaksen, S. A., and Rognerud, B.: Estimation of Arctic ozone loss in winter 2006/2007 using a chemical transport model and data assimilation, Q. J. Roy. Meteor. Soc., 137, 118-128, 2011.

Spang, R., Stroh, F., von Hobe, M., Gerber, D., Moyna, B., Oldfield, M., Rea, S., Reburn, J., Siddans, R., Kerridge, B., Oelhaf, H., and Woiwode, W.: Data Acquisition Report of the PremierEX Scientific Flights, Final Report for ESTEC Contract No. 2670/09/NL/CT “PREMIER Experiment", 3139, 3151 https://earth.esa.int/documents/10174/87248/PremierEX_ FinalReport_v2.pdf, 25 May 2012.

SPARC: SPARC Report $\mathrm{N}^{\circ} 5$ (2010) Chemistry-Climate Model Validation, SPARC, 2010.

Stefanutti, L., Sokolov, L., MacKenzie, A. R., Balestri, S., and Khattatov, V.: The M-55 Geophysica as a platform for the Airborne Polar Experiment, J. Atmos. Oceanic Technol., 16, 1303-1312, 1999.

Stimpfle, R. M., Wilmouth, D. M., Salawitch, R. J., and Anderson, J. G.: First measurements of $\mathrm{ClOOCl}$ in the stratosphere: The coupling of $\mathrm{ClOOCl}$ and $\mathrm{ClO}$ in the Arctic polar vortex, J. Geophys. Res., 109, D03301, doi:10.1029/2003JD003811, 2004.

Stolarski, R. S., Krueger, A. J., Schoeberl, M. R., McPeters, R. D., Newman, P. A., and Alpert, J. C.: Nimbus-7 Satellite Measurements of the Springtime Antarctic Ozone Decrease, Nature, 322, 808-811, 1986.

Stroh, F., Grooß, J. U., Heinecke, F., von Hobe, M., SumińskaEbersoldt, O., Volk, C. M., and Wegner, T.: Polar Vortex ClOx Chemistry from RECONCILE $\mathrm{ClO}$ and $\mathrm{ClO}$ dimer measurements Quadrennial Ozone Symposium, Toronto, Canada, 2012.

Sumińska-Ebersoldt, O., Lehmann, R., Wegner, T., Grooß, J.-U., Hösen, E., Weigel, R., Frey, W., Griessbach, S., Mitev, V., Emde, C., Volk, C. M., Borrmann, S., Rex, M., Stroh, F., and von Hobe, $\mathrm{M} . \mathrm{ClOOCl}$ photolysis at high solar zenith angles: analysis of the RECONCILE self-match flight, Atmos. Chem. Phys., 12, 13531365, doi:10.5194/acp-12-1353-2012, 2012.

Tabazadeh, A., Turco, R. P., and Jacobson, M. Z.: A Model for Studying the Composition and Chemical Effects of Stratospheric Aerosols, J. Geophys. Res.-Atmos., 99, 12897-12914, 1994.

Tabazadeh, A., Santee, M. L., Danilin, M. Y., Pumphrey, H. C., Newman, P. A., Hamill, P. J., and Mergenthaler, J. L.: Quantifying denitrification and its effect on ozone recovery, Science, 288, 1407-1411, 2000.

Tabazadeh, A., Drdla, K., Schoeberl, M. R., Hamill, P., and Toon, O. B.: Arctic "ozone hole" in a cold volcanic stratosphere, P. Natl. Acad. Sci., 99, 2609-2612, doi:10.1073/pnas.052518199, 2002.

Tilmes, S. and Garcia, R. R.: Polar Stratospheric Clouds and Sulfate Aerosol Particles: Microphysics, Denitrification and Heterogeneous Chemistry, in: Stratospheric Ozone Depletion and Climate Change, edited by: Müller, R., RSC Publishing, Cambridge, 279-298, 2012.

Toon, O. B., Hamill, P., Turco, R. P., and Pinto, J.: Condensation of $\mathrm{HNO}_{3}$ and $\mathrm{HCl}$ in the winter polar stratospheres, Geophys. Res. Lett., 13, 1284-1287, doi:10.1029/GL013i012p01284, 1986.

Ulanovsky, A. E., Yushkov, V. A., Sitnikov, N. M., and Ravegnani, F.: The FOZAN-II fast-response chemiluminescent airborne ozone analyzer, Instr. Exp. Techn., 44, 249-256, 2001.

Ungermann, J., Kalicinsky, C., Olschewski, F., Knieling, P., Hoffmann, L., Blank, J., Woiwode, W., Oelhaf, H., Hösen, E., Volk, 
C. M., Ulanovsky, A., Ravegnani, F., Weigel, K., Stroh, F., and Riese, M.: CRISTA-NF measurements with unprecedented vertical resolution during the RECONCILE aircraft campaign, Atmos. Meas. Tech., 5, 1173-1191, doi:10.5194/amt-5-1173-2012, 2012.

Urban, J., Pommier, M., Murtagh, D. P., Santee, M. L., and Orsolini, Y. J.: Nitric acid in the stratosphere based on Odin observations from 2001 to 2009 - Part 1: A global climatology, Atmos. Chem. Phys., 9, 7031-7044, doi:10.5194/acp-9-7031-2009, 2009.

van der A, R. J., Allaart, M. A. F., and Eskes, H. J.: Multi sensor reanalysis of total ozone, Atmos. Chem. Phys., 10, 11277-11294, doi:10.5194/acp-10-11277-2010, 2010.

Viciani, S., D’Amato, F., Mazzinghi, P., Castagnoli, F., Toci, G., and Werle, P.: A cryogenically operated laser diode spectrometer for airborne measurement of stratospheric trace gases, Appl. Phys. B-Lasers and Optics, 90, 581-592, 2008.

Vogel, B., Feng, W., Streibel, M., and Müller, R.: The potential impact of $\mathrm{ClOx}$ radical complexes on polar stratospheric ozone loss processes, Atmos. Chem. Phys., 6, 3099-3114, doi:10.5194/acp6-3099-2006, 2006.

Voigt, C., Schlager, H., Luo, B. P., Dörnbrack, A., Roiger, A., Stock, P., Curtius, J., Vössing, H., Borrmann, S., Davies, S., Konopka, P., Schiller, C., Shur, G., and Peter, T.: Nitric Acid Trihydrate (NAT) formation at low NAT supersaturation in Polar Stratospheric Clouds (PSCs), Atmos. Chem. Phys., 5, 13711380, doi:10.5194/acp-5-1371-2005, 2005.

von Hobe, M., Grooß, J.-U., Müller, R., Hrechanyy, S., Winkler, U., and Stroh, F.: A re-evaluation of the $\mathrm{ClO} / \mathrm{Cl}_{2} \mathrm{O}_{2}$ equilibrium constant based on stratospheric in-situ observations, Atmos. Chem. Phys., 5, 693-702, doi:10.5194/acp-5-693-2005, 2005.

von Hobe, M.: Atmospheric science - Revisiting ozone depletion, Science, 318, 1878-1879, 2007.

von Hobe, M., Ulanovsky, A., Volk, C. M., Grooß, J. U., Tilmes, S., Konopka, P., Günther, G., Werner, A., Spelten, N., Shur, G., Yushkov, V., Ravegnani, F., Schiller, C., Müller, R., and Stroh, F.: Severe ozone depletion in the cold Arctic winter 2004-05, Geophys. Res. Lett., 33, L17815, doi:10.1029/2006GL026945, 2006.

von Hobe, M., Salawitch, R. J., Canty, T., Keller-Rudek, H., Moortgat, G. K., Grooß, J.-U., Müller, R., and Stroh, F.: Understanding the kinetics of the $\mathrm{ClO}$ dimer cycle, Atmos. Chem. Phys., 7, 3055-3069, doi:10.5194/acp-7-3055-2007, 2007.

von Hobe, M., Stroh, F., Beckers, H., Benter, T., and Willner, H.: The UV/Vis absorption spectrum of matrix-isolated dichlorine peroxide, ClOOCl, Phys. Chem. Chem. Phys., 11, 1571-1580, 2009.

von Hobe, M., Griessbach, S., and Wegner, T.: Impact of Arctic and Antarctic Ozone depletion on UV radiation, Quadrennial Ozone Symposium, Toronto, Canada, 2012a.

von Hobe, M., Sumińska-Ebersoldt, O., Emde, C., and Stroh, F.: How well can we quantify the actinic flux driving catalytic ozone chemistry at high solar zenith angles?, in: Geophys. Res. Abst., EGU General Assembly, Vienna, 8030, 2012b.

Waibel, A. E., Peter, T., Carslaw, K. S., Oelhaf, H., Wetzel, G., Crutzen, P. J., Pace, G., Pöschl, U., Tsias, A., Reimer, E., and Fischer, H.: Arctic ozone loss due to denitrification, Science, 283, 2064-2069, doi:10.1126/science.283.5410.2064, 1999.

Waters, J. W., Froidevaux, L., Harwood, R. S., Jarnot, R. F., Pickett, H. M., Read, W. G., Siegel, P. H., Cofield, R. R., Filipak, M. J., Flower, D. A., Holden, J. R., Lau, G. K., Livesey, N. J., Man- ney, G. L., Pumphrey, H. C., Santee, M. L., Wu, D. L., Cuddy, D. T., Lay, R. R., Loo, M. S., Perun, C. S., Schwartz, M. J., Stek, P. C., Thurstans, R. P., Boyles, M. A., Chandra, K. M., Chavez, M. C., Chen, G. S., Chudasama, B. V., Dodge, R., Fuller, R. A., Girard, M. A., Jiang, J. H., Jiang, Y., Knosp, B. W., LaBelle, R. C., Lam, J. C., Lee, K. A., Miller, D., Oswald, J. E., Patel, N. C., Pukala, D. M., Quintero, O., Scaff, D. M., Snyder, W. V., Tope, M. C., Wagner, P. A., and Walch, M. J.: The Earth Observing System Microwave Limb Sounder (EOS MLS) on the Aura Satellite, IEEE T. Geosci. Remote Sensing, 44, 1075-1092 doi:10.1109/TGRS.2006.873771, 2006.

Waugh, D. W. and Polvani, L. M.: Stratospheric polar vortices in the Stratosphere: Dynamics, Chemistry, and Transport, AGU, Geophys. Monogr. Ser., 190, 43-57, 2010.

Waugh, D. W., Oman, L., Kawa, S. R., Stolarski, R. S., Pawson, S., Douglass, A. R., Newman, P. A., and Nielsen, J. E.: Impacts of climate change on stratospheric ozone recovery, Geophys. Res. Lett., 36, L03805, doi:10.1029/2008GL036223, 2009.

Wegner, T., Grooß, J.-U., Müller, R., Stroh, F., Lehmann, R., Volk, C. M., Hösen, E., Vom Scheidt, M., Wintel, J., Riediger, O., Schlager, H., Scheibe, M., Stock, P., Ravegnani, F., Ulanovsky, A., Yushkov, V. A., and von Hobe, M.: Chasing air masses in the Arctic vortex: An evaluation of trajectory calculations using an active Match, American Geophysical Union, Fall Meeting 2010, San Francisco, USA, 2010.

Wegner, T., Grooß, J.-U., von Hobe, M., Stroh, F., SumińskaEbersoldt, O., Volk, C. M., Hösen, E., Mitev, V., Shur, G., and Müller, R.: Heterogeneous chlorine activation on stratospheric aerosols and clouds in the Arctic polar vortex, Atmos. Chem. Phys., 12, 11095-11106, doi:10.5194/acp-12-11095-2012, 2012.

Wegner, T., Kinnison, D. E., Garcia, R. R., Madronich, S., Solomon, S., and von Hobe, M.: On the depletion of $\mathrm{HCl}$ in the Antarctic polar vortex, J. Geophys. Res., submitted, 2013a.

Wegner, T., Kinnison, D. E., Garcia, R. R., and Solomon, S.: Simulation of polar stratospheric clouds in the specified dynamics version of the whole atmosphere community climate model, J. Geophys. Res., 118, 4991-5002, doi:10.1002/jgrd.50415, 2013b.

Weigel, K., Riese, M., Hoffmann, L., Hoefer, S., Kalicinsky, C., Knieling, P., Olschewski, F., Preusse, P., Spang, R., Stroh, F., and Volk, C. M.: CRISTA-NF measurements during the AMMASCOUT-O3 aircraft campaign, Atmos. Meas. Tech., 3, 14371455, doi:10.5194/amt-3-1437-2010, 2010.

Weigel, R., Hermann, M., Curtius, J., Voigt, C., Walter, S., Böttger, T., Lepukhov, B., Belyaev, G., and Borrmann, S.: Experimental characterization of the COndensation PArticle counting System for high altitude aircraft-borne application, Atmos. Meas. Tech., 2, 243-258, doi:10.5194/amt-2-243-2009, 2009.

Weigel, R., Borrmann, S., Ebert, M., Kandler, K., Frey, W., Molleker, S., Volk, C. M., Günther, G., Schlager, H., Cairo, F., Di Donfrancesco, G., and Khaykin, S.: Non-volatile aerosol in the Arctic Winter Stratosphere and its role for PSC formation, European Aerosol Conference, Granada, Spain, 2012.

Werner, A., Volk, C. M., Ivanova, E. V., Wetter, T., Schiller, C., Schlager, H., and Konopka, P.: Quantifying transport into the Arctic lowermost stratosphere, Atmos. Chem. Phys., 10, 11623 11639, doi:10.5194/acp-10-11623-2010, 2010.

Westbrook, C. D.: The fall speeds of sub-100 $\mu \mathrm{m}$ ice crystals, Quart. J. Roy. Meteor. Soc., 134, 1243-1251, 2008. 
Wetzel, G., Oelhaf, H., Kirner, O., Friedl-Vallon, F., Ruhnke, R., Ebersoldt, A., Kleinert, A., Maucher, G., Nordmeyer, H., and Orphal, J.: Diurnal variations of reactive chlorine and nitrogen oxides observed by MIPAS-B inside the January 2010 Arctic vortex, Atmos. Chem. Phys., 12, 6581-6592, doi:10.5194/acp12-6581-2012, 2012.

Wienhold, F. G.: http://www.iac.ethz.ch/groups/peter/research/ Balloon_soundings/COBALD_data_sheet, COBALD Data Sheet, 2012.

WMO: Scientific assessment of ozone depletion 2010, World Meteorological Organization, Global ozone research and monitoring project, Geneva, Switzerland52, 2011.

Wohltmann, I. and Rex, M.: The Lagrangian chemistry and transport model ATLAS: validation of advective transport and mixing, Geosci. Model Dev., 2, 153-173, doi:10.5194/gmd-2-153-2009, 2009.

Wohltmann, I., Lehmann, R., and Rex, M.: The Lagrangian chemistry and transport model ATLAS: simulation and validation of stratospheric chemistry and ozone loss in the winter 1999/2000, Geosci. Model Dev., 3, 585-601, doi:10.5194/gmd-3-585-2010, 2010.

Wohltmann, I., Wegner, T., Müller, R., Lehmann, R., Rex, M., Manney, G. L., Santee, M. L., Bernath, P., Sumińska-Ebersoldt, O., Stroh, F., von Hobe, M., Volk, C. M., Hösen, E., Ravegnani, F., Ulanovsky, A., and Yushkov, V.: Uncertainties in modelling heterogeneous chemistry and Arctic ozone depletion in the winter 2009/2010, Atmos. Chem. Phys., 13, 3909-3929, doi:10.5194/acp-13-3909-2013, 2013.

Woiwode, W.: Qualification of the airborne FTIR spectrometer MIPAS-STR and study on denitrification and chlorine deactivation in Arctic winter 2009/10, KIT Scientific Publishing, Dissertation, Karlsruhe Institute of Technology, doi:10.5445/KSP/1000035958, 2013.

Woiwode, W., Oelhaf, H., Gulde, T., Piesch, C., Maucher, G., Ebersoldt, A., Keim, C., Höpfner, M., Khaykin, S., Ravegnani, F., Ulanovsky, A. E., Volk, C. M., Hösen, E., Dörnbrack, A., Ungermann, J., Kalicinsky, C., and Orphal, J.: MIPAS-STR measurements in the Arctic UTLS in winter/spring 2010: instrument characterization, retrieval and validation, Atmos. Meas. Tech., 5, 1205-1228, doi:10.5194/amt-5-1205-2012, 2012.

Wolff, E. W. and Mulvaney, R.: Reactions on sulphuric acid aerosol and on polar stratospheric clouds in the Antarctic stratosphere, Geophys. Res. Lett., 18, 1007-1010, doi:10.1029/91g101158, 1991.
Wolff, M. A., Kerzenmacher, T., Strong, K., Walker, K. A., Toohey, M., Dupuy, E., Bernath, P. F., Boone, C. D., Brohede, S., Catoire, V., von Clarmann, T., Coffey, M., Daffer, W. H., De Mazière, M., Duchatelet, P., Glatthor, N., Griffith, D. W. T., Hannigan, J., Hase, F., Höpfner, M., Huret, N., Jones, N., Jucks, K., Kagawa, A., Kasai, Y., Kramer, I., Küllmann, H., Kuttippurath, J., Mahieu, E., Manney, G., McElroy, C. T., McLinden, C., Mébarki, Y., Mikuteit, S., Murtagh, D., Piccolo, C., Raspollini, P., Ridolfi, M., Ruhnke, R., Santee, M., Senten, C., Smale, D., Tétard, C., Urban, J., and Wood, S.: Validation of $\mathrm{HNO}_{3}, \mathrm{ClONO}_{2}$, and $\mathrm{N}_{2} \mathrm{O}_{5}$ from the Atmospheric Chemistry Experiment Fourier Transform Spectrometer (ACE-FTS), Atmos. Chem. Phys., 8, 3529-3562, doi:10.5194/acp-8-3529-2008, 2008.

Young, I. A. K., Murray, C., Blaum, C. M., Cox, R. A., Jones, R. L., and Pope, F. D.: Temperature dependent structured absorption spectra of molecular chlorine, Phys. Chem. Chem. Phys., 13, 15318-15325, 2011.

Young, I. A. K., Jones, R. L., and Pope, F. D.: The UV and visible spectra of chlorine peroxide: Constraining the photolysis rate, in preparation, 2013.

Yushkov, V., Oulanovsky, A., Lechenuk, N., Roudakov, I., Arshinov, K., Tikhonov, F., Stefanutti, L., Ravegnani, F., Bonafe, U., and Georgiadis, T.: A chemiluminescent analyzer for stratospheric measurements of the ozone concentration (FOZAN), J. Atmos. Ocean. Tech., 16, 1345-1350, 1999.

Zhou, T., Geller, M. A., and Lin, W.: An Observational Study on the Latitudes Where Wave Forcing Drives Brewer-Dobson Upwelling, J. Atmos. Sci., 69, 1916-1935, 2012.

Zobrist, B., Marcolli, C., Pedernera, D. A., and Koop, T.: Do atmospheric aerosols form glasses?, Atmos. Chem. Phys., 8, 52215244, doi:10.5194/acp-8-5221-2008, 2008.

Zöger, M., Afchine, A., Eicke, N., Gerhards, M. T., Klein, E., McKenna, D. S., Morschel, U., Schmidt, U., Tan, V., Tuitjer, F., Woyke, T., and Schiller, C.: Fast in situ stratospheric hygrometers: A new family of balloon-borne and airborne Lyman alpha photofragment fluorescence hygrometers, J. Geophys. Res., 104, 1807-1816, 1999. 